\title{
MITIGATING MOISTURE SUSCEPTIBILITY IN HOT-MIX ASPHALT CONCRETE
}

\author{
A thesis presented to \\ the Faculty of California Polytechnics State University,
}

San Luis Obispo

In partial fulfillment

of the requirements for the Degree of

Master of Science in Civil and Environmental Engineering

by

Tom P. Nguyen

March 2011 
(C) 2011

Tom P. Nguyen

ALL RIGHTS RESERVED 


\section{COMMITTEE MEMBERSHIP}

TITLE:

AUTHOR:

DATE SUBMITTED:

COMMITEE CHAIR:

COMMITTEE MEMBER:

COMMITTEE MEMBER:
Mitigating Moisture Susceptibility in Hot-

Mix Asphalt Concrete

Tom Nguyen

March 2011

Ashraf Rahim, Associate Professor

Damian Kachlakev, Professor

Sara Moazzami, Professor 


\section{ABSTRACT \\ Mitigating Moisture Susceptibility in Hot-Mix Asphalt Concrete}

\section{Tom P. Nguyen}

Moisture damage in asphalt pavement has always been a problem for drivers, bicyclists, and pedestrians. The primary objective of this study is to evaluate moisture susceptibility of Hot-Mix Asphalt (HMA) and to investigate mitigation techniques using different antistripping agents. Three types of antistripping agents were used in this research investigation. Two of which are chemical based and the other is hydrated lime. The two types of liquid antistripping agents used in this study include Arr Maz CC LOF-6500 and Arr Maz CC XL-9000. These two liquid antistripping agents were tested at $0.25 \%, 0.50 \%$, and $0.75 \%$. Hydrated Lime was tested at $1.0 \%$, $1.5 \%$, and $2.0 \%$. The binder used in this study is Asphalt Performance Grade (PG) 64-16 provided by Oxnard Refinery. The crushed stone aggregate used in this study was provided by Cal Portland. This study follows the guidelines of standardized AASHTO, ASTM, and SuperPave mix design for all preparation and test procedures. A total of 120 -inch by 2.83 -inch core specimens with void ratios between 6 to 8 percent were created to test for moisture susceptibility in accordance with the Modified Lottman Test, which tested for Indirect Tensile Strength and Immersion Compression Test, which tested for Compression Strength and Elasticity. During the test, half of these specimens were placed in a hot water bath for 24 hours to condition the sample to represent field performance and the other half were unconditioned. Based on the results, the best liquid antistripping agent is XL-9000 at $0.50 \%$ and hydrated lime is most efficient at a dosage rate of $1.5 \%$. The best performing antistripping additive for the value is hydrated lime at $1.5 \%$. 


\section{ACKNOWLEDGEMENTS}

I would like to thank the following:

Dr. Ashraf Rahim for giving me the opportunity to do this research and for his continued guidance and support.

Dr. Damian Kachlakev for his encouragement, support, and wise words of wisdom.

Eltahry Elghandour, Dr. Daniel Jansen, Sara Moazzami, and Dr. Robb Moss for their support and guidance.

Xi Shen for all his assistance with laboratory technicalities.

John Bricker at Oxnard Refinery for taking the time to teach me how to use all the equipment necessary for this research project.

Pat Imhoff at Cal Portland, Ivann Harnish at Arr Maz Custom Chemicals, Todd Thalmann at Rainhart Co. for their time, insight, and donations.

Anthony Boyes for his help in the laboratory.

My parents and sister for their love, support, and continued encouragement to finish this project.

My friends who kept me sane throughout this research project. 


\section{TABLE OF CONTENTS}

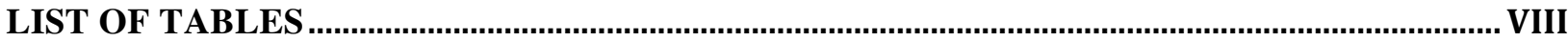

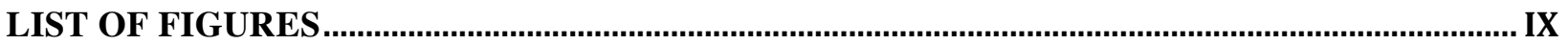

CHAPTER 1 - INTRODUCTION

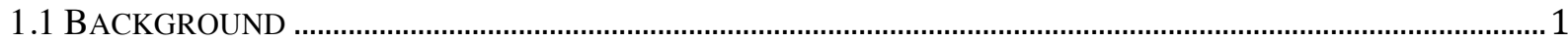

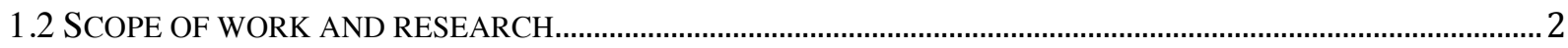

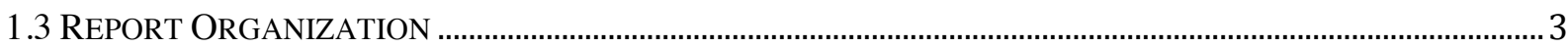

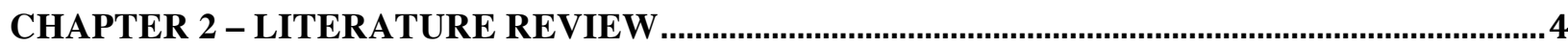

2.1 INTRODUCTION

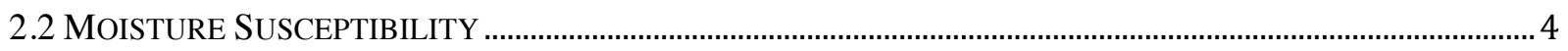

2.3 MITIGATION METHODS FOR MOISTURE SUSCEPTIBILITY ……..........................................................

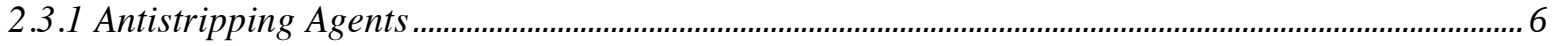

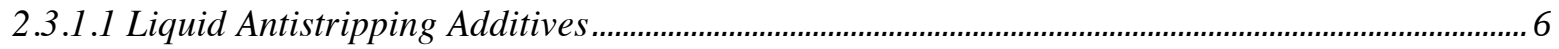

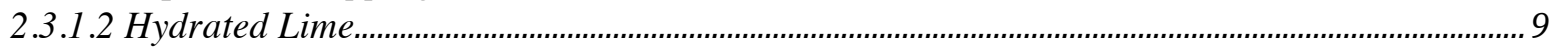

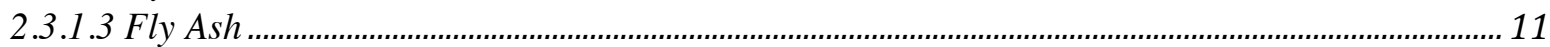

2.3.1.4 Bottom Ash

2.4 EVALUATION METHODS For MoISTURE SUSCEPTIBILITY ….................................................................... 12

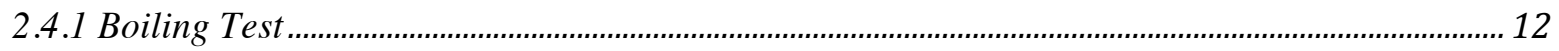

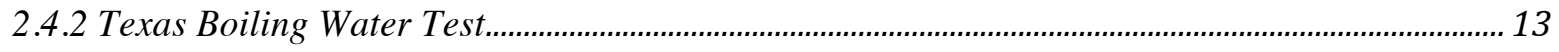

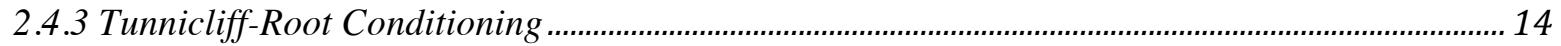

2.4.4 Immersion-Compression Test

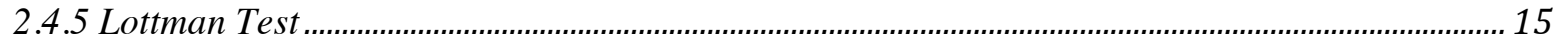

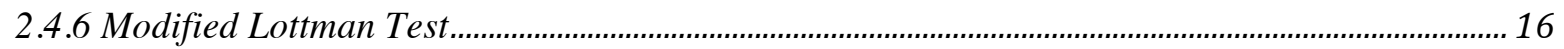

2.4.7 Hamburg Wheel Test .......................................................................................................... 17

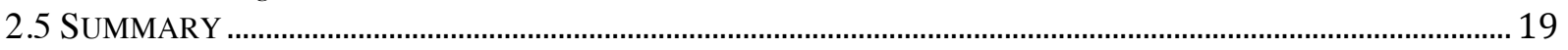

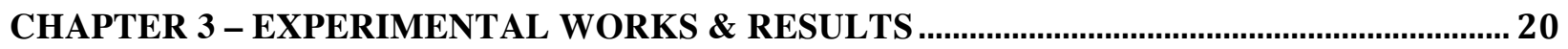

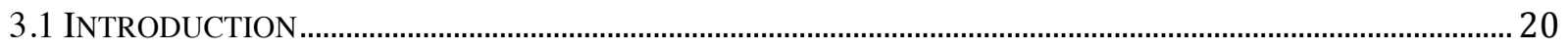

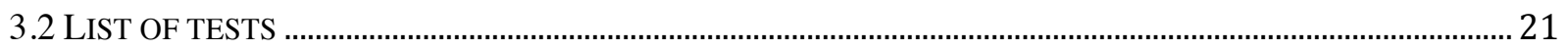

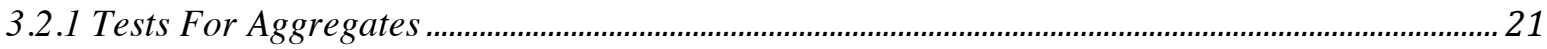

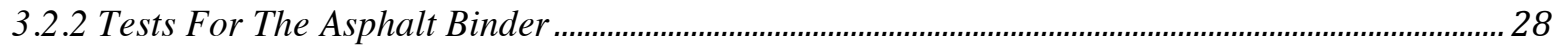

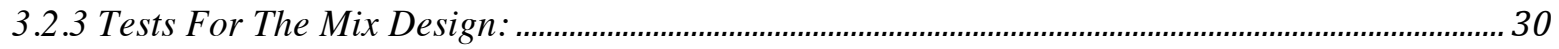

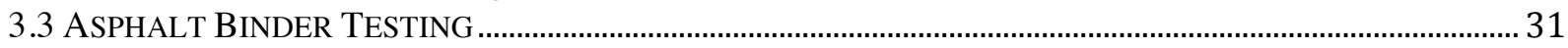

3.4 HOT MIX ASPHALT PREPARATION ............................................................................................................... 34

3.5 LOTTMAN TEST (INDIRECT TENSILE TEST) ………............................................................................. 40

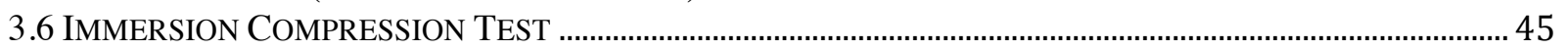

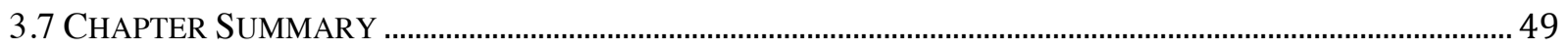

CHAPTER 4 - ANALYSIS AND DISCUSSION OF RESULTS ...................................................51

4.1 INTRODUCTION

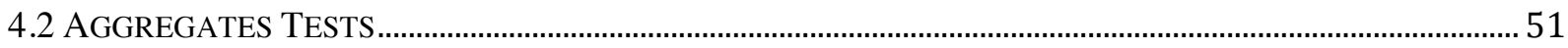

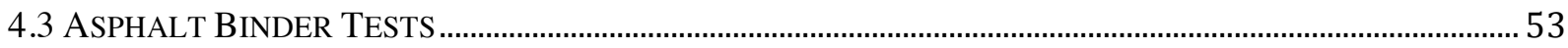

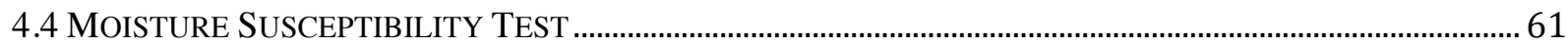

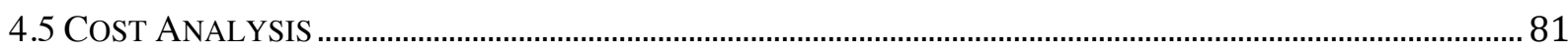

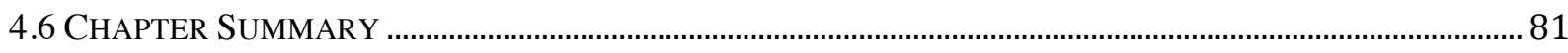

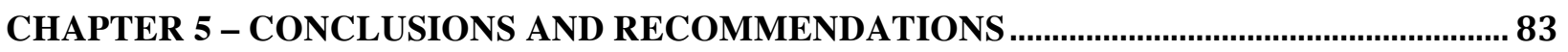


5.1 INTRODUCTION

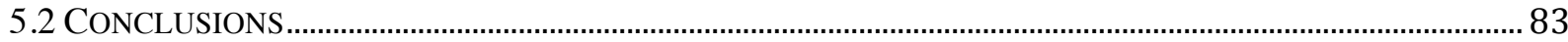

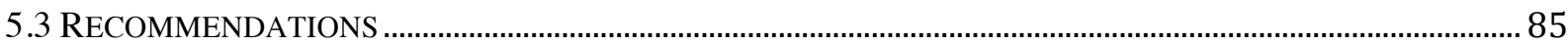

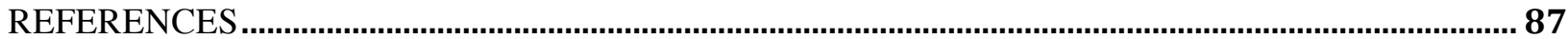




\section{LIST OF TABLES}

TABLE 3.1: SIEVE ANALYSIS TEST RESULTS ……….............................................................................................................22

TABLE 3.2: SPECIFIC GRAVITY OF COARSE AND FINE AGGREGATES.................................................................................23

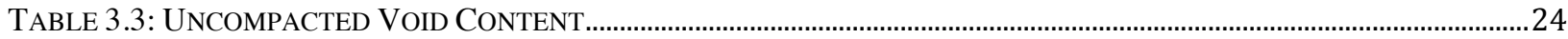

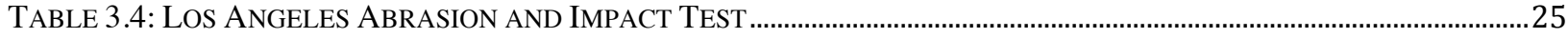

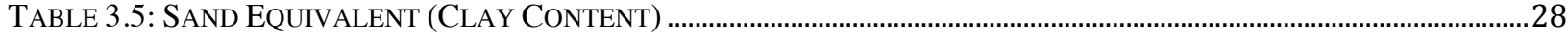

TABLE 3.6: TREATMENT COMBINATION …………………...........................................................................................32

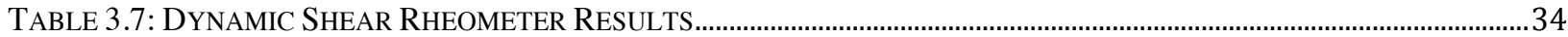

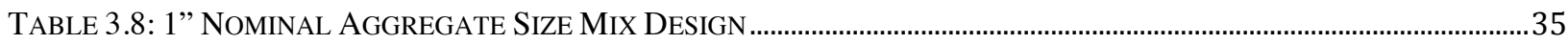

TABLE 3.9: MAXIMUM THEORETICAL SPECIFIC GRAVITY FOR VARYING MIXES....................................................................36

TABLE 3.10: ASPHALT BINDER CONTENT RESULTS ........................................................................................................................40

TABLE 3.11: AVERAGE BULK SPECIFIC GRAVITY OF THE MIXTURE........................................................................................ 41

TABLE 3.12: INDIRECT TENSILE STRENGTH TABLE SUMMARY ………………………….................................................... 45

TABLE 3.13: AVERAGED BULK SPECIFIC GRAVITY OF THE MIXTURE.................................................................................. 46

TABLE 3.14: COMPRESSION STRENGTH TABLE SUMMARY …………………............................................................................ 49 


\section{LIST OF FIGURES}

Figure 2.1: AgGREGATE Without ANTISTRIPPING AGENT (SOURCE: WWW.ROHMHASS.COM) ……………..................... 8

FiguRE 2.2: AGGREGATE With ANTISTRIPPING AGENT (SOURCE: WWW.ROHMHASS.COM) ………….............................. 8

Figure 2.3: Hamburg Wheel Test Measuring Rut Depth Over the Number of WheEl Passes (Source:

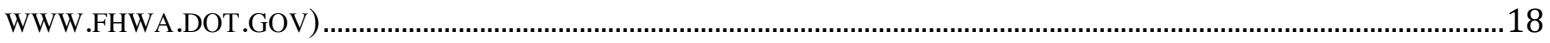

FIGURE 3.1: SIEVE ANALYSIS SHAKER …………………………………………………………………………….....22

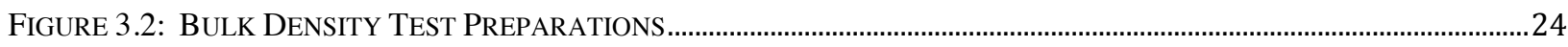

FIGURE 3 3: UNCOMPACTED VOID CONTENT TESTING APPARATUS ....................................................................................25

FIGURE 3 4: LOS ANGELES ABRASION TESTING DEVICE

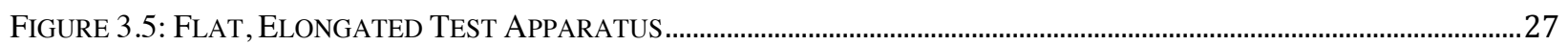

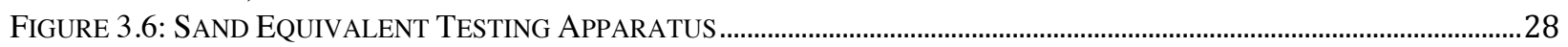

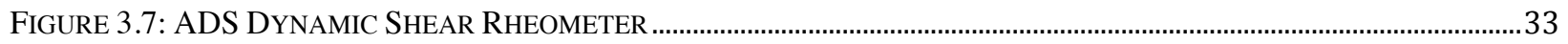

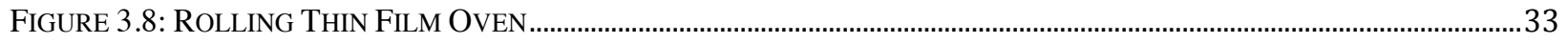

FIGURE 3 9: SUPERPAVE GYRATORY COMPACTOR …………………………………………………………………….....

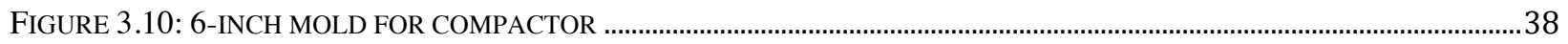

FIGURE 3 11: 6 INCH SPECIMEN USED FOR MIX DESIGN TRIALS...........................................................................................38

FIGURE 3.12: EXTRA FINE BLEND WITH 6.0\% ASPHALT BINDER ……………………........................................................ 40

FIGURE 3.13: SATEC COMPRESSION MACHINE ………............................................................................................... 42

FIGURE 3 .14: INDIRECT TENSILE STRENGTH TEST APPARATUS …………………………………………………............. 42

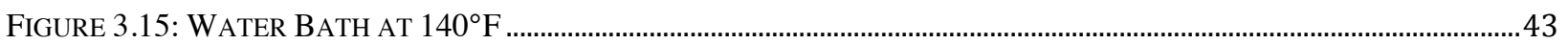

FIGURE 3 .16: PoST INDIRECT TENSILE TEST TOP VIEW....................................................................................................... 43

FIgURE 3.17: Post INDIRECT TENSILE TEST SIDE VIEW ................................................................................................... 44

FIGURE 3.18: IMMERSION COMPRESSION TEST WITH SATEC MACHINE ...................................................................................4

FIGURE 3.19: IMMERSION COMPRESSION TEST ON CONTROL SPECIMEN …………………................................................ 48

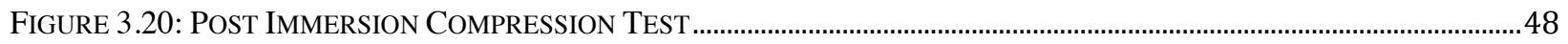

FIGURE 4.1: SUPERPAVE TRAIL GRADATION RESULTS ................................................................................................52

FIGURE 4.2: COMPLEX MODULUS RESULTS FOR UNCONDITIONED BINDER ……………………………….......................5

FIGURE 4.3: ELASTIC MODULUS RESULTS FOR UNCONDITIONED BINDER …………….......................................................56

FIGURE 4 4: PHASE ANGLE RESULTS FOR UNCONDITIONED BINDER ………………….........................................................57

FIGURE 4.5: COMPLEX MODULUS RESULTS FOR CONDITIONED BINDER …………………………………………………....59

FIGURE 4.6: ELASTIC MODULUS RESULTS FOR CONDITIONED BINDER ................................................................................60

FIGURE 4 4.7: PHASE ANGLE RESULTS FOR CONDITIONED BINDER …………………………………………..................61

FiguRE 4.8: TENSILE STRENGTH RESULTS For UnCONDITIONED LIQUID ANTISTRIPPING SPECIMENS .............................62

FiguRE 4.9: TENSILE STRENGTH RESULtS For UnCONDITIONED HydRATED Lime SPECIMENS ......................................63

FigURE 4.10: TENSILE STRENGTH RESULTS FOR ALL UNCONDITIONED ANTISTRIPPING SPECIMENS ...............................64

FiguRE 4.11: TENSILE STRENGTH RESULTS FOR CONDITIONED LIQUID ANTISTRIPPING SPECIMENS ...............................65

FiguRE 4.12: TENSILE STRENGTH RESULtS For CONDITIONED HydRATED LIME SPECIMENS............................................66

FiguRE 4.13: TENSILE STRENGTH RESULTS FOR ALL CONDITIONED SPECIMENS...............................................................67

FigURE 4.14: TENSILE STRENGTH RATIO (TSR) RESULTS FOR LIQUID ANTISTRIPPING SPECIMENS ................................68

FigURE 4.15: TENSILE STRENGTH RATIO (TSR) RESULTS For HYDRATED LIME SPECIMENS ...........................................68

FIGURE 4.16: MAXIMUM COMPRESSIVE STRENGTH RESUlTS FOR UNCONDITIONED LIQUID ANTISTRIPPING

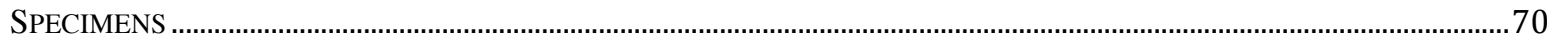

FigURE 4.17: MAXIMUM COMPRESSIVE STRENGTH RESUlTS FOR UNCONDITIONED HYDRATED LIME SPECIMENS .....71

Figure 4.18: MAXIMUM COMPRESSIVE STRENGTH RESUlTS For ALl UnCONDITIONED ANTISTRIPPING SPECIMENS72

FIGURE 4.19: YOUNG'S MODULUS RESULTS FOR UNCONDITIONED LIQUID ANTISTRIPPING SPECIMENS..........................73

FigURE 4.20: YOUNG'S MODULUS RESULTS FOR UNCONDITIONED HYDRATED LIME SPECIMENS ....................................74

Figure 4.21: MAXIMUM COMPRESSIVE STRENGTH RESUlts For CONDITIONED LIQUid ANTISTRIPPING SPECIMENS75

Figure 4.22: MAXIMUM COMPRESSIVE STRENGTH RESUlTS For CONDITIONED HYDRATED LiME SPECIMENS............76

Figure 4.23: MAXIMUM COMPRESSIVE STRENGTH ReSUlts For All CONDITIONED ANTISTRIPPING SPECIMENS .....77

FiguRE 4.24: YOUNG'S MODULUS RESULTS FOR CONDITIONED LIQUID ANTISTRIPPING SPECIMENS................................78

FIGURE 4.25: YOUNG'S MODULUS RESULTS FOR CONDITIONED HYDRATED LIME SPECIMENS ..........................................79

FiguRE 4.26: COMPRESSIVE STRENGTH RATIO (CSR) RESULTS FoR LiQUID ANTISTRIPPING SPECIMENS........................80

FiguRE 4.27: COMPRESSIVE STRENGTH RATIO (CRS) RESUlTS FOR HYDRATED LIME SPECIMENS ..................................80 


\section{CHAPTER 1 - INTRODUCTION}

\subsection{Background}

According to the Federal Highway Administration, there are 4.04 million miles of road in the United States, including Alaska and Hawaii, but not Puerto Rico. The nation's highway system consists of 46,751 miles of Interstate Highways. The Interstate miles and another 116,948 miles of major roads comprise the National Highway System, which provides most of the highway freight and traffic in the U.S. Of the remaining 3.9 million miles of road, about 2.6 million miles are paved including roads in urban areas. This leaves about 1.3 million miles in the U.S. that are unpaved gravel or dirt roads.

Between 1998 and 2008, the U.S. built an average of 14,000 center-line miles of new roads per year. These roads are mostly local roads in new residential neighborhoods. Along with this, road widening added about 33,000 more lane-miles per year. This shows how the highway system has rapidly grown in a short period of time.

According to the Federal Highway Administration, "Federal investment in highway improvements in FY 2009 included $\$ 40.7$ billion through the core highway program plus a one-time investment of $\$ 27.5$ billion through the stimulus law reaching, a total of $\$ 68.2$ billion. For FY 2010, Congress has appropriated $\$ 41.8$ billion for the core highway program, which increased in core funding of 2.7 percent. Most federal highway investment is used to upgrade and maintain the nation's core highways, including the Interstate Highway System, and to repair and replace deficient bridges”. 
One major type of distresses that affect the quality and service life of asphalt pavements is moisture related damage, known as stripping. Moisture damage and stripping is recognized as the loss of bond between aggregates and asphalt binder. When moisture enters the asphalt pavement mixture, it seeps between the aggregates and asphalt binder leading to many distresses including stripping. The underlying effects of moisture damage, more specifically how the water penetrates the asphalt pavement, will lead to other pavement distresses such as rutting, cracking, raveling, and weathering which creates potholes. These distresses may propagate from the bottom or top of the pavement announcing a universal problem in pavement design.

The purpose of this research is to investigate different methods to mitigate-related damage (stripping) in asphalt pavements. This will lead to a reduction in road repairs and the money spent on these repairs.

\subsection{Scope of work and research}

The study is intended to determine the performance of hydrated lime and liquid antistripping agents as compared to non-enhanced asphalt mixes. Moisture damage will be determined through indirect tensile strength test and immersion compression test. Conditioning the specimens in water will be incorporated to determine the effects of moisture. Cal Portland Aggregate was the sole supplier for Crushed Stone aggregate. Performance grade 64-16 binder is used in this study. The asphalt binder viscosity is tested using a dynamic shear rheometer. Binder viscosity is tested under virgin and aged, non-enhanced and enhanced conditions. Industrial hydrated lime from a local surplus store is used. Hydrated lime is added at $1.0 \%, 1.5 \%$, and $2.0 \%$. Two liquid antistripping agents are obtained from Arr Maz Custom Chemicals. Ad-Here LOF-6500 is a low odor 
and reported to be effective antistrip for a wide range of aggregate types. This chemical additive will be tested at $0.25 \%, 0.50 \%$, and $0.75 \%$. XL-9000 is a newer antistripping agent from Arr Maz CC and will be used to compare the effectiveness of minimizing moisture-related damage. Similar to Ad-Here LOF-6500, this chemical additive will also be tested at $0.25 \%, 0.50 \%$, and $0.75 \%$. The specimen compaction process is completed with a gyratory compactor. Specimens' compaction follows SuperPave mix design. The two methods of evaluation used for this research include Indirect Tensile Strength Test and Immersion Compression Test. According to Indirect Tensile Strength and Immersion Compression test procedures, specimens will be compacted to a diameter of 4 inches and a height of approximately 2.83 inches. Each test requires 6 specimens per treatment combination, therefore, a minimum of 120 specimens will be made to accommodate for the tests.

\subsection{Report Organization}

This research thesis will be organized in the following order: Chapter 1 includes an introduction and an overview of the research. Chapter 2 provides a comprehensive literature review introducing the background coverage of the problem. Also included in this chapter are ways to evaluate moisture damage and possible methods to mitigate the problem. The focus is geared towards possible mitigation techniques for California.

Chapter 3 presents the experimental work and results of the research. Chapter 4 provides analysis of the results. Lastly, Chapter 5 provides conclusions and recommendations for future studies. 


\section{CHAPTER 2 - LITERATURE REVIEW}

\subsection{Introduction}

The United States has an enormous network of roads. These roads are all susceptible to various pavement distresses. Five years after the initial road construction, it is common that roads start to show signs of deterioration. It is commonly known that moisture plays a huge role in pavement distresses. This occurs when water penetrates through asphalt pavement and causes the pavement to deteriorate. Moisture susceptibility is root cause of stripping in asphalt pavements. Moisture susceptibility can be mitigated through many methods including, but not limited to, Liquid Antistrip Additives, Hydrated Lime, Bottom Ash, and Fly Ash. To evaluate moisture susceptibility, several methods are used including Texas Boiling Water Test, Tunnicliff and Root Conditioning, Immersion Compression Test, and Modified Lottman Test.

\subsection{Moisture Susceptibility}

Moisture damage is a crucial problem for asphalt pavements. When several mechanical combinations do not function or coincide together, such as poor bonding between aggregate and binder, moisture damage is the typical result. The three common mechanisms that moisture degrades asphalt mixture are: (a) loss of cohesion within the asphalt mastic, (b) failure of the adhesive bond between aggregate and asphalt (stripping), and (c) degradation of the aggregate. This study primarily focuses on the failure of the adhesive bond between aggregate and asphalt. This type of degradation weakens the asphalt matrix and has the potential to lose its strength (Copeland et al. 2007). Numerous 
tests and methods have been developed in order to evaluate and mitigate moisture damage, respectively.

\subsection{Mitigation Methods For Moisture Susceptibility}

Moisture-sensitive asphalt pavements can experience severe reduced service life. In United States, various additives to reduce moisture sensitivity and stripping are used. Additives such as hydrated lime, liquid antistripping, Portland cement, fly ash, bottom ash, and flue dust are utilized. These anti- stripping additives, whether powder or liquid, are used to promote adhesion of asphalt binder onto the aggregate's surface.

In 2007, Sebaaly et al found that lime mixtures held up better resistance against moisture damage rather than liquid chemicals (antistripping). This was proved based on using the ratio of dynamic modulus in tension of moisture-conditioned to that of dry mixtures. Similarly, in 1991, Kennedy and Ping found that the relative effectiveness of both hydrated lime and liquid antistrip immensely depended on the aggregate type and test used to evaluate the HMA.

Mohammad et al. (2000) evaluated the effects of commercially available hydrated lime on asphalt cement and the research indicated that the addition of hydrated lime could alter the physical characteristics and composition of an asphalt binder where it typically increases asphalt binder viscosity. This may cause the binder to harden early and lead to cracking during temperature changes. Methods used to evaluate moisture damage included: indirect tensile strength, permanent deformation characteristics, resilient modulus, and fatigue resistance. The results exhibited improvement to the permanent deformation characteristics and fatigue endurance of the asphalt mixtures. Presently 
there is no common consensus as to whether the undesirable effects of anti-stripping agents outweigh their positive moisture-resistive effects.

\subsubsection{Antistripping Agents}

Antistripping agents are greatly beneficial for moisture-sensitive asphalt mixes. However, incorrect use of anti-stripping additives, such as incorrect proportion of the additive and/or an incorrect method of application could actually be counterproductive. There have been many studies that focused towards the optimum proportion and method of application. Unfortunately, the optimum solution for the proportion and method of application to asphalt mixes has not yet been determined. AASHTO T-283, tensile strength test (ITS) is a common method to measure the performance of antistripping additives. AASHTO T-283 test method provides results that are indicative to the moisture damage experienced on the highway. The most commonly used anti-stripping agents, but not limited to, are lime additives and liquid additives (Tunnicliff \& Root, 1984). These additive types will be discussed further in the next few sections.

\subsubsection{Liquid Antistripping Additives}

Liquid anti-stripping agents are chemical compounds that contain amines, diamines, and or polymers. Amines or chemical compounds that contain amines are agents that have strong basic compounds derived from ammonia. Most antistrip agents are cationic and are designed to promote adhesion between acidic aggregate surfaces. Some may contain both cationic properties and anionic properties and this may improve adhesion with all aggregates and asphalt binder, not just acidic aggregates or acidic asphalt cement [Lu et al. 2006]. Most anti-stripping agents reduce the loss of adhesion between the aggregate surface and asphalt binder when moisture is present (Sebaaly et al. 1998). A reduction in 
surface tension will promote an increase in adhesion of the asphalt to the aggregate. Therefore, most liquid anti-stripping agents are surface-active agents (Roberts et al. 1996). Heating the asphalt to a liquid state is an economical method of mixing the liquid anti-stripping agent to the asphalt. An alternative method to adding the additive is applying it directly into the aggregate before adding the binder (Kennedy, Roberts, Lee 1983).

Recent studies by Wasiuddin et al. (2009) shows that most liquid anti-stripping agents are of the surface-active type, commonly known as surface free energy. Surface free energy (SFE) of asphalt binder is related to the work of cohesion done within the binder and the work of adhesion done between binder and aggregate. The SFE of an asphalt binder mainly comprises of an apolar component and an acid-base component.

Roberts et al. 1996 and Tunnifcliff et al. 1984 has reported that liquid antistripping additives reduce the SFE of asphalt binders. A reduced SFE leads to an increased surface area to promote adhesion between the binder and the aggregate. Then in 2009, Wasiuddin et al. discovered that liquid antistripping additives does not decrease the SFE of an asphalt binder, however, it increases the SFE. The increased SFE promotes an increase in the free energy of adhesive strength between the asphalt binder and the aggregate. The increased free energy of adhesion provides increased resistance to stripping. The more the SFE of an asphalt binder and the more the free energy of adhesion between the highly acidic aggregate and the binder, the more resistant the bond is to stripping

Low level of surface free energy is presented in the Figure 2.1 below. 


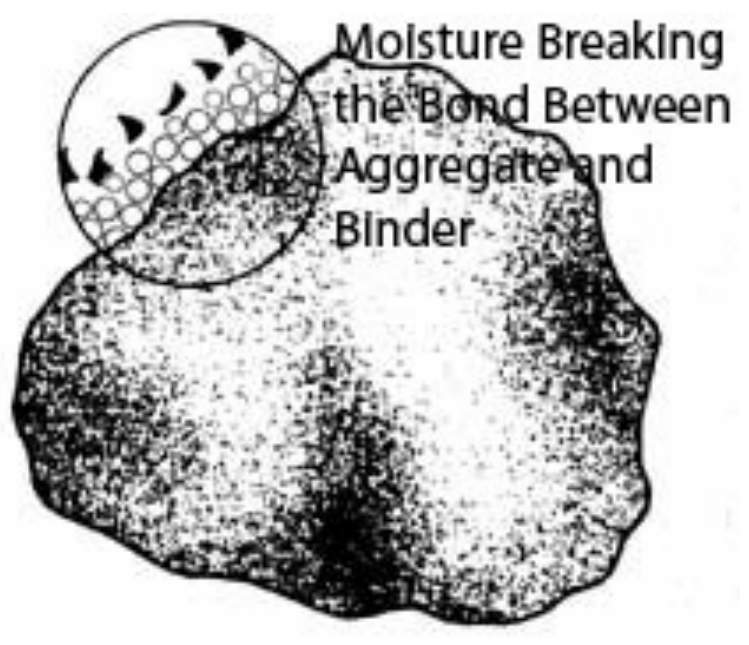

Figure 2.1: Aggregate Without Antistripping Agent (Source: www.rohmhass.com)

Figure 2.2 below shows how liquid anti-stripping additives allow the asphalt cement to create a strong bond between the asphalt and aggregate, which will help reduce moisture susceptibility.

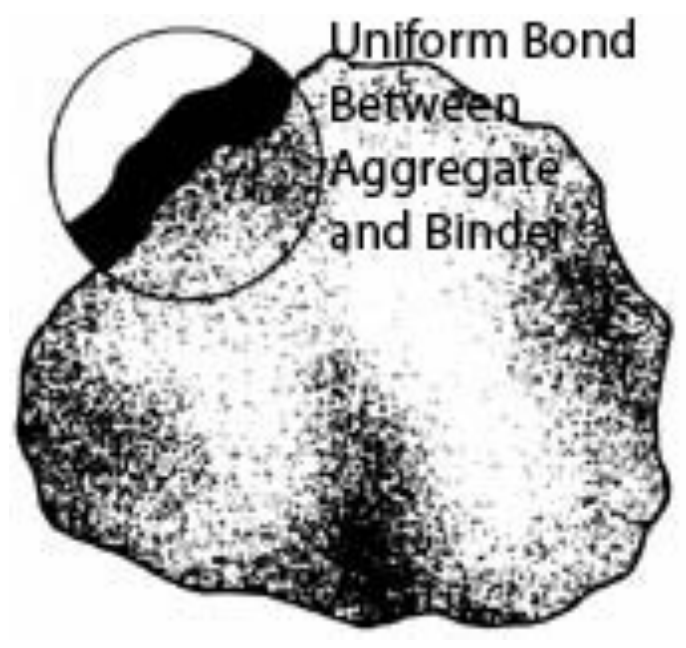

Figure 2.2: Aggregate With Antistripping Agent (Source: www.rohmhass.com) 
Yoon and Tarrer (1988) investigated the heat stability of antistripping agents by investigating the additive concentration and additive performance by holding the specimens in hot water at $162.8^{\circ} \mathrm{C}$. Yoon and Tarrer used the Boiling Water Test in their experimental design. Conducting the Boiling Water Test through different curing temperatures showed a positive correlation on how additive performance decreases as the additive concentration decreases. Although these properties decreased, the overall performance of the asphalt-aggregate mixtures was observed to improve remarkably when stored (cured) at $149^{\circ} \mathrm{C}$ for several hours.

Hao et al. (2006) studied the various effects of antistripping additives on moisture susceptibility of asphalt mixtures. The conclusions drawn from this study suggested that liquid antistripping agents provide performance enhancements for moisture susceptibility but it deteriorates over long-term aging. According to the study, the moisture susceptibility of asphalt mixtures with liquid antistripping agent decreases significantly compared to asphalt mixtures treated with hydrated lime for long-term aging.

\subsubsection{Hydrated Lime}

Hydrated lime has been widely used in asphalt mixtures for a long time. It has been used as mineral filler, antistripping agent, or both. The general practice is to add 1 to 1.5 percent lime of the aggregate dry weight to the mix. If an aggregate has more fines present, it may be necessary to replace passing \#200 aggregates with lime additive. Three common lime types used include: hydrated lime $\left(\mathrm{Ca}(\mathrm{OH})_{2}\right)$, quick lime $(\mathrm{CaO})$, and Dolomitic limes (both types S and N) (Roberts et al. 1996). 
Several methods exist for adding lime to mixtures. Dry hydrated lime is added prior to the addition of asphalt cement to the aggregate. California DOT adds the dry hydrated lime to aggregates in two different methods. Hydrated lime can be added as lime slurry, which needs to be made prior to applying to the aggregates or a damp method where hydrated lime is mixed into aggregates, which has been dampened with water.

To evaluate the properties of bituminous mixtures containing hydrated lime, Mohammad et al. (2000) used the Tensile Strength Ratio (TSR) values via indirect tensile strength test and strain, rutting via permanent deformation characteristics, resilient modulus, and fatigue resistance. They found that if the hydrated lime was added as mineral filler, the permanent deformation and fatigue endurance improved. Also, test results illustrated that adding lime increased the tensile strength of HMA mixtures. Lu et al. (2005) have conducted long-term studies using the indirect tensile strength test and the flexural beam fatigue test. Tests have been done on a yearlong basis and effects have been recorded every 4 months. The longest time of condition for the specimens is one full year. Lu et al. (2005) have concluded that hydrated lime does not change the ITS or fatigue response significantly, but it significantly increases the flexural stiffness in dry conditions and the effectiveness for hydrated lime in the condition state increases over time.

In California, asphalt mixtures treated with hydrated lime are the method of choice. Public and private companies use this method extensively because of the quality modified HMA produced at reasonable price. 


\subsubsection{Fly Ash}

According to the American Coal Ash Association, fly ash is the finely divided residue that results from the combustion of pulverized coal and is transported from the combustion chamber by exhaust gases. Over 72.4 million tons of fly ash was produced in 2008 (USEPA 2010). The process of fly ash being produced starts with coal that is fed to boiler's combustion chamber where it immediately ignites and generates heat when producing a molten mineral residue. Ash is formed and the lighter fine ash particles, is termed fly ash, which remains suspended in the flue gas, unlike the bottom ash. Fly ash is removed from the chamber by particulate emission control devices, such as "electrostatic precipitators" or "filter fabric bag houses." This is completely prior to exhausting the flue gas.

Fly ash applications include: portland cement concrete (PCC), soil and road base stabilization, flowable fills, grouts, structural fill and asphalt mix filler. It is good as mineral filler in hot mix asphalt applications because of its spherical shape and particle size distribution. Fly ash is also commonly used as a pozzolan, a siliceous siliceous and aluminous material, which reacts with calcium hydroxide at normal temperatures to produce cementitious compounds. ACAA states that the consistency and abundance of fly ash in many areas present unique opportunities for use in structural fills and other highway applications.

In a recent study, Huang et al. (2010) tested fly ash among other cementitious fillers and discovered that fly ash had a weak chemical bond between the binder and itself. However, fly ash was slightly more moisture resistant than the control (Lime aggregate with PG64-22). The study showed that the stronger the chemical activity of the 
cementitious filler, the more effective they are in improving moisture resistance, thus, further research is needed.

\subsubsection{Bottom Ash}

The majority of unused coal ash from coal-fired electric power and steam generating plants is called bottom ash. Bottom ash is produced from coal that is ignited in a boiler, which precipitates molten mineral residue. The heavy ash that falls to the bottom of the combustion chamber is deemed bottom ash. This bottom ash is often disposed of in landfills open-space areas near the mines. The bottom ash is left there until it is needed for use. Although bottom ash is not as common as fly ash, recent studies have shown that bottom ash may be as useful, if not more, than fly ash. Similar to fly ash, bottom ash would be used to replace a portion of the fine aggregate in the asphalt mix to enhance the quality of asphalt pavement. The downside to bottom ash is that it must be free of pyrites or other metals that might affect asphalt pavement as it replaces the powder $(<\# 200)$ in the mix design.

\subsection{Evaluation Methods For Moisture Susceptibility}

Boiling Test, Texas Boiling Test, Tunnicliff-Root Conditioning, Immersion-Compression Test, Lottman Test, Modified Lottman Test, and Hamburg Wheel Test are test methods used to evaluate moisture susceptibility. These methods are further described in the following sub-sections.

\subsubsection{Boiling Test}

The Boiling Water Test (ASTM D3625) is an empirical test for the effects that moisture has on a loose HMA mix. This test is one of the many initial tests needed to evaluate the 
HMA mix. The boiling water test serves as an inexpensive method of measurement for quality control.

For the Boiling Water Test, loose HMA mix is added to boiling water. The mix remains in the boiling water for 10 minutes. Moisture damage is measured by observing the loose HMA in the water. The percentage of the total visible area of the aggregate that retained its original coating of asphalt binder is estimated. Ratings are either above or below 95 percent where below 95 percent means that there is a likely chance of asphalt stripping. It is difficult to determine the amount of stripping that occurs in fine aggregate. Roberts et al. (1996) believed that this testing method tends to work better when using liquid antistripping agents.

\subsubsection{Texas Boiling Water Test}

Similar to The Boiling Test, The Texas Boiling Test measures the amount of stripping of the asphalt from aggregate surfaces after the specimens had been conditioned under boiling water for a specified time by visual determination.

The Texas Boiling Water Test (TBWT) is a visual rating of the extent of stripping after the mixture is boiled. Asphalt binder is heated at $325^{\circ} \mathrm{F}\left(103^{\circ} \mathrm{C}\right)$ for 25 hours $+/-1$ hour. Having the choice of either 100 grams or 300 grams, these unwashed aggregates are heated at the same temperature for 1 to 1.5 hours. The aggregate and asphalt binder are mixed together then cooled for two hours. The mixture is then placed in boiling water for 10 minutes. Floating asphalt binder in the boiling water is removed. The mixture is emptied onto a paper towel then graded. Grading requires three people, who grade the dried mixture at that very moment and repeated the next day. A mixture that retains less 
than 70 percent of asphalt binder is considered moisture susceptible (Kennedy, Roberts, Lee 1983).

\subsubsection{Tunnicliff-Root Conditioning}

Tunnicliff-Root Conditioning (ASTM D4867) is a strength test that is fairly similar to the Indirect Strength Test. Six specimens with air voids between 6 and 8 percent are needed for the test. The six specimens are split into two groups. The first group is the control group without any conditioning and the second group is vacuum saturated at $28.6 \mathrm{in}$. HG for five minutes. Saturation limits for the specimens are 55 to 80 percent. After saturation, the conditioned cores are placed in a $140^{\circ} \mathrm{F}\left(60^{\circ} \mathrm{C}\right)$ water bath for 24 hours then about 3 hours at $77^{\circ} \mathrm{F}\left(25^{\circ} \mathrm{C}\right)$. After conditioning, the ITS Test is performed with a loading rate of $2 \mathrm{in} / \mathrm{min}$. The minimum Tensile Strength Ratio (TSR) used is 0.70 to ensure adequate performance (Tunnicliff et al. 1984).

\subsubsection{Immersion-Compression Test}

The Immersion-Compression Test (ASTM D1075) also utilizes six cores. Each core has a requirement of four inches in diameter and four inches in height but the height does not have to be exact as there is a conversion factor. The six cores are split into two groups with the first group being the control group. The control group needs to be stored in an air bath at $77^{\circ} \mathrm{F}\left(25^{\circ} \mathrm{C}\right)$ for not less than 4 hours. The second group is conditioned in a water bath at $140^{\circ} \mathrm{F}\left(60^{\circ} \mathrm{C}\right)$ for 24 hours.

After conditioning, the unconfined compressive strength of each core is determined. A testing temperature of $77^{\circ} \mathrm{F}\left(25^{\circ} \mathrm{C}\right)$ and a loading rate of $0.2 \mathrm{in} / \mathrm{min}$ are used. A converted loading rate of $0.20 \%$ of the specimen height can be used if the height is not four inches 
high. The index of retained strength is calculated. Similarly a strength index of 70 percent is adequate [Roberts et al. 1996].

\subsubsection{Lottman Test}

The Lottman Laboratory Test is composed of two major elements. The first element is the incorporation of indirect tensile strength testing to bituminous mixtures (Kennedy et al. 1983). The second element is the incorporation of moisture susceptibility testing to bituminous mixtures (Lottman 1982). This test originated at University of Idaho by Dr. R.P. Lottman. The Lottman Test is well known as common laboratory procedure for asphalt testing that was developed and designated as NCHRP 246. Moisture damage is measured similarly as the indirect tensile test in a strength ratio.

For the original Lottman test, nine specimens are required. These 9 specimens are split into 3 groups. The first group is the control group in which there is no conditioning. The second group is vacuum saturated in water for 30 minutes at $660 \mathrm{mmHg}$. Vacuum saturation predicts HMA performance in the first 4 years post construction. The third group is also vacuum saturated, as well as, going through a freeze-thaw cycle. They are frozen at $0^{\circ} \mathrm{F}\left(-18^{\circ} \mathrm{C}\right)$ for approximately 15 hours. Then they are thawed in a water bath at $140^{\circ} \mathrm{F}\left(60^{\circ} \mathrm{C}\right)$ for 24 hours. Group three is designed to reflect field performance from the fourth to the twelfth year (Lottman 1982; Roberts et al. 1996).

The Indirect Tensile Strength Test (ITS) is performed on each specimen after the respective conditioning procedures are completed. Again, ITS can be performed at either $55^{\circ} \mathrm{F}\left(13^{\circ} \mathrm{C}\right)$ or $73^{\circ} \mathrm{F}\left(23^{\circ} \mathrm{C}\right)$. Although for the original Lottman test, it requires using a lower loading rate of $0.065 \mathrm{in} / \mathrm{min}$. The retained tensile strength (TSR) is calculated for 
the specimens all groups. The TSR is the ratio of the ITS of the conditioned specimens to the ITS of the control specimens. It is recommended that a TSR be greater than 0.7 (Lottman 1982, Roberts et al. 1996).

\subsubsection{Modified Lottman Test}

AASHTO accepted the Modified Lottman Test (AASHTO T-283) in 1985. It is a combination of the Lottman Test, and the Tunnicliff and Root Test. The procedures call for six specimens of $100 \mathrm{~mm}$ diameter by $63.5 \mathrm{~mm}$ specimens with void ratios between 6 and 8 . The higher percentage of air voids will accelerate moisture damage on the cores. AASHTO T-283 allows the use of SuperPave gyratory compacted specimens as well as the traditional Marshall hammer compacted specimens. AASHTO T-283 was adopted in the SuperPave system as the moisture test method of choice (Solaimanian et al. 2003, Stroup-Gardiner et al. 1992). The six specimens are split into two groups of three. The first group is the control group, which experience no conditioning. The second group is conditioned. The conditioned specimens are vacuum saturated until saturation level of 70 to 80 percent is achieved. The specimens are then placed in the freezer $\left(0^{\circ} \mathrm{F}\right.$ or $\left.-18^{\circ} \mathrm{C}\right)$ for 16 to 18 hours. The frozen cores are then moved to a water bath at $140^{\circ} \mathrm{F}\left(60^{\circ} \mathrm{C}\right)$ for 24 hours (Epps et al. 2000). After conditioning, the ITS Test is performed on both groups. The ITS Test is performed at $77^{\circ} \mathrm{F}\left(25^{\circ} \mathrm{C}\right)$ with a loading rate of $2 \mathrm{in} / \mathrm{min}$. The severity of moisture damage is based on the ratio of conditioned to dry specimens' tensile strength ratio (Lottman 1978). The minimum acceptable TSR used is 0.7 (Lottman 1982, Roberts et al. 1996). There are agencies that suggest TSR of 0.80 as a minimum. 


\subsubsection{Hamburg Wheel Test}

The Hamburg Wheel Test is used to measure the combined effects of rutting and moisture damage by rolling a steel wheel across the surface of an asphalt concrete slab that is immersed in hot water. Esso A.G. of Hamburg, Germany developed the device in the 1970's. This device is based on a similar British device that had a rubber tire. The device tests two slabs simultaneously using two reciprocating solid steel wheels. The load is fixed at $685 \mathrm{~N}$ and the average contact stress is $0.73 \mathrm{MPa}$, which is an approximation of the stress produced by one rear tire on a double-axle truck. Generally, 10,000 wheel passes was needed to show the effects of moisture damage. The number of wheel passes being used in the United States is 20,000. Colorado Department of Transportation (CDOT) recommends maximum allowable rut depths of $4 \mathrm{~mm}$ at 10,000 wheel passes and $10 \mathrm{~mm}$ at 20,000 wheel passes, based on correlations between the test results and moisture damage in dense-graded hot-mix asphalt pavements.

According to the FWHA, the machine tests slabs that typically have a length of $320 \mathrm{~mm}$, a width of $260 \mathrm{~mm}$, and a thickness of either 40,80 , or $120 \mathrm{~mm}$. Maximum allowed thickness is $150 \mathrm{~mm}$. The thickness of the slab is specified to be a minimum of three times the nominal maximum aggregate size. Pavement cores having a minimum diameter of $250 \mathrm{~mm}$ can also be tested. The test temperature for the Hamburg is $50^{\circ} \mathrm{C}$. 


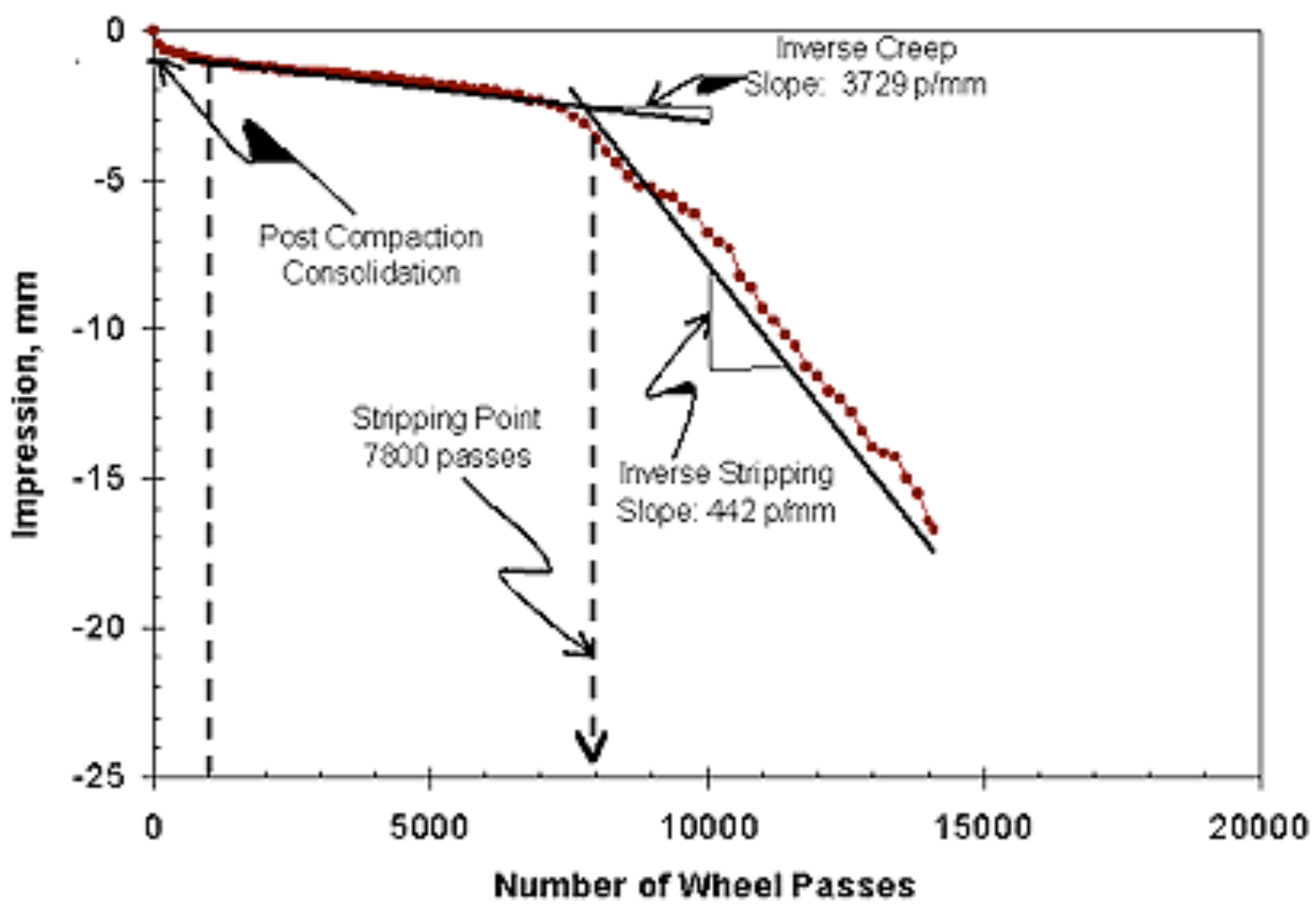

Figure 2.3: Hamburg Wheel Test Measuring Rut Depth Over the Number of Wheel Passes (Source: www.fhwa.dot.gov)

According to FWHA, the post-compaction consolidation is the deformation, in mm, at 1,000 wheel passes. The creep slope is used to measure rutting susceptibility. It measures the accumulation of permanent deformation primarily due to mechanisms other than moisture damage. Figure 1 explains the points and slopes of the Hamburg Wheel Test. The stripping inflection point and the stripping slope are used to measure moisture damage. The stripping inflection point is the number of wheel passes at the intersection of the creep slope and the stripping slope. This is the number of wheel passes at which 
moisture damage starts to dominate performance. The stripping slope measures the accumulation of permanent deformation primarily due to moisture damage.

\subsection{Summary}

The problem of asphalt stripping has been around for decades. Many solutions to mitigate stripping in asphalt pavements and improve the performance have been employed. Many methods to evaluate moisture susceptibility of HMA mixes, such as Boiling Test, Texas Boiling Water Test, Tunnicliff-Root conditioning, Immersion-Compression Test, Lottman Test, Modified Lottman Test, and Hamburg Wheel Test, have been developed. There are two different categories for types of tests. The first category is the qualitative tests, which are subjective tests that do not give concrete results such as all boiling tests and static immersion test. The advantages of these tests are a reasonably low cost. These tests are inexpensive to conduct, do not require extensive amount of time, and use simpler equipment and procedures. However, these tests are subjective to the evaluator, as well as it does not provide a true representation of traffic, environment, and mix design. The second category is the quantitative strength tests that include indirect tensile strength and immersion compression testing. These strength tests are beneficial because they take traffic, environment, and mix design into consideration, as well as produce results that can be quantified. Many agencies have used these tests, which are fairly accurate and indicative of the asphalt pavement strength. In order to evaluate moisture damage on liquid antistripping agents and hydrated lime, tensile strength and immersioncompression tests will be conducted. 


\section{CHAPTER 3 - EXPERIMENTAL WORKS \& RESULTS}

\subsection{Introduction}

The purpose of this research study is to determine the effects of the antistripping additives on the moisture susceptibility of asphalt pavement. The two main tests that are used in this study include the Modified Lottman Test (AASHTO TP9), which measures the indirect tensile strength, and the Immersion Compression Test (ASTM D1074), which measures the compressive strength of the mix.

Cal Portland Aggregates was the sole supplier for Crushed Stone aggregate. The aggregates were sieved according to SuperPave mix design limits. Oxnard Refinery donated their most common binder, Performance grade 64-16 (PG 64-16), which was the sole binder used in this study. The asphalt binder viscosity was analyzed by using a dynamic shear rheometer. Binder viscosity was tested under virgin and aged, nonenhanced and enhanced conditions. Mitigation methods for this research consist of industrial hydrated lime, which was purchased from a local surplus store and liquid antistrip additives donated by Arr Maz Custom Chemicals. Hydrated lime was added at $1.0 \%, 1.5 \%$, and $2.0 \%$. Ad-Here LOF-6500 antistripping is a low odor and reported to be effective antistrip for a wide range of aggregate types. This chemical additive was tested at $0.25 \%, 0.50 \%$, and $0.75 \%$. XL-9000 antistripping is a newer antistripping agent from Arr Maz CC and was used to compare the effectiveness of preventing moisture-related damage. Similar to Ad-Here LOF-6500, this chemical additive was also tested at $0.25 \%$, $0.50 \%$, and $0.75 \%$. 
The specimen compaction process was completed with a gyratory compactor from Rainhart Co. Specimen compaction followed SuperPave mix design. The two methods of evaluations used for this research includes Indirect Tensile Strength Test and Immersion Compression Test. According to Indirect Tensile Strength and Immersion Compression test procedures, specimens were compacted to a diameter of $100 \mathrm{~mm}$ and a height of $72 \mathrm{~mm}$. Each test required a batch of 6 specimens per treatment combination; therefore, a minimum of 120 specimens was made to accommodate the tests. For testing, each combination specimens (6 in a batch) were divided into two groups. One group was unconditioned, but placed in a room temperature water bath, and the other was conditioned in a water bath at a temperature of $140^{\circ} \mathrm{F}$.

\subsection{List of tests}

The tests used in this research range from aggregate testing to moisture susceptibility. All tests are done in accordance with AASHTO, ASTM, SuperPave, and Cal Trans standards.

\subsubsection{Tests For Aggregates}

One type of aggregate was used for this study; namely crushed stone. The crushed stone aggregate was provided by Cal Portland located in San Luis Obispo, CA. This type of aggregate was chosen because of the availability and its common use in the central coast. Cal Portland's quarry source is located in Paso Robles, CA. This aggregate is commonly used in this area as it was recently used to repave Highway 101 in the San Luis Obispo County. 


\subsubsection{Sieve Analysis Test}

The Sieve Analysis test in accordance with (AASHTO T27-99) was conducted to determine the gradation of the aggregates used in this research. The results are used to determine the compliance of the particle size distribution with the proper specification requirements. It is also used to provide necessary data for control of the production of asphalt design mixtures. The results are shown in Table 3.1.

Table 3.1: Sieve Analysis Test Results

\begin{tabular}{|c|c|c|c|c|}
\hline \multicolumn{5}{|c|}{ Sieve Analysis: Percent Passing per Sieve (\%) } \\
\hline & Maximum & te Size & & \\
\hline Sieve Size & 3/4" & $1 / 2 "$ & No. 4 & Fine \\
\hline 1" & 99.2 & $\mathrm{~N} / \mathrm{A}$ & $\mathrm{N} / \mathrm{A}$ & $\mathrm{N} / \mathrm{A}$ \\
\hline $3 / 4^{\prime \prime}$ & 47.5 & 100.0 & N/A & N/A \\
\hline $1 / 2^{\prime \prime}$ & $\mathrm{N} / \mathrm{A}$ & $\mathrm{N} / \mathrm{A}$ & $\mathrm{N} / \mathrm{A}$ & $\mathrm{N} / \mathrm{A}$ \\
\hline $3 / 8^{\prime \prime}$ & 0.6 & 6.5 & 96.7 & 99.7 \\
\hline No. 4 & 0.4 & 0.4 & 17.6 & 85.0 \\
\hline No. 8 & 0.4 & 0.4 & 0.9 & 85.0 \\
\hline No. 30 & N/A & N/A & $\mathrm{N} / \mathrm{A}$ & $\mathrm{N} / \mathrm{A}$ \\
\hline No. 200 & 0.4 & 0.5 & 0.8 & 7.5 \\
\hline
\end{tabular}

Figure 3.1 shows the shaker used in running the sieve analysis. 


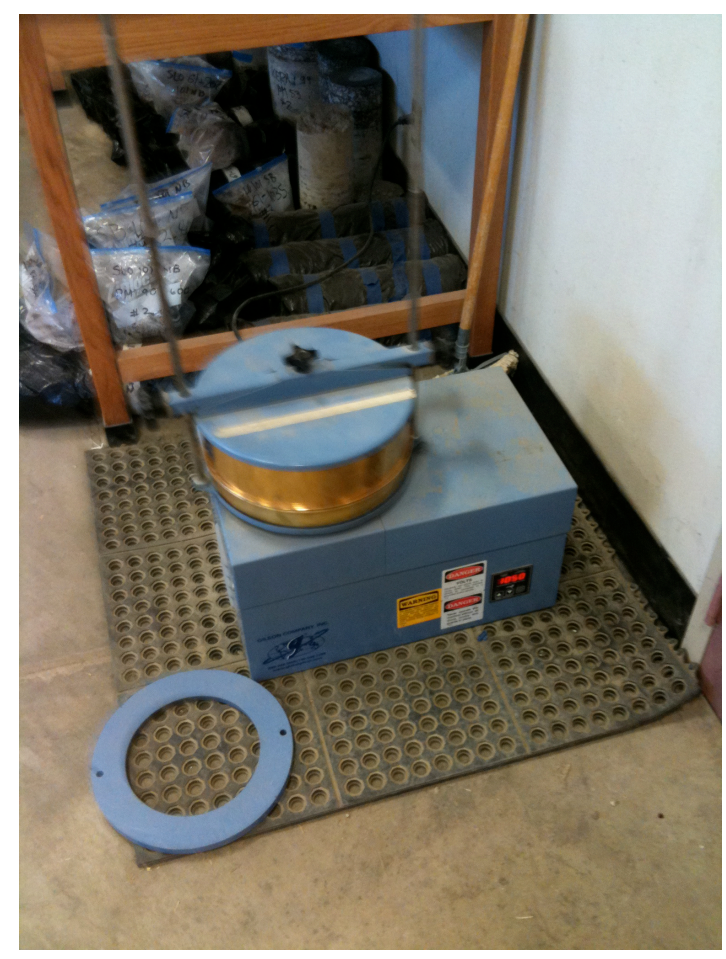

Figure 3.1: Sieve Analysis Shaker

\subsubsection{Specific Gravity of Coarse and Fine Aggregates}

"Specific Gravity and Absorption of Fine Aggregate" (AASHTO T 84-00) is done to determine the bulk specific gravity, as well as, the absorption of fine aggregates. This test requires the aggregates to be soaked in water for 15 hours. Table 3.2 presents the bulk specific gravity of the coarse and fine aggregates.

Table 3.2: Specific Gravity of Coarse and Fine Aggregates

\begin{tabular}{|c|c|c|c|c|}
\hline Aggregate Type & $\begin{array}{c}\text { Bulk Specific } \\
\text { Gravity }\end{array}$ & $\begin{array}{c}\text { Bulk Specific } \\
\text { Gravity } \\
\text { (Saturated } \\
\text { Surface Dry) }\end{array}$ & $\begin{array}{c}\text { Apparent } \\
\text { Specific } \\
\text { Gravity }\end{array}$ & $\begin{array}{c}\text { Absorption, } \\
\%\end{array}$ \\
\hline Coarse & 2.51 & 2.54 & 2.6 & 1.4 \\
\hline Fine & 2.49 & 2.53 & 2.58 & 1.47 \\
\hline
\end{tabular}


Figure 2 shows the preparation of aggregates used for bulk density testing.

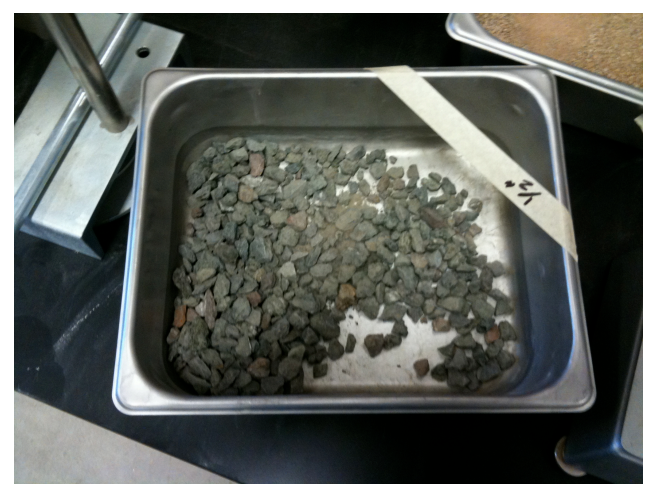

Figure 3.2: Bulk Density Test Preparations

\subsubsection{Uncompacted Void Content of Fine Aggregate}

“Uncompacted Void Content of Fine Aggregate" (AASHTO T 304-96 (2000) was used to determine the loose uncompacted void content of a specimen of fine aggregate. When measured on the aggregates, void content provides an indication of the possible effects of the workability of a mixture with the fine aggregates. Table 3.3 presents the uncompacted void content of the fine aggregate used in the study.

\section{Table 3.3: Uncompacted Void Content}

\begin{tabular}{|c|c|}
\hline $\begin{array}{c}\text { Aggregate } \\
\text { Type }\end{array}$ & $\begin{array}{c}\text { Uncompacted Void } \\
\text { Content, \% }\end{array}$ \\
\hline Fine & 42.39 \\
\hline
\end{tabular}

Figure 3 presents the equipment used for uncompacted void content test. 


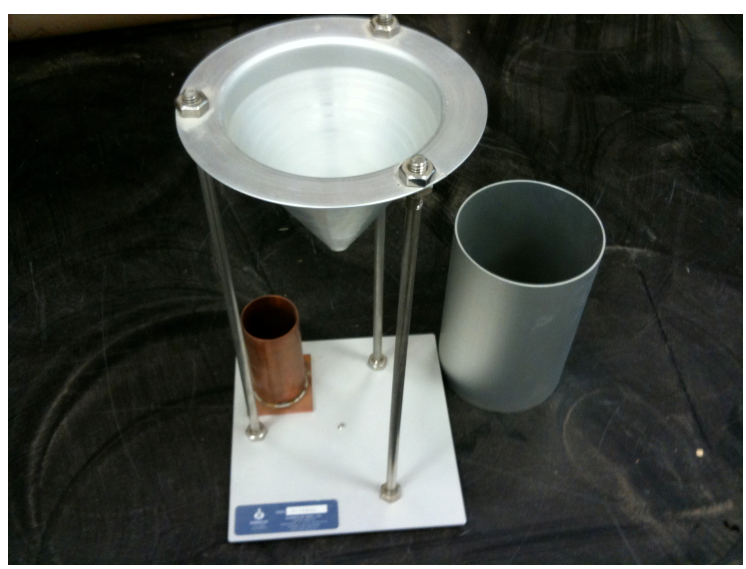

Figure 3.3: Uncompacted Void Content Testing Apparatus

\subsubsection{Los Angeles Abrasion and Impact Test}

"Resistance to Degradation of Small-size Coarse Aggregate by Abrasion and Impact in the Los Angeles Machine" (ASTM C 131-01) was done to measure the degradation of mineral aggregates of standard grading, typically smaller than 1.5 inch. Table 3.4 presents the percent loss of aggregates post testing.

Table 3.4: Los Angeles Abrasion and Impact Test Los Angeles Abrasion Test

\begin{tabular}{l|l} 
\% Loss & 39.97
\end{tabular}

Figure 3.4 presents the Los Angeles Abrasion Machine. 


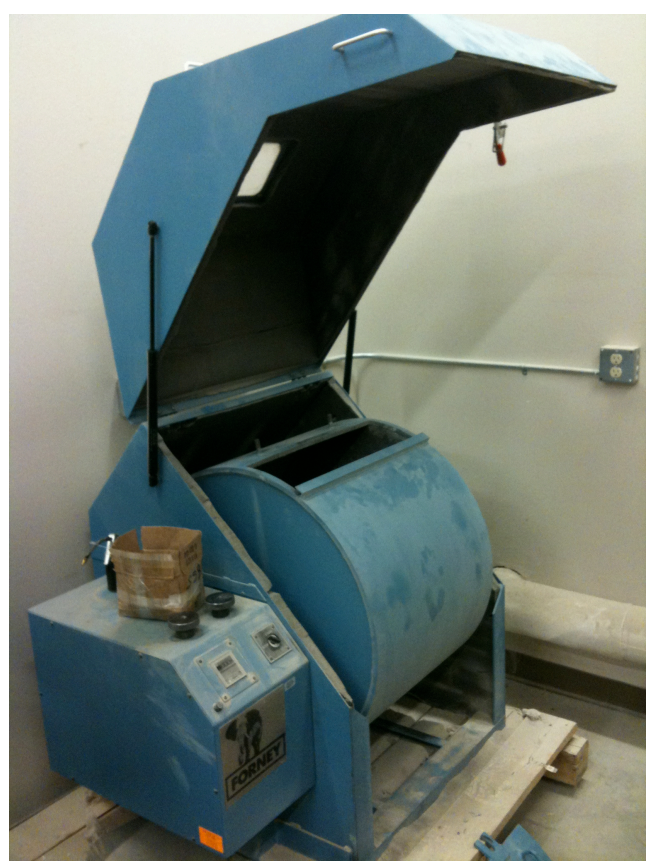

\section{Figure 3.4: Los Angeles Abrasion Testing Device}

\subsubsection{Flat, Elongated, or Flat and Elongated Particle Test}

One of the aggregate selection tests is the flat, elongated particles test. "Flat Particles, Elongated Particles, or Flat and Elongated Particles in Coarse Aggregate" (ASTM D4791-99) was done to determine the percentage of flat particles, elongated particles, or flat and elongated particles in coarse aggregates. The purpose of this is to prevent any interference with consolidation during compaction. This test method provides a means for checking compliance with specifications that limit such particles and/or to determine the relative shape characteristics of coarse aggregates. This test is performed on coarse aggregate particles (larger than $4.75 \mathrm{~mm}$ ). The criteria for the flat, elongated particles test is a maximum of $10 \%$. The percentage obtained in this study is $0 \%$ for flat, elongated, flat and elongated particles. In this case, the aggregates readily satisfy the requirement. 
Figure 3.5 presents the apparatus used to measure the flat, elongated, and flat and elongated aggregates.

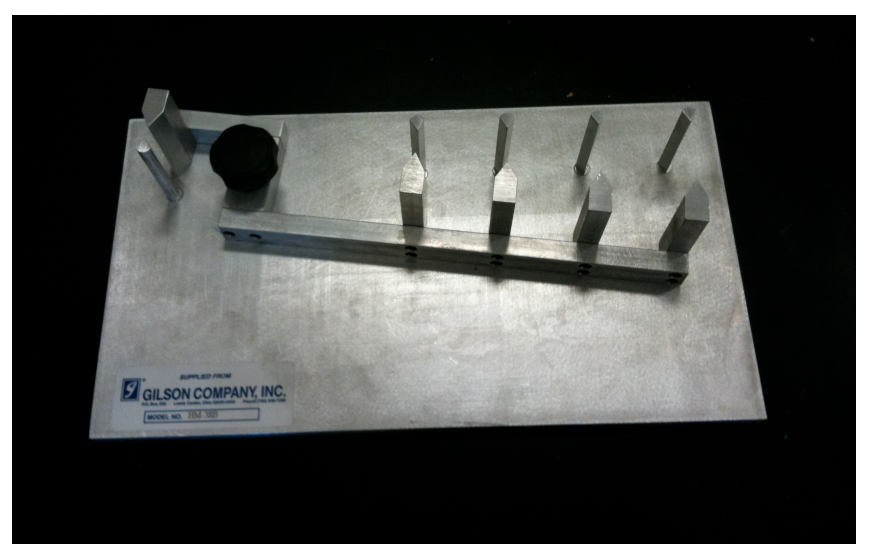

Figure 3.5: Flat, Elongated Test Apparatus

\subsubsection{Sand Equivalent Test}

Another aggregate selection test used is the Sand Equivalent Test. "Plastic Fines in

Graded Aggregates and Soils by Use of the Sand Equivalent Test" (AASHTO T 176-02) was done to determine the relative proportions of fine dust or claylike material in soils and graded aggregates. Although this test is intended to serve as a rapid field test, it was performed in the lab as extra precaution. This test is performed on the fine aggregates (smaller than $4.75 \mathrm{~mm}$ ). The minimum criteria for this test is $45 \%$ sand equivalent. Result of the San Equivalent Test is presented in Table 3.5 and the apparatus used is shown in Figure 3.6. 
Table 3.5: Sand Equivalent (Clay Content)

\begin{tabular}{|c|c|}
\hline Aggregate & Sand Equivalent, \% \\
\hline Cal Portland Sand & 85 \\
& \\
\hline
\end{tabular}

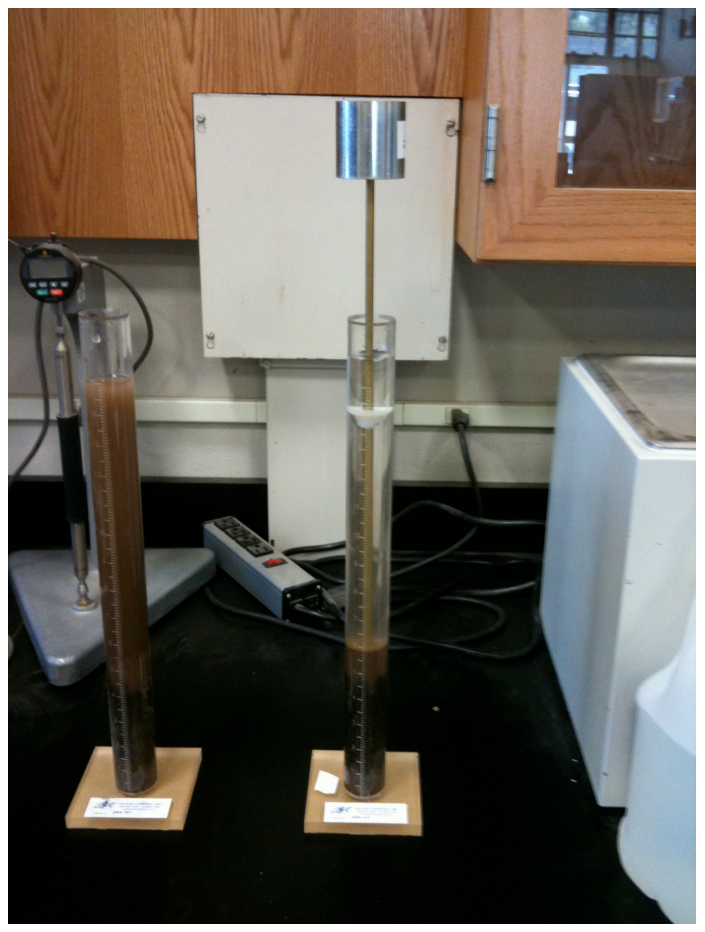

Figure 3.6: Sand Equivalent Testing Apparatus

\subsubsection{Tests For The Asphalt Binder}

Tests for the asphalt binder include the dynamic shear rheometer and rolling thin film

oven. These two tests determine the binder properties under virgin and aged conditions. 


\subsubsection{Dynamic Shear Rheometer}

Determining the Rheological Properties of Asphalt Binder Using a Dynamic Shear Rheometer (DSR), in accordance with AASHTO T315-04. The significance of this test is to determine the dynamic shear modulus and phase angle of asphalt binder that is tested in dynamic (oscillatory) shear using parallel plate test geometry. It is also intended for determining the viscoelastic behavior of asphalt binders. The complex shear modulus and the phase angle obtained from the DSR test define the resistance to shear deformation of the asphalt binder in the linear viscoelastic region.

The DSR test was done on 9 different treatment combinations at two tests each combination. Two specimens for the original binder, two for lime at $1.0 \%$, two for lime at $1.5 \%$, two for Ad-Here LOF-6500 at $0.25 \%$, two for Ad-Here LOF-6500 at $0.50 \%$, two for Ad-Here LOF-6500 at 0.75\%, two for XL-9000 at 0.25\%, two for XL-9000 at 0.50\%, two for XL-9000 at $0.75 \%$,

\subsubsection{Rolling Thin Film Oven Test}

Rolling Thin Film Oven Test, RTFO Test in accordance with AASHTO T240-03. This test determines the change in properties of asphalt during conventional hot-mixing at about $150^{\circ} \mathrm{C}\left(302^{\circ} \mathrm{F}\right)$ as appropriate for hot-mix. The test yields a residue, which approximates the asphalt condition as seen in the pavement in the fields. This method was also used to determine the mass change of the asphalt binder, which is a measure of asphalt volatility. After aging in accordance with AASHTO T240, the same DSR test (in accordance with AASHTO T315) was used on the same number of treatment combinations as stated above. 


\subsubsection{Tests For The Mix Design:}

Mix design was done in accordance with the SuperPave mix design procedures. Other supporting tests were conducted and their results were used in the calculations of HMA design.

\subsubsection{Qualitative Tests For HMA Design}

Strategic Highway Research Program (SHRP) developed Superior Performing Asphalt Pavement (SuperPave) to replace older asphalt pavement design methods (Hveem and Marshall). SuperPave is a more efficient and effective design process because it incorporates climate and traffic volume, as well as the type of binder and aggregate. This design method has been used to create the mix design for this research and is further described in this chapter.

Theoretical Maximum Specific Gravity and Density of Bituminous Paving Mixtures (AASHTO T209-99 (2004)) determines the maximum theoretical density of bituminous paving mixtures. This test will provide target values for the compaction of paving mixtures. According to AASHTO, The theoretical maximum specific gravities and densities of bituminous paving mixtures are intrinsic properties whose values are influenced by the composition of the mixtures in terms of types and amounts of aggregates and bituminous materials. The data table can be seen in Table 3.9.

Bulk Specific Gravity of Compacted Asphalt Mixtures Using Saturated Surface-Dry Specimens (AASHTO T 166-00) is to determine the bulk specific gravity of core specimens made in a laboratory or some the field. This test was applied to all specimens tested in this study. Results are presented in this chapter. 


\subsubsection{Performance Tests For HMA Design}

Resistance of Compacted Asphalt Mixtures to Moisture Induced Damage (AASHTO T 283-03) evaluates the effects of saturation and accelerated water conditioning of compacted asphalt mixtures. This test provided information for preparations of the specimens as well as the measurements of the change of diametral tensile strength that resulted from the effects of water saturation. The mix design gradations were modified to accommodate to reach the standard specific gravity values $\left(\mathrm{G}_{\mathrm{mm}}\right)$ and specimen heights. The design procedure required optimizing the gradations (intermediate, coarse, and fine). For this study, an extra fine mixture was developed in order to meet the SuperPave design criteria. The specimens are tested for indirect tensile strength by loading the specimens at a constant rate and measuring the force required to break the specimen. The tensile strength of the conditioned specimens is compared to the control specimens to determine the tensile strength ratio. The data is further described in this chapter.

Standard Test Method for Compressive Strength of Bituminous Mixtures (ASTM D 1074-96) This test determines the compressive strength for HMA under conditioned and unconditioned states. It also determines the strain received on each specimen by the constant compressive force applied. The data is further described in this chapter.

\subsection{Asphalt Binder Testing}

In this study, one asphalt binder was used to prepare the Hot Mix Asphalt (HMA) specimens. The asphalt binder was provided by Oxnard Refinery, located in Oxnard, CA and has a performance grade of 64-16 (PG 64-16) with a specific gravity of 1.027. PG 64-16 is the common binder used in the central-coast. 
The asphalt binder has undergone a series of tests to determine the dynamic shear modulus and phase angle of asphalt binder. There were 10 different treatment combinations that were prepared in this study. The treatment combinations are shown in Table 3.6.

Table 3.6: Treatment Combination

\begin{tabular}{|c|c|c|c|}
\hline Additive & \multicolumn{3}{|c|}{ Dosage Rate, \% } \\
\hline Control & \multicolumn{3}{|c|}{0} \\
\hline LOF-6500 & 0.25 & 0.50 & 0.75 \\
\hline XL-9000 & 0.25 & 0.50 & 0.75 \\
\hline Lime & 1.0 & 1.5 & 2.0 \\
\hline
\end{tabular}

Figure 3.7 presents the ADS Dynamic Shear Rheometer machine used to run the test. 


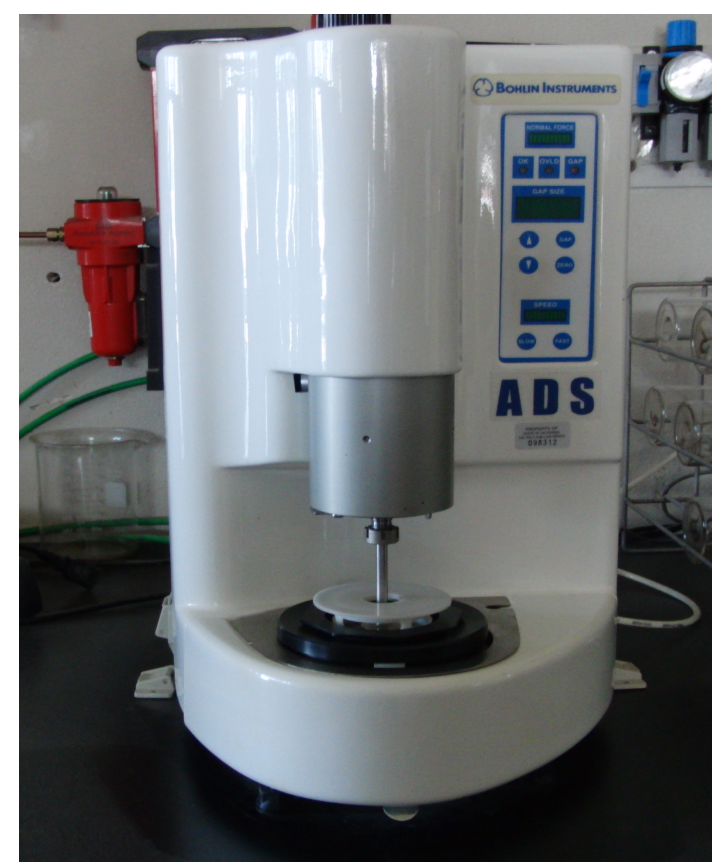

Figure 3.7: ADS Dynamic Shear Rheometer

Dynamic Shear Rheometer (AASHTO T315-04) test was conducted on the virgin binder and the aged binder. Binder aging was conducted using the Rolling Thin Film Oven in accordance with AASHTO T240-03. Figure 3.8 shows the Rolling Thin Film Oven.

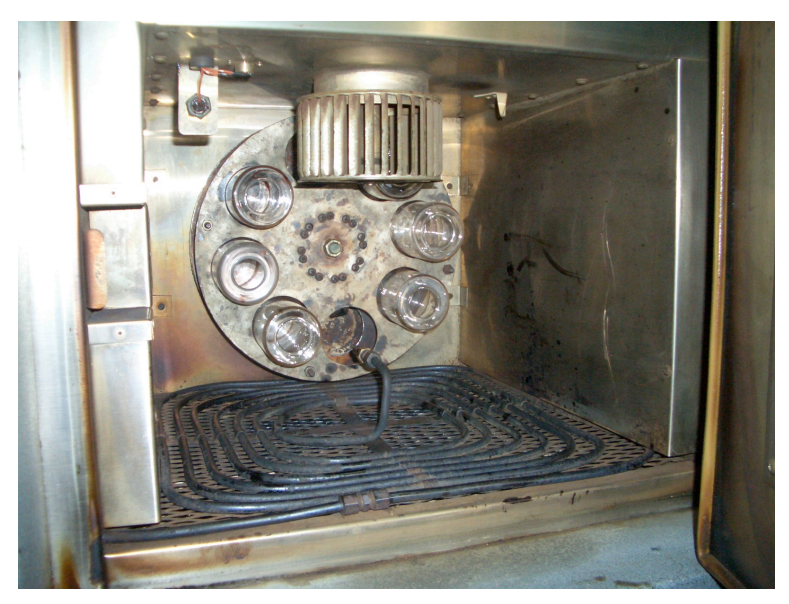

Figure 3.8: Rolling Thin Film Oven 
Table 3.7 shows the results from the DSR test. The most important parameters are the complex shear modulus, viscous modulus, phase angle, and others are presented below.

Table 3.7: Dynamic Shear Rheometer Results

\begin{tabular}{|c|c|c|c|c|c|c|c|c|}
\hline Treatment & $\begin{array}{c}\text { Additive } \\
\text { Percentage, } \\
\%\end{array}$ & $\begin{array}{c}\text { Complex } \\
\text { Modulus, } \\
\text { Pa }\end{array}$ & $\begin{array}{c}\text { Elastic } \\
\text { Modulus, } \\
\mathrm{Pa}\end{array}$ & $\begin{array}{c}\text { Viscous } \\
\text { Modulus, } \mathrm{Pa}\end{array}$ & $\begin{array}{c}\text { Complex } \\
\text { Viscosity } \\
\text {, Pas }\end{array}$ & $\begin{array}{c}\text { Phase Angle, } \\
\circ\end{array}$ & $\begin{array}{c}\text { Shear } \\
\text { Stress, } \mathrm{Pa}\end{array}$ & Strain \\
\hline \multicolumn{9}{|l|}{ Virgin Batch } \\
\hline Control & 0 & 2047.250 & 54.645 & 1628.000 & 162.450 & 88.090 & 193.000 & 0.119 \\
\hline LOF $0.25 \%$ & 0.25 & 836.600 & 12.800 & 836.500 & 83.440 & 89.120 & 99.880 & 0.119 \\
\hline LOF $0.50 \%$ & 0.5 & 467.100 & 10.070 & 467.000 & 46.580 & 88.800 & 56.790 & 0.121 \\
\hline LOF $0.75 \%$ & 0.75 & 345.300 & 13.610 & 345.050 & 34.435 & 87.725 & 48.055 & 0.138 \\
\hline XL9 $0.25 \%$ & 0.25 & 674.200 & 11.520 & 674.100 & 67.240 & 89.020 & 83.030 & 0.123 \\
\hline XL9 0.50\% & 0.5 & 347.400 & 4.864 & 347.400 & 34.650 & 89.200 & 41.600 & 0.119 \\
\hline XL9 $0.75 \%$ & 0.75 & 306.850 & 6.928 & 306.750 & 30.600 & 88.705 & 37.420 & 0.121 \\
\hline Lime $1.0 \%$ & 1 & 2294 & 74.43 & 2293 & 228.8 & 88.1 & 278.2 & 0.1213 \\
\hline Lime $1.5 \%$ & 1.5 & 3505 & 129.9 & 3503 & 349.6 & 87.9 & 424.7 & 0.1212 \\
\hline Lime $2.0 \%$ & 2 & 4843.5 & 258.55 & 4836.5 & 483.1 & 86.94 & 606.25 & 0.1252 \\
\hline \multicolumn{9}{|l|}{ Aged Batch } \\
\hline Control & 0 & 2775.000 & 185.100 & 2769.000 & 276.800 & 86.180 & 323.600 & 0.117 \\
\hline LOF $0.25 \%$ & 0.25 & 2366.667 & 132.633 & 2362.667 & 236.033 & 86.800 & 279.967 & 0.118 \\
\hline LOF $0.50 \%$ & 0.5 & 2235.333 & 125.547 & 2231.333 & 222.967 & 87.023 & 266.200 & 0.119 \\
\hline LOF $0.75 \%$ & 0.75 & 912.800 & 13.440 & 912.700 & 91.040 & 89.160 & 107.500 & 0.118 \\
\hline XL9 0.25\% & 0.25 & 2622.667 & 160.900 & 2617.333 & 261.567 & 86.507 & 313.600 & 0.120 \\
\hline XL9 0.50\% & 0.5 & 2016.000 & 108.560 & 2012.667 & 201.033 & 87.120 & 237.300 & 0.118 \\
\hline XL9 $0.75 \%$ & 0.75 & 728.100 & 15.740 & 727.900 & 72.620 & 88.760 & 88.160 & 0.121 \\
\hline Lime 1.0\% & 1 & 3981.5 & 316.7 & 3969 & 397.1 & 85.325 & 478.45 & 0.12065 \\
\hline Lime 1.5\% & 1.5 & 5360.5 & 370.2 & 5347.5 & 534.6 & 86.045 & 626.7 & 0.117 \\
\hline Lime $2.0 \%$ & 2 & 11850 & 1298 & 11780 & 1182 & 83.71 & 1478.5 & 0.1248 \\
\hline
\end{tabular}

\subsection{Hot Mix Asphalt Preparation}

In this research, all specimens were designed in accordance with SuperPave mix design

procedures. The design procedure began with aggregate selection, followed by an asphalt

binder content selection.

The SuperPave specification for aggregate gradation was adopted in this study. Four

aggregate structures were considered for the study: intermediate blend, coarse blend, fine 
blend, and extra fine blend. The intermediate blend is prepared to produce a gradation that is not close to any control point limits. The coarse blend is prepared to produce a gradation that is near the lower range of SuperPave specifications. The fine blend is prepared to produce a gradation that is close to the upper range of the SuperPave specifications. The extra fine blend is prepared to produce a gradation that is the closest possible to the maximum percent passing the nominal maximum size. The extra fine blend was selected for this study because it provided the lowest air void ratio (about 7\%) during our trials. Table 3.8 presents the sieve analysis test results for the different aggregate sizes and gradations for the four different trial mixes investigated in this study.

Table 3.8: 1" Nominal Aggregate Size Mix Design

\begin{tabular}{|l|c|c|c|c|c|c|}
\cline { 2 - 7 } \multicolumn{1}{c|}{} & \multicolumn{7}{c|}{ Percent Passing } \\
\hline \multicolumn{1}{c|}{ Sieve Size } & 25 & 19 & 12.5 & 9.5 & 2.36 & 0.075 \\
\hline SuperPave Range & $90-100 \%$ & $0-90 \%$ & $\mathrm{n} / \mathrm{a}$ & $\mathrm{n} / \mathrm{a}$ & $19-45 \%$ & $1-7 \%$ \\
\hline Coarse Blend & 7 & 22 & 19 & 28 & 21.0 & 3 \\
\hline Intermediate Blend & 6 & 17 & 13 & 36 & 24.8 & 3.2 \\
\hline Fine Blend & 2.5 & 7.5 & 12 & 46 & 28.5 & 3.5 \\
\hline Extra Fine Blend & 2 & 4 & 7 & 50 & 33.0 & 4 \\
\hline
\end{tabular}

The maximum theoretical specific gravity is another important factor asphalt mix design. The significance of this test is to determine the percent air voids in loose bituminous paving mixtures. Essentially, this test provides target values for the compaction of paving mixtures. According to AASHTO T-209, the theoretical maximum specific gravities and densities of bituminous paving mixtures are intrinsic properties whose values are influenced by the composition of the mixtures in terms of types and amounts of aggregates and bituminous materials. The following equation was used to obtain the Specific Gravity values: 


$$
\text { Specific Gravity }=\frac{A}{(A+B-C)}
$$

Where,

$$
\begin{aligned}
& \mathrm{A}=\text { Mass of the flask with oven-dry specimen in air } \\
& \mathrm{B}=\text { Mass of the flask filled with water at } 77^{\circ} \mathrm{F}\left(25^{\circ} \mathrm{C}\right) \\
& \mathrm{C}=\text { Mass of the flask filled with specimen and water at } 77^{\circ} \mathrm{F}\left(25^{\circ} \mathrm{C}\right)
\end{aligned}
$$

Three aggregate gradations were prepared and mixed with a target initial binder content of $5.0 \%$. The gradations include coarse, intermediate, and fine. Table 3.9 presents the Maximum Theoretical Specific Gravity for the theoretical mixes considered for mix design.

Table 3.9: Maximum Theoretical Specific Gravity For Varying Mixes

\begin{tabular}{|c|c|c|}
\hline Intermediate & Course & Fine \\
\hline 2.40 & 2.42 & 2.39 \\
\hline
\end{tabular}

The SuperPave Gyratory Compactor designed by Rainhart Co. used for specimen compaction is shown in Figure 3.9. 


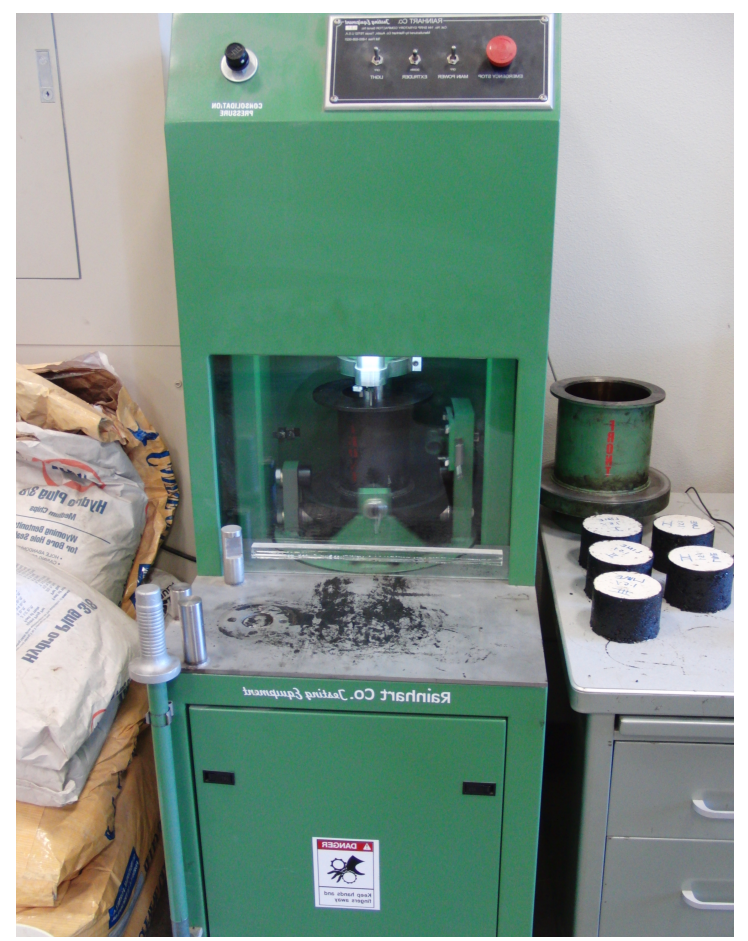

Figure 3.9: SuperPave Gyratory Compactor

The SuperPave Gyratory Compactor compacts the asphalt specimen by applying a pressure of $600 \mathrm{kPa}(87 \mathrm{psi})$ to the mix while gyrating the mold at an angle of 1.25 degrees, simulating the actions of a roller compactor in the field. The height of the specimen, speed of gyration, angle of gyration, and pressure are monitored continually. Figure 3.10 presents the mold used to compact specimens using the SuperPave gyratory compactor and Figure 3.11 presents the specimens of the compaction. 


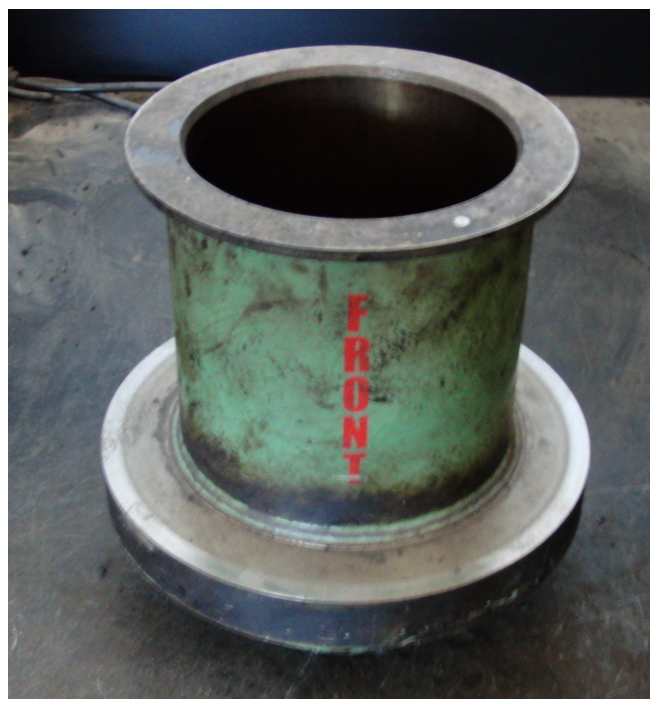

Figure 3.10: 6-inch mold for compactor

Figures 3.11 show the gyratory compacted specimens. The final mix design used in this research consists of $6 \%$ asphalt binder and an extra fine blend.

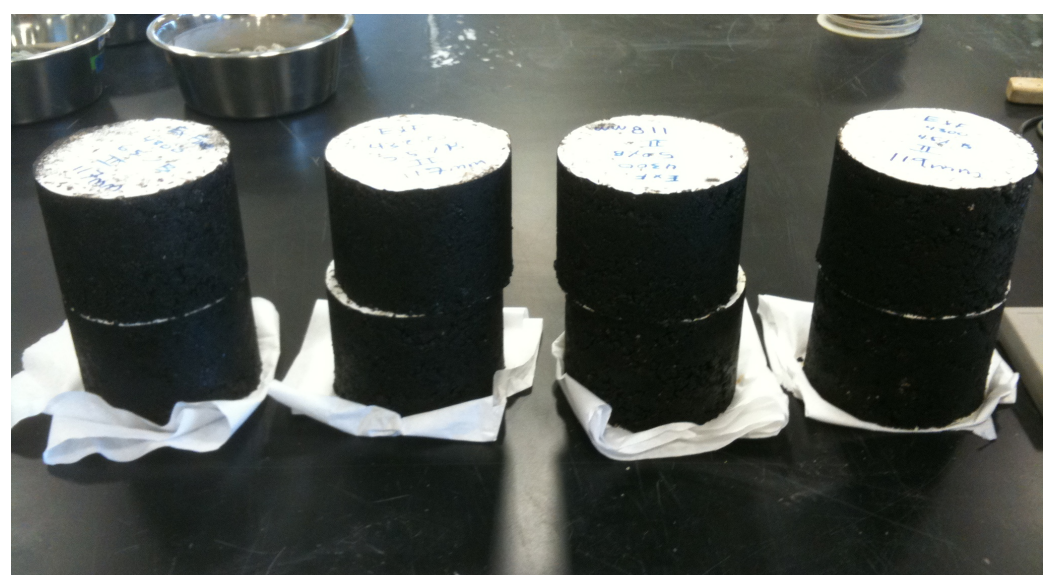

Figure 3.11: 6 inch Specimen Used for Mix Design Trials

The final mix design in this research was determined by the percent air voids of the compacted specimen. The percent air void is calculated with the Bulk Specific Gravity and Theoretical Maximum Specific Gravity values. The percent air voids in the compacted bituminous paving mixture were calculated as follows: 


$$
\text { Percent Air Voids }=\left(1-\frac{A}{B}\right) \times 100
$$

Where,

A = Bulk Specific Gravity (T-166)

B = Theoretical Maximum Specific Gravity (T-209)

The optimized air voids percentage is about $7 \%$. This percentage was achieved with an extra fine blend of aggregates and 6\% asphalt binder content.

The next step is to evaluate the selected trial blend by compacting specimens and determining the volumetric properties of the extra fine blend. The trial asphalt binder content can be determined based on the volumetric properties. Two samples were compacted for each trial using an initial asphalt content of 5.0\%. The volumetric properties of each trial blend at the estimated binder content were analyzed. The blend that produces an air void content of 5.0\% was selected and used for the mix design. Mix trials consisting of $+/-0.5 \%$ and $+1.0 \%$ of the estimated asphalt content were prepared. Table 3.10 below presents the volumetric properties along with its corresponding binder percentage for the extra fine blend. In this case, $6 \%$ binder was the ideal binder content for the study based on its low percent air voids. 
Table 3.10: Asphalt Binder Content Results

\begin{tabular}{|c|c|c|}
\hline \multicolumn{2}{|l|}{ Extra Fine Blend } & \\
\hline Binder \% & Specimen & \% Air Voids \\
\hline \multirow{2}{*}{4.5} & 1 & 11.38 \\
\cline { 2 - 3 } & 2 & 11.18 \\
\hline \multirow{2}{*}{5} & 1 & 7.51 \\
\cline { 2 - 3 } & 2 & 10.43 \\
\hline \multirow{2}{*}{5.5} & 1 & 9.00 \\
\cline { 2 - 3 } & 2 & 9.33 \\
\hline \multirow{3}{*}{6} & 1 & 7.73 \\
\cline { 2 - 3 } & 2 & 7.03 \\
\cline { 2 - 3 } & 3 & 8.21 \\
\hline \multirow{2}{*}{6.5} & 1 & 8.23 \\
\cline { 2 - 3 } & 2 & 9.96 \\
\hline
\end{tabular}

Figure 3.12 presents an aggregate gradation being mixed with $6.0 \%$ of asphalt binder.

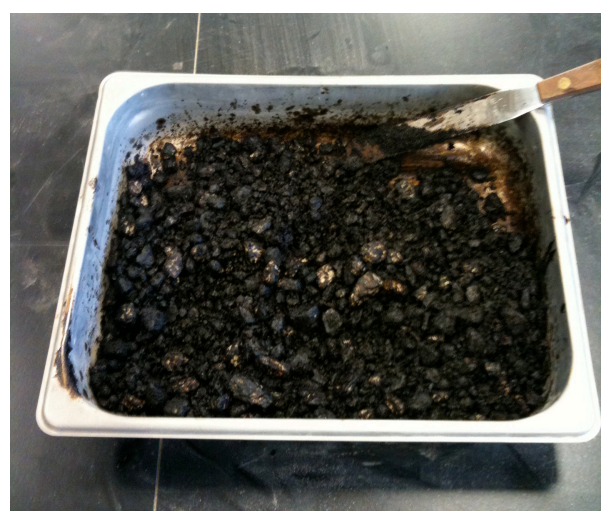

Figure 3.12: Extra Fine Blend with 6.0\% Asphalt Binder

\subsection{Lottman Test (Indirect Tensile Test)}

Following the mix design, smaller samples were prepared using the design mix. They were compacted to about 2.8 inches with a diameter of 4 inches with a total weight of approximately 1200 grams of aggregate. These specimens were later tested for Indirect Tensile Strength (ITS) following Lottman Test method (AASHATO T 283). 
The bulk specific gravity of each compacted specimen is recorded after the compaction is done. The values are averaged within each mixture combination. The averaged Bulk Specific Gravity, $\mathrm{G}_{\mathrm{mb}}$ of the Mixture is presented in Table 3.11.

\section{Table 3.11: Average Bulk Specific Gravity of the Mixture}

\begin{tabular}{|c|c|}
\hline \multicolumn{2}{|c|}{ Lottman } \\
\hline Original & 2.31 \\
\hline Ad-Here LOF6500 0.25\% & 2.29 \\
\cline { 2 - 2 } Ad-Here LOF6500 0.50\% & 2.31 \\
\cline { 2 - 2 } Ad-Here LOF6500 0.75\% & 2.30 \\
\cline { 2 - 2 } XL9000 0.25\% & 2.30 \\
\hline XL9000 0.50\% & 2.30 \\
\hline XL9000 0.75\% & 2.29 \\
\hline Lime $1.0 \%$ & 2.25 \\
\hline Lime $1.5 \%$ & 2.25 \\
\hline
\end{tabular}

Six specimens were prepared per treatment combination, a total of 120 specimens were compacted for this test. The six specimens were split into two groups, one group was conditioned in the water bath at room temperature $\left(77^{\circ} \mathrm{F}\right)$ for two hours and the other at $140^{\circ} \mathrm{F}$ for twenty-four hours.

Figure 3.13 and 3.14 shows the Satec Compression Machine with steel loading strips that was used for Indirect Tensile Strength Testing. 


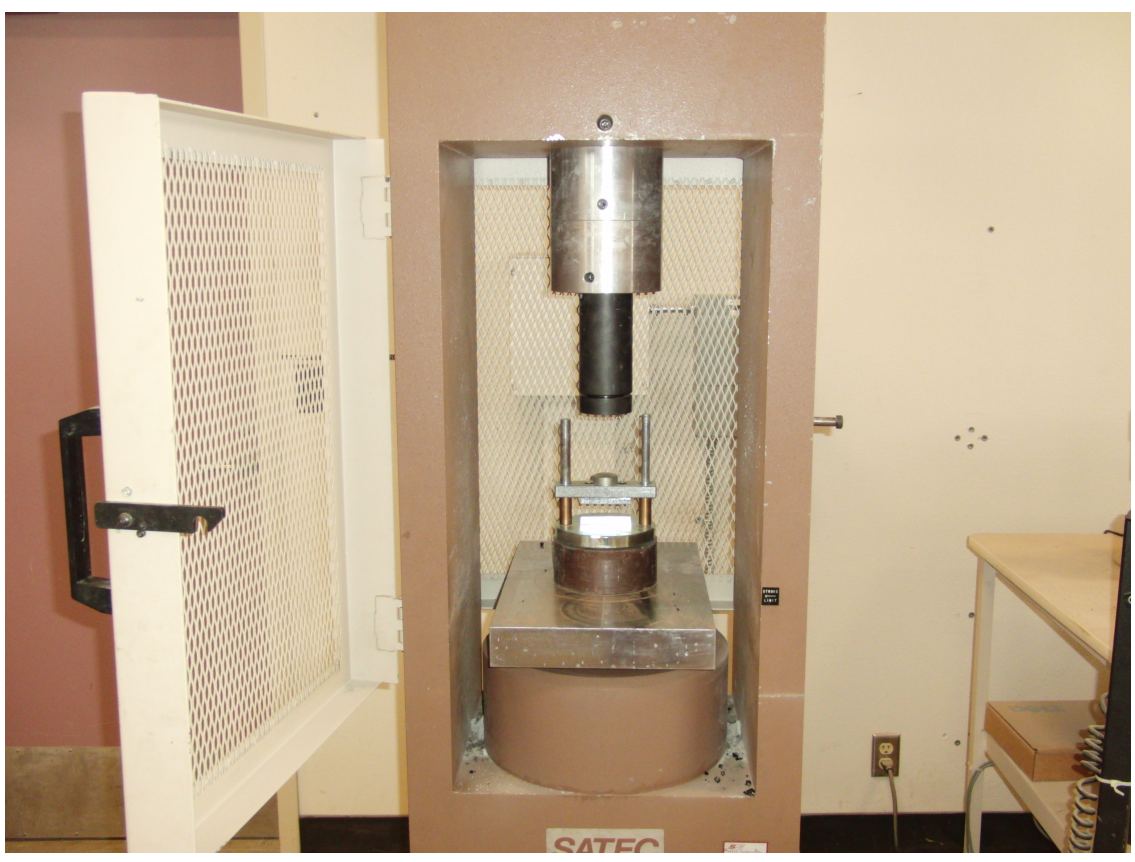

Figure 3.13: Satec Compression Machine

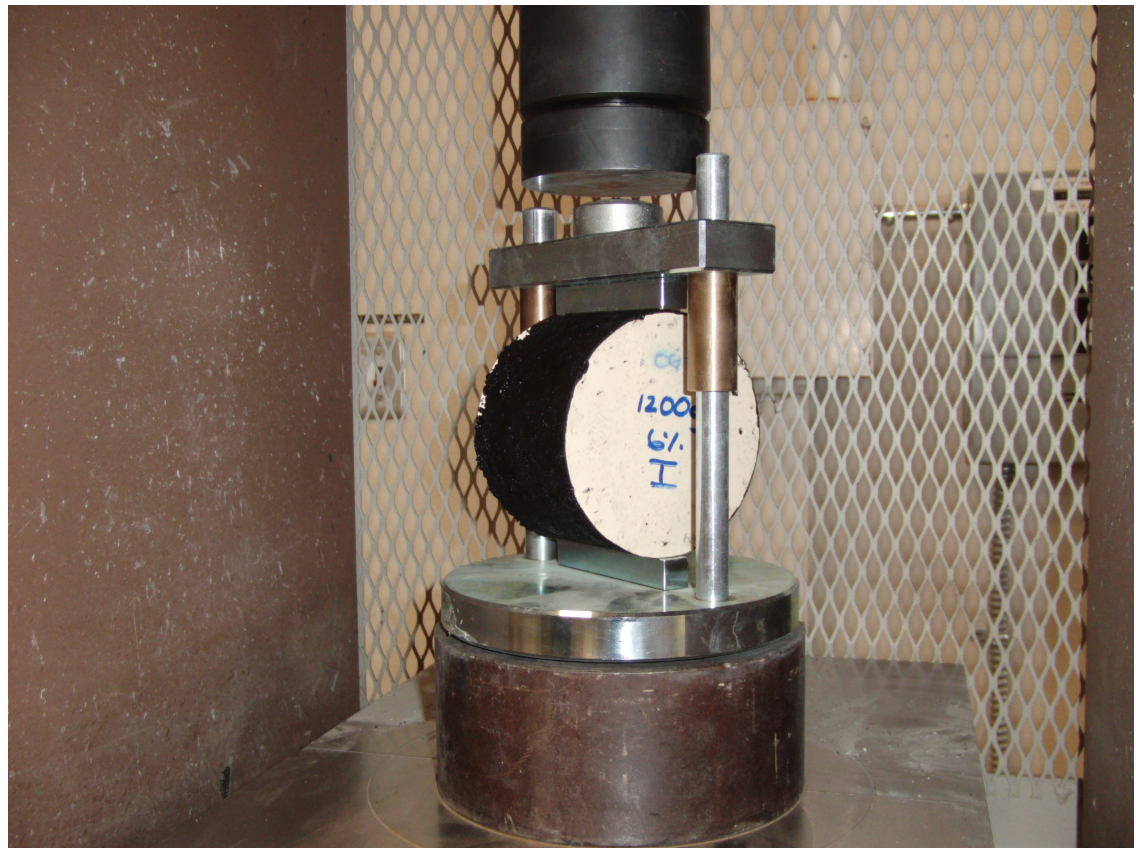

Figure 3.14: Indirect Tensile Strength Test Apparatus 
These conditioning techniques were implemented for all treatment combination and are shown in Figure 3.15.

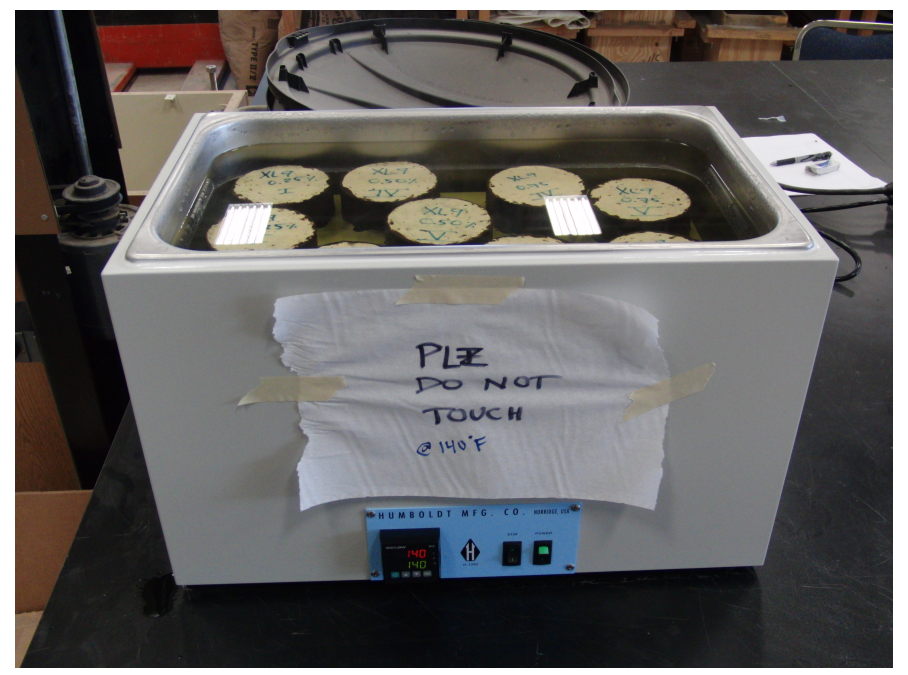

Figure 3.15: Water Bath at $140^{\circ} \mathrm{F}$

Figures 3.16 and 3.17 shows a specimen that has been tested in Indirect Tensile.

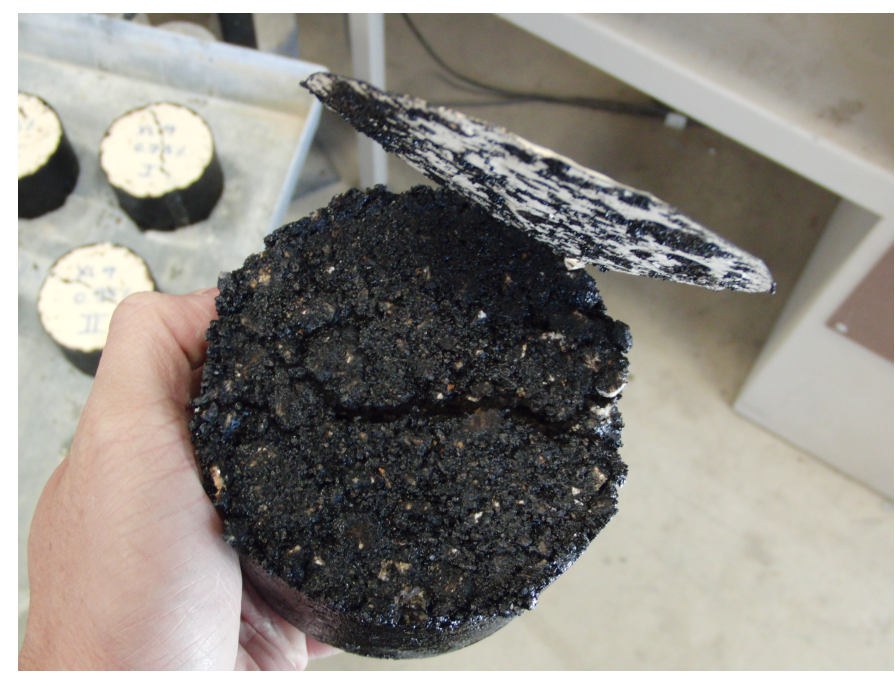

Figure 3.16: Post Indirect Tensile Test Top View 


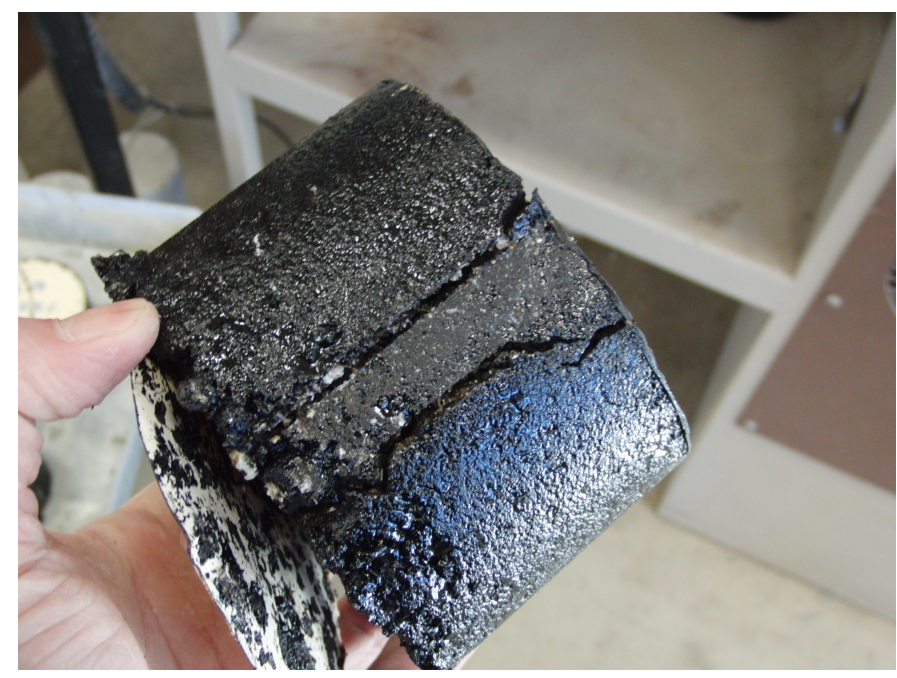

Figure 3.17: Post Indirect Tensile Test Side View

The Tensile Strength Ratio (TSR) is calculated as follows:

$$
\text { Tensile Strength Ratio (TSR) }=\frac{S_{2}}{S_{1}} \times 100
$$

Where,

$\mathrm{S}_{1}=$ average Indirect Tensile Strength of dry subset

$\mathrm{S}_{2}=$ average Indirect Tensile Strength of conditioned subset

Table 3.12 shows a summary of the Indirect Tensile Strength Test Values. 
Table 3.12: Indirect Tensile Strength Table Summary

\begin{tabular}{|c|c|c|c|c|c|c|}
\hline Treatment & \begin{tabular}{|l} 
Additive \\
Percentage
\end{tabular} & Condition & $\begin{array}{l}\text { Maximum Load (P), } \\
\text { lbs }\end{array}$ & $\begin{array}{l}\text { Tensile Strength }(\mathrm{St}) \text {, } \\
\mathrm{psi}\end{array}$ & $\begin{array}{c}\text { Tensile Strength Ratio, } \\
\text { TSR }\end{array}$ & $\begin{array}{l}\text { Tensile Strength Ratio w/ } \\
\text { Respect to Unconditioned } \\
\text { Control }\end{array}$ \\
\hline Control & 0 & $\begin{array}{l}\text { Dry } \\
\text { Cond. }\end{array}$ & $\begin{array}{l}7765.00 \\
6092.00\end{array}$ & $\begin{array}{l}433.92 \\
339.43\end{array}$ & $78.23 \%$ & $\begin{array}{l}100.00 \% \\
78.23 \%\end{array}$ \\
\hline LOF $0.25 \%$ & 0.25 & $\begin{array}{l}\text { Dry } \\
\text { Cond. }\end{array}$ & $\begin{array}{l}7363.00 \\
6242.00\end{array}$ & $\begin{array}{l}409.27 \\
345.42\end{array}$ & $84.40 \%$ & $\begin{array}{l}94.32 \% \\
79.61 \%\end{array}$ \\
\hline LOF $0.50 \%$ & 0.5 & $\begin{array}{l}\text { Dry } \\
\text { Cond. }\end{array}$ & $\begin{array}{l}7017.33 \\
6176.00\end{array}$ & $\begin{array}{l}391.15 \\
345.45\end{array}$ & $88.32 \%$ & $\begin{array}{l}90.14 \% \\
79.61 \%\end{array}$ \\
\hline LOF $0.75 \%$ & 0.75 & $\begin{array}{l}\text { Dry } \\
\text { Cond. }\end{array}$ & $\begin{array}{l}6792.00 \\
5499.33 \\
\end{array}$ & $\begin{array}{l}380.03 \\
308.06 \\
\end{array}$ & $81.06 \%$ & $\begin{array}{l}87.58 \% \\
70.99 \%\end{array}$ \\
\hline XL9 $0.25 \%$ & 0.25 & $\begin{array}{l}\text { Dry } \\
\text { Cond. }\end{array}$ & $\begin{array}{l}7582.67 \\
6359.33\end{array}$ & $\begin{array}{l}423.33 \\
353.07\end{array}$ & $84.33 \%$ & $\begin{array}{l}97.56 \% \\
81.37 \%\end{array}$ \\
\hline XL9 $0.50 \%$ & 0.5 & $\begin{array}{l}\text { Dry } \\
\text { Cond. }\end{array}$ & $\begin{array}{l}7277.67 \\
6990.67\end{array}$ & $\begin{array}{l}404.90 \\
387.60\end{array}$ & $95.73 \%$ & $\begin{array}{l}93.31 \% \\
89.33 \%\end{array}$ \\
\hline XL9 $0.75 \%$ & 0.75 & $\begin{array}{l}\text { Dry } \\
\text { Cond. }\end{array}$ & $\begin{array}{l}6895.00 \\
6654.33\end{array}$ & $\begin{array}{l}383.94 \\
368.62 \\
\end{array}$ & $96.01 \%$ & $\begin{array}{l}88.48 \% \\
84.95 \% \\
\end{array}$ \\
\hline Lime $1.0 \%$ & 1 & $\begin{array}{l}\text { Dry } \\
\text { Cond. }\end{array}$ & $\begin{array}{l}5642.00 \\
5410.00\end{array}$ & $\begin{array}{l}306.98 \\
297.81\end{array}$ & $97.01 \%$ & $\begin{array}{l}70.75 \% \\
68.63 \%\end{array}$ \\
\hline Lime $1.5 \%$ & 1.5 & $\begin{array}{l}\text { Dry } \\
\text { Cond. }\end{array}$ & $\begin{array}{l}5714.00 \\
6527.33\end{array}$ & $\begin{array}{l}312.61 \\
355.69\end{array}$ & $113.78 \%$ & $\begin{array}{l}72.04 \% \\
81.97 \%\end{array}$ \\
\hline Lime $2.0 \%$ & 2 & $\begin{array}{l}\text { Dry } \\
\text { Cond. }\end{array}$ & $\begin{array}{l}5792.67 \\
6456.33\end{array}$ & $\begin{array}{l}317.77 \\
354.23\end{array}$ & $111.48 \%$ & $\begin{array}{l}73.23 \% \\
81.64 \%\end{array}$ \\
\hline
\end{tabular}

\subsection{Immersion Compression Test}

The Immersion Compression Test measures the strength of the specimens under a continuous compressive load. The asphalt mix specimens were compressed until failure in order to obtain a complete stress vs. strain curve. The test requires six specimens per treatment combination. A total of 60 specimens were compacted and tested.

The bulk specific gravity of each compacted specimen is recorded after the compaction is done. The values are averaged within each mixture combination. The averaged Bulk Specific Gravity, $\mathrm{G}_{\mathrm{mb}}$ of the Mixture is presented in Table 3.13. 
Table 3.13: Averaged Bulk Specific Gravity of the Mixture

\begin{tabular}{|c|c|}
\hline \multicolumn{2}{|c|}{ Immersion } \\
\hline Original & 2.31 \\
\cline { 2 - 2 } Ad-Here LOF6500 0.25\% & 2.31 \\
\cline { 2 - 2 } Ad-Here LOF6500 0.50\% & 2.32 \\
\cline { 2 - 2 } Ad-Here LOF6500 0.75\% & 2.31 \\
\cline { 2 - 2 } XL9000 0.25\% & 2.32 \\
\cline { 2 - 2 } XL9000 0.50\% & 2.32 \\
\cline { 2 - 2 } XL9000 0.75\% & 2.32 \\
\cline { 2 - 2 } Lime $1.0 \%$ & 2.27 \\
\hline Lime $1.5 \%$ & 2.29 \\
\cline { 2 - 2 } Lime $2.0 \%$ & 2.29 \\
\hline
\end{tabular}

Figure 3.18 displays the equipment used for the Immersion Compression Test. The loading cell is an eight inch steel unit with a flexible head to compensate for any misaligned tests. 


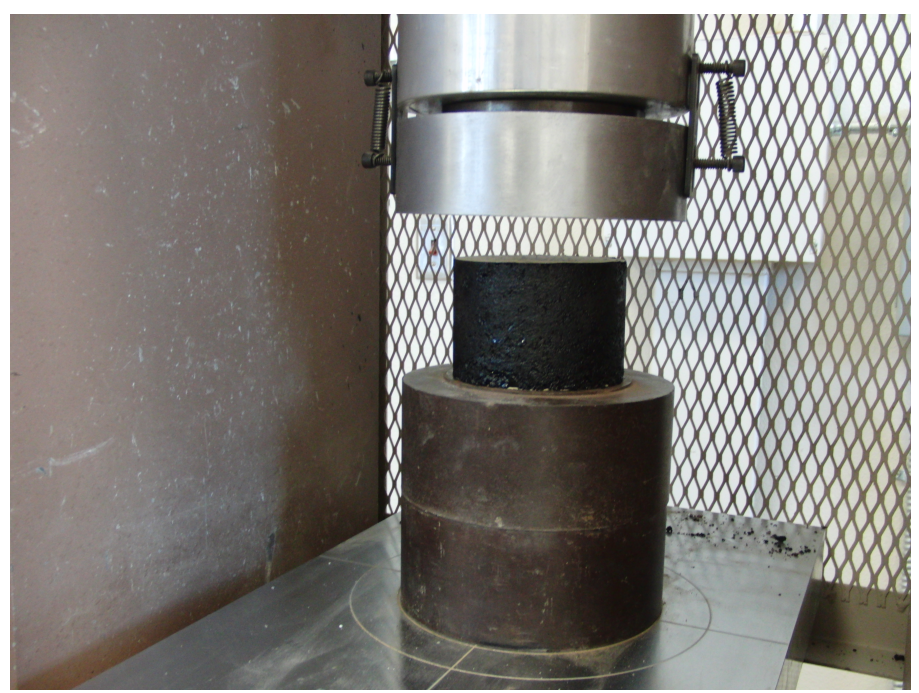

\section{Figure 3.18: Immersion Compression Test With Satec Machine}

Once the specimen is set up, testing is initiated via computer software. Parameters are input into the system and the test is activated. Figure 3.20 shows one control specimen experiencing a compressive loading rate of $0.14 \mathrm{in} / \mathrm{min}$. The specimens were then tested to a threshold of $20 \%$ of peak strength. This means that the specimen will stop loading when strength drops to $20 \%$ of its peak strength. The Compression Strength of each sample (unconditioned and conditioned) was recorded after each test. The threshold for the Immersion Compression Test is lower than the Indirect Tensile Test because the desired information is obtained by $20 \%$ of peak strength, anything greater than that is unnecessary. 


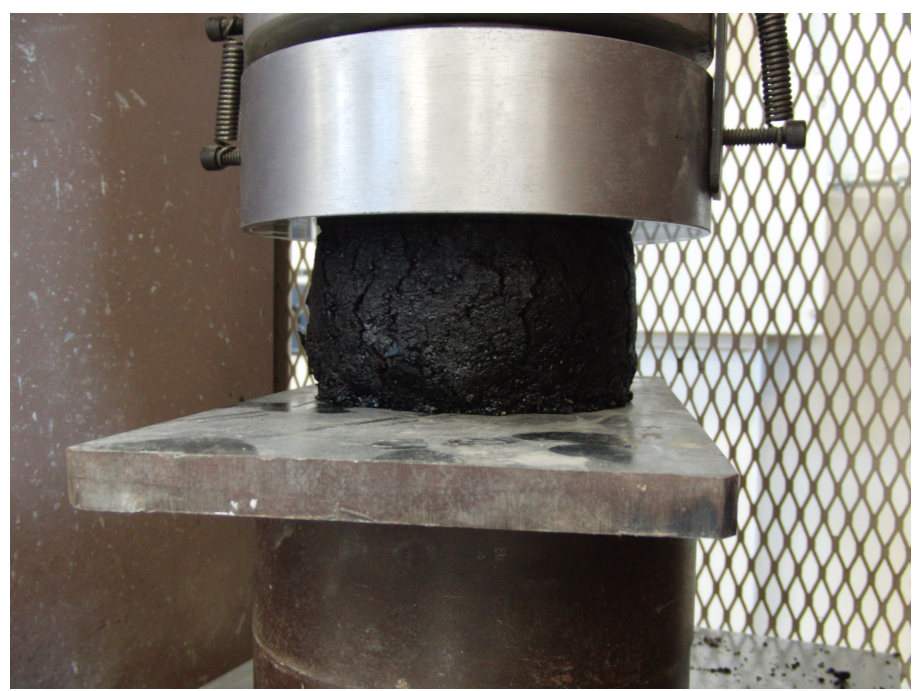

\section{Figure 3.19: Immersion Compression Test on Control Specimen}

The conditioning method for this test is similar to the ITS test. The control specimens were placed in water-resistant plastic bags and then placed in a $77^{\circ} \mathrm{F}\left(25^{\circ} \mathrm{C}\right)$ water bath for about two hours in order to maintain a consistent room temperature. The conditioned specimens were placed directly in the water bath for twenty-four hours before the test was performed. This is implemented to all treatment combinations.

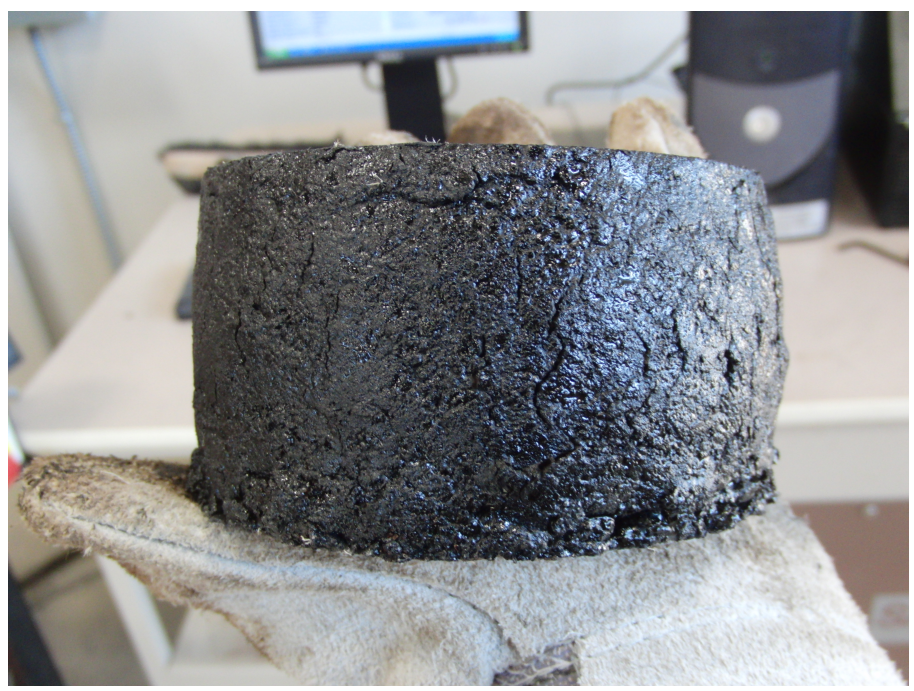

Figure 3.20: Post Immersion Compression Test 
Figure 3.21 shows a specimen that had been tested in Immersion Compression. It is clear that the specimen has a mild concave bulge with cracks, which demonstrates that the specimen has exceeded the elastic limit. From the data collected, the elastic modulus is calculated. The elastic modulus was determined as the slope of the straight-lined portion of the stress-strain curve. Table 3.14 represents the data summary of the Immersion Compression Test. This table shows treatment combination, type of condition, maximum load, compressive strength, initial young's modulus, young's modulus, and compressive strength with respect to the control specimen at room temperature.

\section{Table 3.14: Compression Strength Table Summary}

\begin{tabular}{|c|c|c|c|c|c|c|c|}
\hline Treatment & $\begin{array}{c}\text { Additive } \\
\text { Percentage }\end{array}$ & Condition & $\begin{array}{c}\text { Maximum } \\
\text { Load }(P), \text { Ibs }\end{array}$ & $\begin{array}{c}\text { Compressive Strength, } \\
\text { psi }\end{array}$ & $\begin{array}{l}\text { Young's } \\
\text { Modulus, E }\end{array}$ & \begin{tabular}{|c|} 
Compressive \\
Strength \\
Ratio
\end{tabular} & $\begin{array}{l}\text { Compressive Strength } \\
\text { Ratio w/ Respect to } \\
\text { Unconditioned Control }\end{array}$ \\
\hline Control & 0 & $\begin{array}{l}\text { Dry } \\
\text { Cond. }\end{array}$ & $\begin{array}{l}23125.00 \\
18144.00\end{array}$ & $\begin{array}{l}1840.23 \\
1443.85\end{array}$ & $\begin{array}{l}83537.77 \\
62467.52\end{array}$ & $78.46 \%$ & $\begin{array}{c}100.00 \% \\
78.46 \%\end{array}$ \\
\hline LOF $0.25 \%$ & 0.25 & $\begin{array}{l}\text { Dry } \\
\text { Cond. }\end{array}$ & $\begin{array}{c}19374.00 \\
1988.55\end{array}$ & $\begin{array}{l}1541.73 \\
1582.43\end{array}$ & $\begin{array}{l}95108.25 \\
99296.00\end{array}$ & $102.64 \%$ & $\begin{array}{l}83.78 \% \\
85.99 \%\end{array}$ \\
\hline LOF $0.50 \%$ & 0.5 & $\begin{array}{l}\text { Dry } \\
\text { Cond. }\end{array}$ & $\begin{array}{l}22053.00 \\
20582.50\end{array}$ & $\begin{array}{l}1754.92 \\
1637.90\end{array}$ & $\begin{array}{l}79166.33 \\
72230.47\end{array}$ & $93.33 \%$ & $\begin{array}{l}95.36 \% \\
89.01 \%\end{array}$ \\
\hline LOF $0.75 \%$ & 0.75 & $\begin{array}{l}\text { Dry } \\
\text { Cond. }\end{array}$ & $\begin{array}{l}19857.00 \\
16684.00\end{array}$ & $\begin{array}{l}1580.17 \\
1327.67\end{array}$ & $\begin{array}{l}63224.62 \\
45165.38\end{array}$ & $84.02 \%$ & $\begin{array}{l}85.87 \% \\
72.15 \% \\
\end{array}$ \\
\hline XL9 $0.25 \%$ & 0.25 & $\begin{array}{l}\text { Dry } \\
\text { Cond. }\end{array}$ & $\begin{array}{l}17816.00 \\
18553.58\end{array}$ & $\begin{array}{l}1417.75 \\
1476.44\end{array}$ & $\begin{array}{l}30780.00 \\
46378.35\end{array}$ & $104.14 \%$ & $\begin{array}{l}77.04 \% \\
80.23 \%\end{array}$ \\
\hline XL9 $0.50 \%$ & 0.5 & $\begin{array}{l}\text { Dry } \\
\text { Cond. }\end{array}$ & $\begin{array}{l}18724.50 \\
16939.50\end{array}$ & $\begin{array}{l}1490.05 \\
1348.00\end{array}$ & $\begin{array}{l}50730.46 \\
47746.45\end{array}$ & $90.47 \%$ & $\begin{array}{l}80.97 \% \\
73.25 \%\end{array}$ \\
\hline XL9 $0.75 \%$ & 0.75 & $\begin{array}{l}\text { Dry } \\
\text { Cond. }\end{array}$ & $\begin{array}{l}21404.50 \\
16438.50\end{array}$ & $\begin{array}{l}1703.31 \\
1308.13\end{array}$ & $\begin{array}{l}70680.54 \\
49114.80\end{array}$ & $76.80 \%$ & $\begin{array}{l}92.56 \% \\
71.09 \%\end{array}$ \\
\hline Lime $1.0 \%$ & 1 & $\begin{array}{l}\text { Dry } \\
\text { Cond. }\end{array}$ & $\begin{array}{l}27403.50 \\
24358.50\end{array}$ & $\begin{array}{l}2180.70 \\
1938.38\end{array}$ & $\begin{array}{l}84053.80 \\
85838.87\end{array}$ & $88.89 \%$ & $\begin{array}{l}118.50 \% \\
105.33 \%\end{array}$ \\
\hline Lime $1.5 \%$ & 1.5 & $\begin{array}{l}\text { Dry } \\
\text { Cond. }\end{array}$ & $\begin{array}{l}30555.00 \\
26650.50\end{array}$ & $\begin{array}{l}2431.48 \\
2120.78\end{array}$ & $\begin{array}{l}118469.09 \\
117604.72\end{array}$ & $87.22 \%$ & $\begin{array}{l}132.13 \% \\
115.25 \%\end{array}$ \\
\hline Lime $2.0 \%$ & 2 & $\begin{array}{l}\text { Dry } \\
\text { Cond. }\end{array}$ & $\begin{array}{l}30141.50 \\
30789.50\end{array}$ & $\begin{array}{l}2398.58 \\
2450.15\end{array}$ & $\begin{array}{l}108500.61 \\
139855.32\end{array}$ & $102.15 \%$ & $\begin{array}{l}130.34 \% \\
133.14 \%\end{array}$ \\
\hline
\end{tabular}

\subsection{Chapter Summary}

This chapter discussed the experimental designs and testing procedures used for this research. All aggregate testing was done on Crushed Stone aggregate provided by Cal 
Portland. All binder testing, virgin and aged, was done on PG 64-16, which was provided by Oxnard Refinery located in Oxnard, CA. The Dynamic Shear Rheometer is the device used for binder testing. During the moisture damage evaluations, 60 specimens were compacted in accordance with SuperPave mix proportion for Indirect Tensile Test and 40 samples were compacted for the Immersion Compression Test. Both ITS and ICT utilized identical production and conditioning procedures. The Lottman (ITS) and Immersion Compression tests were in accordance with their respective AASHTO test procedures. Data analysis will be discussed in the next chapter. 


\section{CHAPTER 4 - ANALYSIS AND DISCUSSION OF RESULTS}

\subsection{Introduction}

The presence of moisture coupled with the repetitive traffic adversely affects the performance of asphalt pavements. Moisture damage in asphalt pavements is caused through one of two mechanisms: 1) loss of adhesion, known as stripping of the asphalt film from the aggregate surface; and 2) loss of cohesion, which occurs within the binder itself. Other distresses that form as a result of moisture-weakening include rutting, fatigue cracking and potholes, among others. Moisture damage resulted from the loss of adhesion can be minimized by adding lime or antistripping liquids to the mix.

The primary objective of this study is to investigate the use of hydrated lime and two liquid antistripping to mitigate moisture damage in asphalt pavements. Aggregate used for Hot Mix Asphalt (HMA) on the Central Coast of California was used in this study. Performance Grade PG 64-16 supplied by Oxnard Refinery and was used to prepare the HMA. Hydrated lime was obtained from a local surplus store and the liquid antistripping were provided by Arr Maz Custom Chemicals, located in Florida.

\subsection{Aggregates Tests}

The Sieve Analysis of Fine and Coarse Aggregates test was conducted in accordance with AASHTO T27-99 and the results are presented in Chapter 3. This test was done to determine the compliance of the particle size distribution with the specification requirements. Figure 4.1 presents the trial gradation limits in accordance with SuperPave mix design. The extra fine blend used in this study is very close to the upper limit of SuperPave range. 


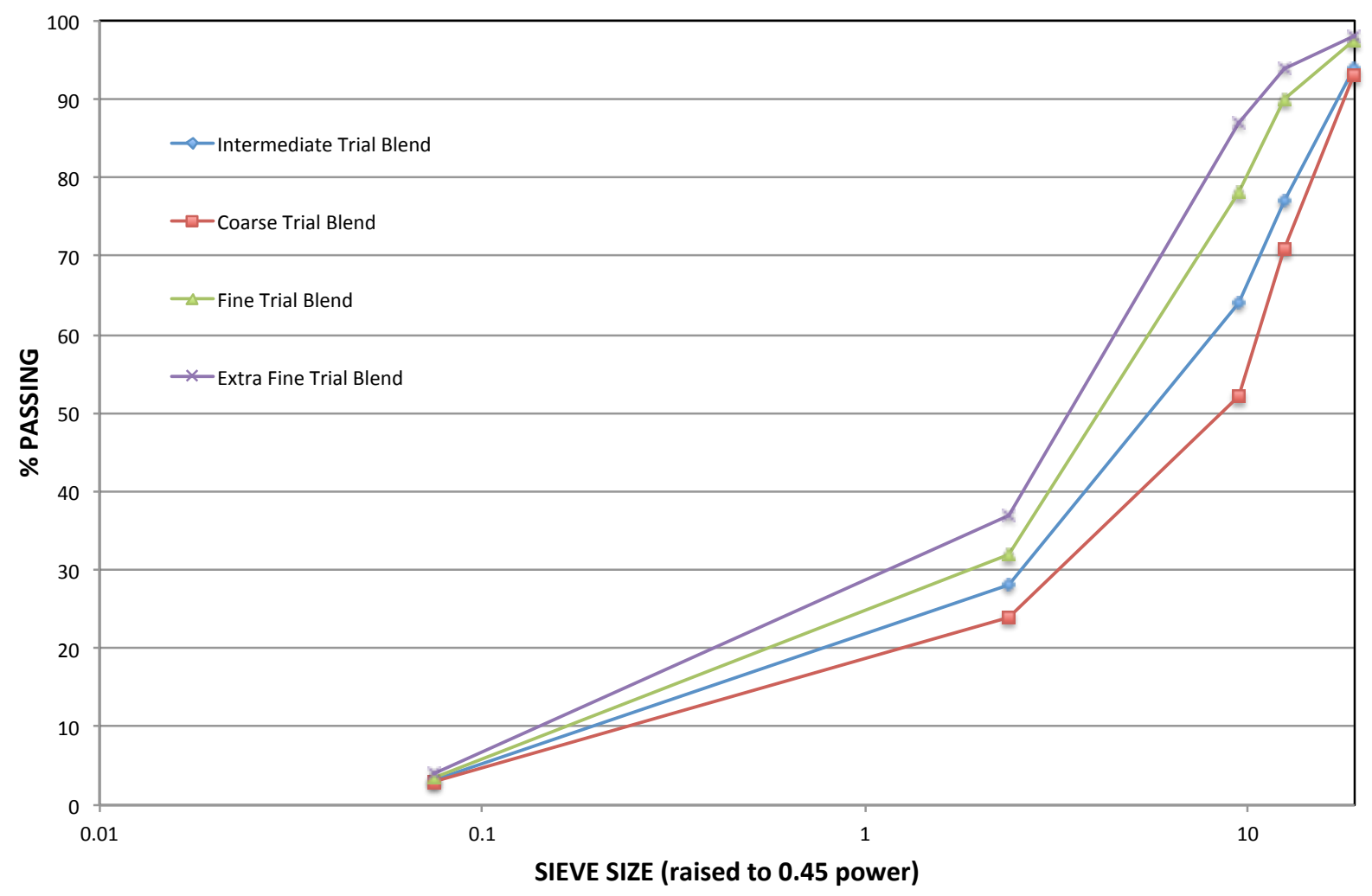

Figure 4.1: SuperPave Trail Gradation Results

Bulk Density (“Unit Weight”) and Voids in Aggregate (AASHTO T 19/T 19M-00), Specific Gravity and Absorption of Fine Aggregate (AASHTO T 84-00), and Specific Gravity and Absorption of Coarse Aggregate (AASHTO T85-91 (2000)) results were within the normal practice and the data can be reviewed in Chapter 3 of this paper.

Uncompacted Void Content of Fine Aggregate test was conducted in accordance with AASHTO T 304-96 (2000). The uncompacted void content obtained is $42.39 \%$, which meets the requirement of $45 \%$.

Resistance to Degradation of Small-size Coarse Aggregate by Abrasion and Impact in the Los Angeles Machine (ASTM C 131-01) is used measure the degradation of mineral 
aggregates of standard grading. The percent loss was for the aggregate used in this study was $39 \%$, which falls within the limits $(10 \%-45 \%)$ of the standardized test.

Flat Particles, Elongated Particles, or Flat and Elongated Particles in Coarse Aggregate (ASTM D4791-99) test is used to determine the percentage of flat particles, elongated particles, or flat and elongated particles in coarse aggregates. The results from this test showed that only $1 \%$ of the aggregate particles tested was classified as flat and elongated.

Performed in the lab as extra precaution, the "Plastic Fines in Graded Aggregates and Soils by Use of the Sand Equivalent (SE) Test" (AASHTO T 176-02) was used to determine the relative proportions of fine dust or claylike material in soils and graded aggregates. The test results showed that the SE value for the aggregate used in this study was $85 \%$, which is within the specifications range.

\subsection{Asphalt Binder Tests}

"Determining the Rheological Properties of Asphalt Binder Using a Dynamic Shear Rheometer" (DSR), in accordance with AASHTO T315-04, was used to determine the viscoelastic properties of the asphalt binder. The DSR test was conducted on 9 different treatment combinations (two tests for each combination). The combinations tested can be reviewed in Chapter 3.

The results obtained from testing on the original binder were similar to that of the results from Oxnard Refinery. This confirms the accuracy of our equipment and test procedures. The results for the complex shear modulus (CSM) are shown in Figure 4.2. The complex shear modulus for the control is a value of 2074.25 Pascal ( $0.30 \mathrm{psi})$. This represents the ratio of the shear stress to the shear strain of the asphalt binder specimen. As noted in 
Figure 4.2 for chemical antistripping additives as the dosage rate increases, the complex shear modulus decreases making the binder less stiff. The difference between LOF-6500 and XL-9000 is that LOF-6500 had a greater complex shear modulus of $836 \mathrm{~Pa}(0.12$ psi), while XL-9000 is only $674 \mathrm{~Pa}(0.09 \mathrm{psi})$ at $0.25 \%$. The trend is then carried through the other dosage rates. Although LOF-6500 had a higher CSM at 0.25\% than XL-9000, they both obtained similar values at $0.75 \%$. This gives XL-9000 a smaller interval of complex shear modulus than LOF-6500; the dosage rate effects of XL-9000 were not as dramatic as LOF-6500.

For hydrated lime treatment the trend was opposite to that for the liquid antistripping agents. As shown in Figure 4.2, as the dosage rate for hydrated lime increases, the complex shear modulus increases. This means that the addition of hydrated lime makes the asphalt binder less viscous and stiffer. The effects of this trend will be further discussed in the moisture susceptibility testing. The effects of complex modulus on varying dosage rates are presented below. 


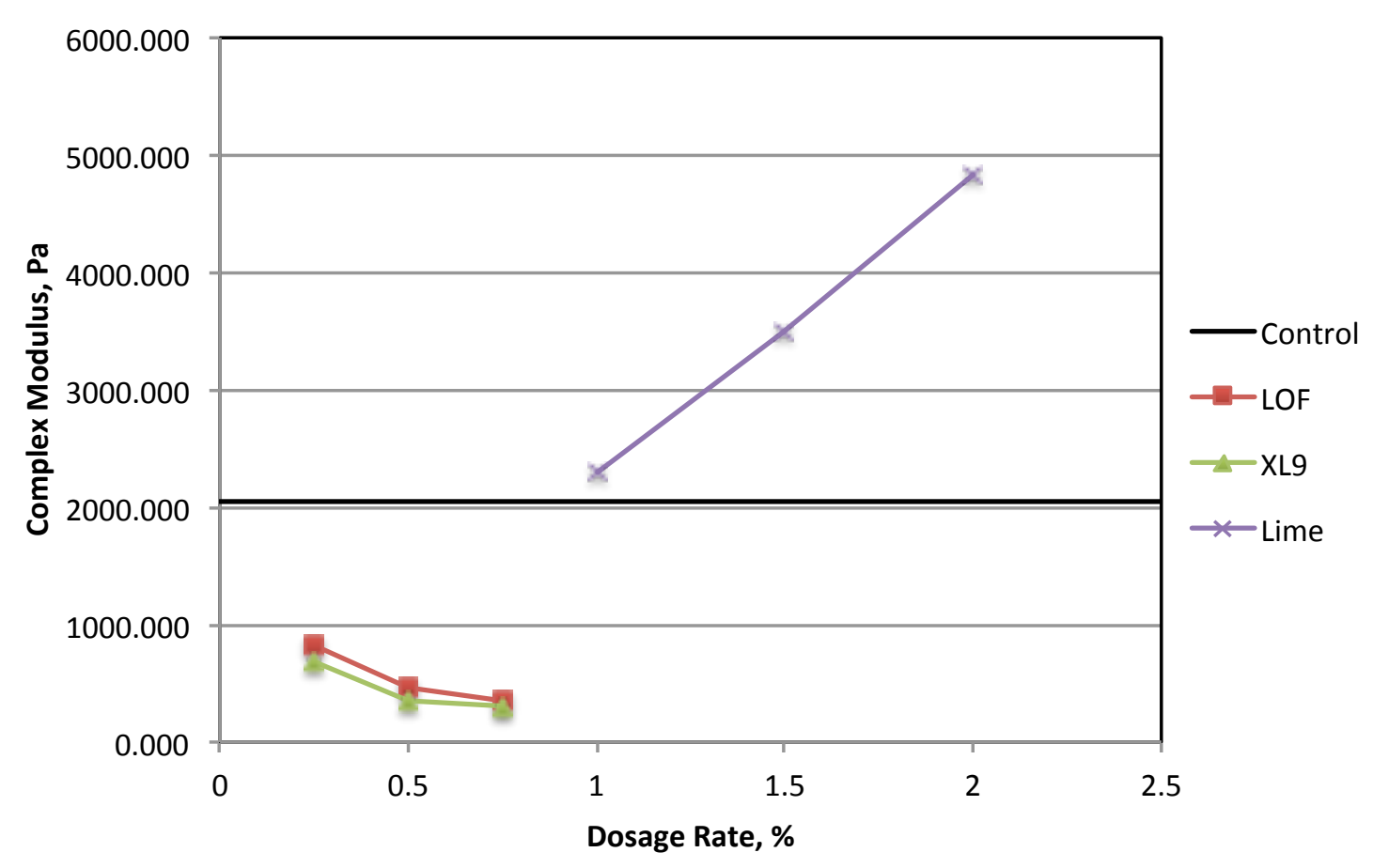

Figure 4.2: Complex Modulus Results For Unconditioned Binder

The elastic moduli for the different treatment combinations are presented in Figure 4.3. The elastic modulus for the control specimen is 54.65 Pascal ( $8.00 \mathrm{psi})$. The elastic moduli for LOF-6500 based on the dosage rates have an averaged standard deviation of $1.5 \mathrm{~Pa}(2.20 \mathrm{E}-5 \mathrm{psi})$ with a median of $12 \mathrm{~Pa}(2.00 \mathrm{E}-3 \mathrm{psi})$, while the XL-9000 had an average standard deviation of $3.5 \mathrm{~Pa}(5.1 \mathrm{E}-4 \mathrm{psi})$ with a median of $6 \mathrm{~Pa}(9.0 \mathrm{E}-4 \mathrm{psi})$. Hydrated Lime had elastic moduli of $74 \mathrm{~Pa}(0.011 \mathrm{psi})$ for $0.25 \%, 129 \mathrm{~Pa}(0.02 \mathrm{psi})$ for $0.50 \%$, and $258 \mathrm{~Pa}(0.04 \mathrm{psi})$ for $0.75 \%$. The range of elastic modulus for the chemical agents is less than hydrated lime and control. This means that under the DSR test, chemically enhanced specimen returns to its original shape after oscillation faster than the other specimens. Essentially, the chemically enhanced specimen is not as elastic as the 
others. Hydrated lime has the greatest range of elasticity, which enhances resistance to permanent deformation.

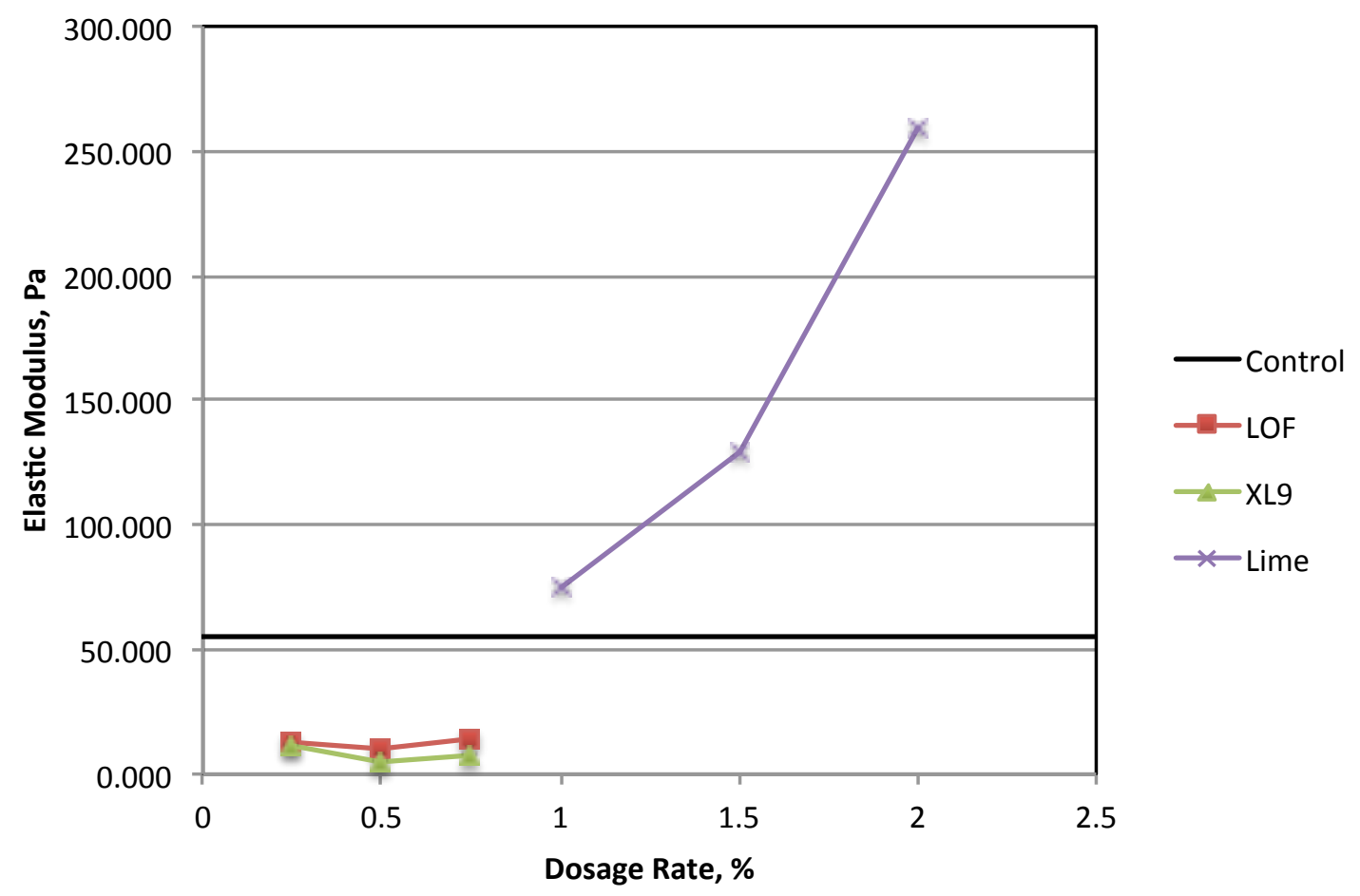

Figure 4.3: Elastic Modulus Results For Unconditioned Binder

Lastly the phase angle is measured. The phase angle is the lag between the applied shear stress and the resulting shear strain. A small phase angle would imply that the elastic component of the complex shear modulus is high. As presented in Figure 4.4 the control specimen has a phase angle of 88 degrees. The trend across the board shows a linear decrease in phase angle with an increase in dosage rates. Both LOF-6500 and XL-9000 specimens had phase angles of $89^{\circ}$ at a dosage rate of $0.25 \%$ and at $0.75 \%$, it decreased to $87.7^{\circ}$ and $88.7^{\circ}$, respectively. Hydrated lime had a phase angle of $88^{\circ}$ at $1.0 \%$. As the 
lime dosage increased, the phase angle for hydrated lime decreased, which means that the binder become more elastic at higher dosages.

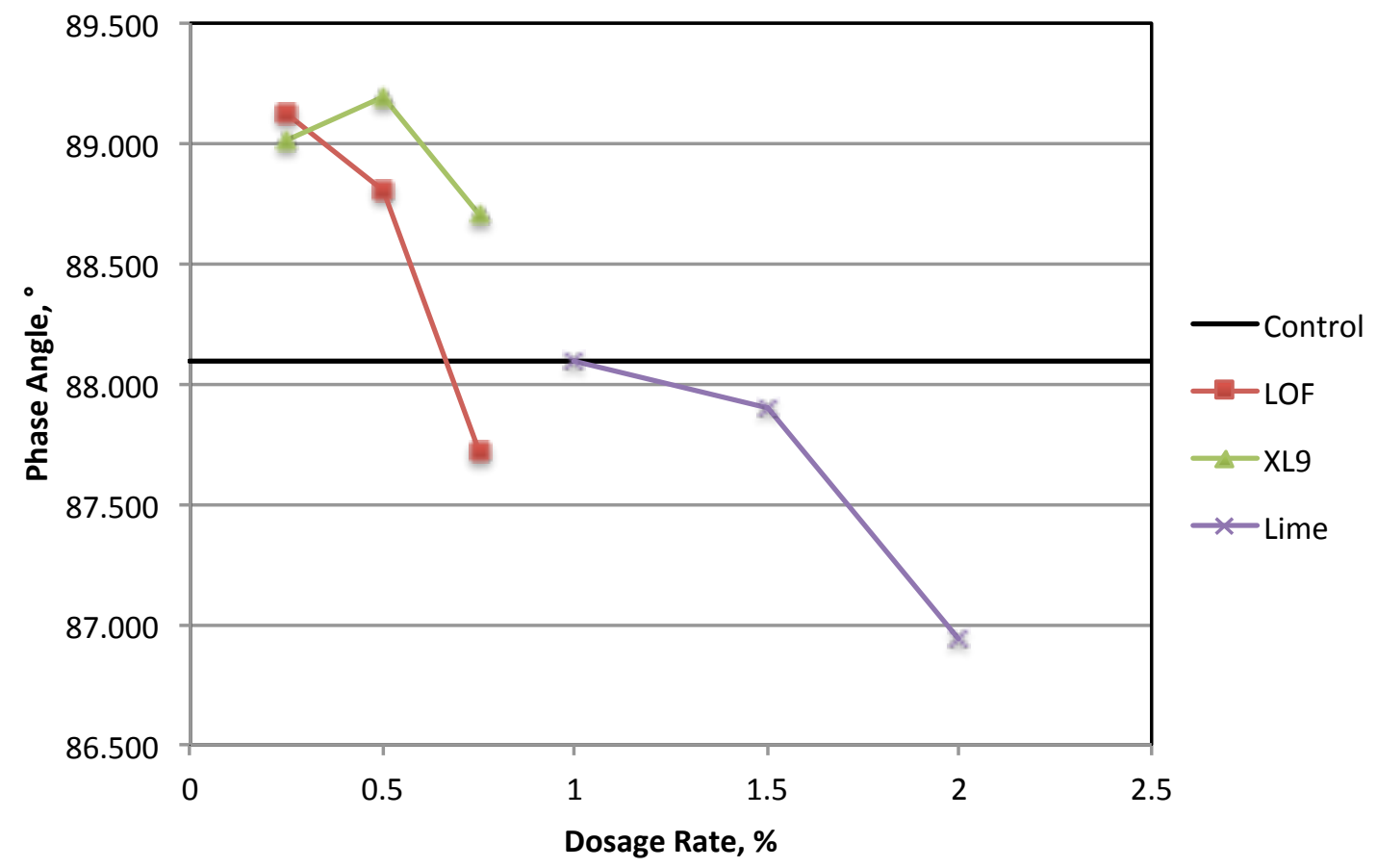

Figure 4.4: Phase Angle Results For Unconditioned Binder

The Rolling Thin Film Oven (RTFO) Test was conducted in accordance with AASHTO T240-03 to evaluate the effect of Heat and Air on the properties of the asphalt binder. This test was used to determine the change in properties of asphalt during conventional HMA production at about $150^{\circ} \mathrm{C}\left(302^{\circ} \mathrm{F}\right)$. This method was also used to determine the mass change of the asphalt binder, which is a measure of asphalt volatility. After aging the binder in the RTFO the DSR test was conducted.

The results of complex modulus are shown in Figure 4.5. The data shows that it had an increase in the modulus for each specimen. This is normal because as the binder is aged, 
it becomes more stiff, which produces a higher complex modulus than it's virgin counterpart. Similar to the virgin specimens, both chemical antistripping additive specimens' complex modulus decreased linearly as the dosage rate increased. The effects of this are the binder becomes less stiff. Again, hydrated lime specimens' complex modulus increased linearly as the dosage rate increased. Unlike the liquid antistripping agents, hydrated lime produces a more stiff binder mixture. Comparing the control complex modulus to the liquid antistripping additive and hydrated lime at $0.25 \%$ and $1.0 \%$, respectively, shows that the control is inferior. This is not the case for the control against the other dosage rates for liquid antistripping additives and hydrated lime. Hydrated lime at all dosage rates produced complex moduli much greater than the rest of the additives. 


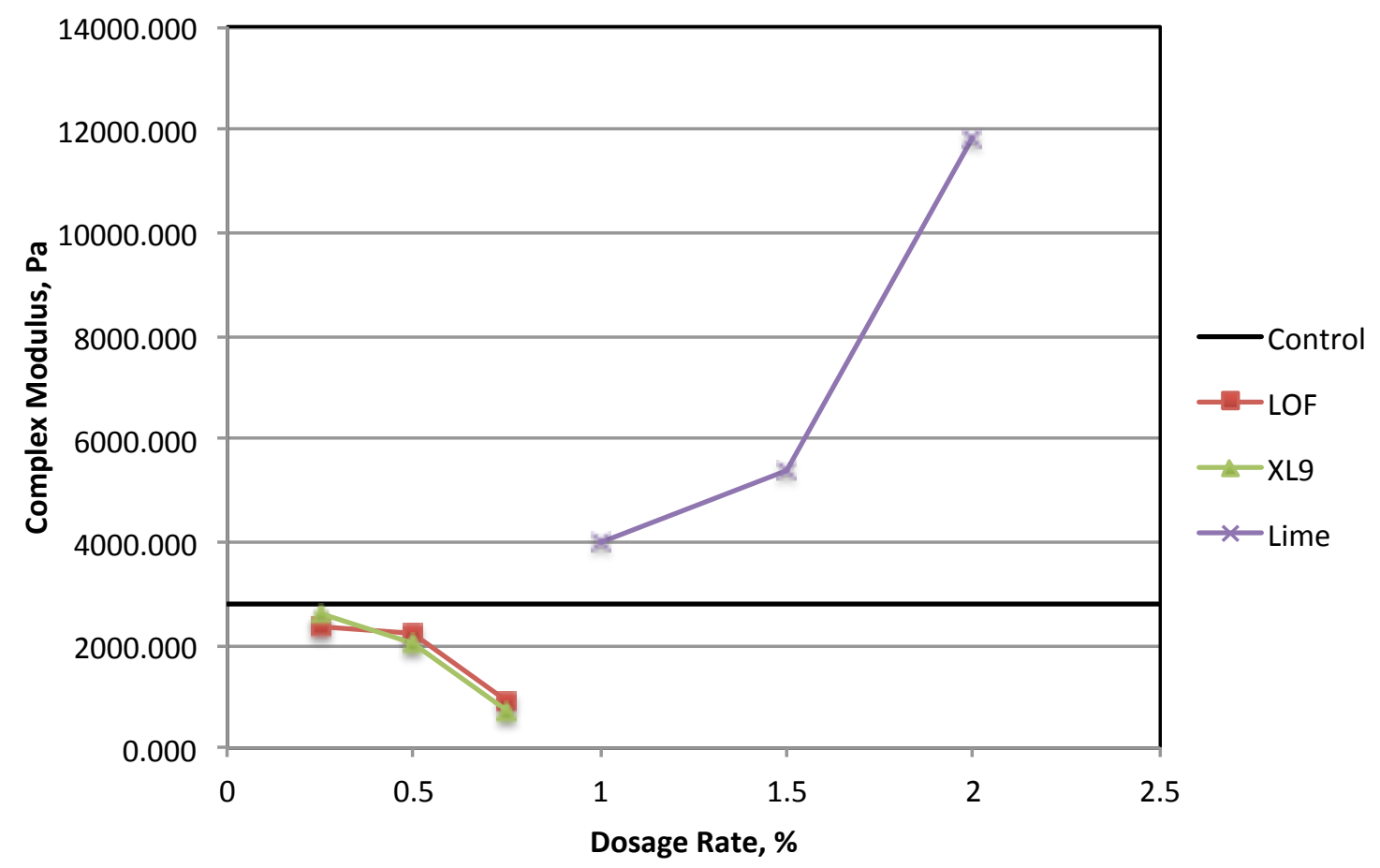

Figure 4.5: Complex Modulus Results For Conditioned Binder

The elastic modulus for the aged specimen is shown in Figure 4.6. The modulus follows a linear trend exactly like the complex modulus for both liquid antistripping additive and hydrated lime. Again, the values for all specimens are greater than their virgin counterparts. The increased elastic moduli demonstrate that all specimens have gained elasticity after enhancement (liquid antistripping or hydrated lime) and aging, in turn, making the asphalt binder more flexible. This gives the specimen a larger stress-strain curve before it reaches permanent failure. Again, hydrated lime produced the largest elastic modulus for all dosage rates tested. 


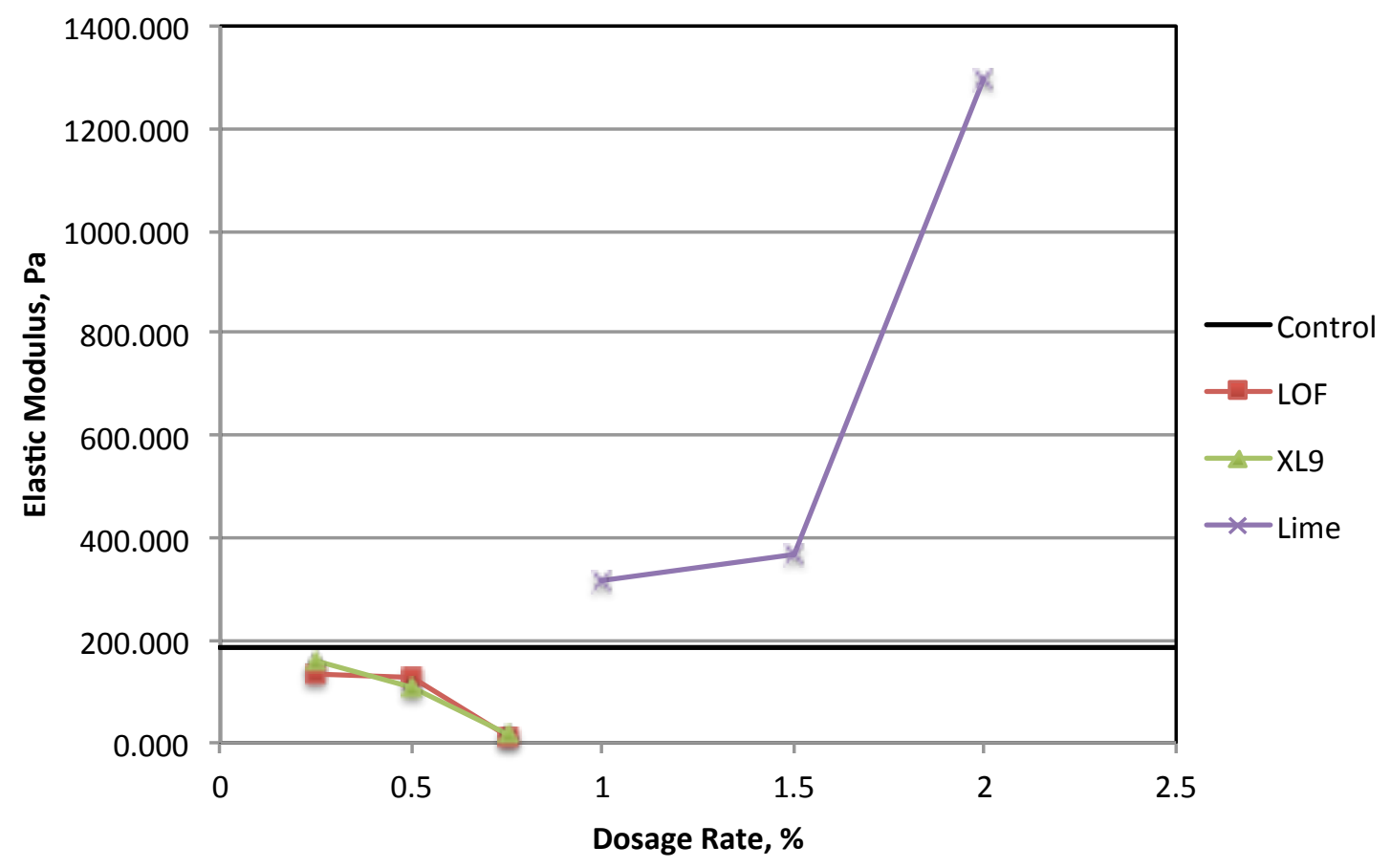

Figure 4.6: Elastic Modulus Results For Conditioned Binder

Phase angle for the aged binder, as shown in Figure 4.7, presents satisfying results. Phase angle increased as dosage rates increased for specimens treated with liquid antistripping agents. The phase angle for HL specimens show a decrease of approximately 2 degrees after its performance peaked at a dosage rate of $1.5 \%$. A phase angle of 90 degree represents a completely viscous material. Results from this study present a smaller phase angle, which means higher elastic modulus making the binder stiffer. 


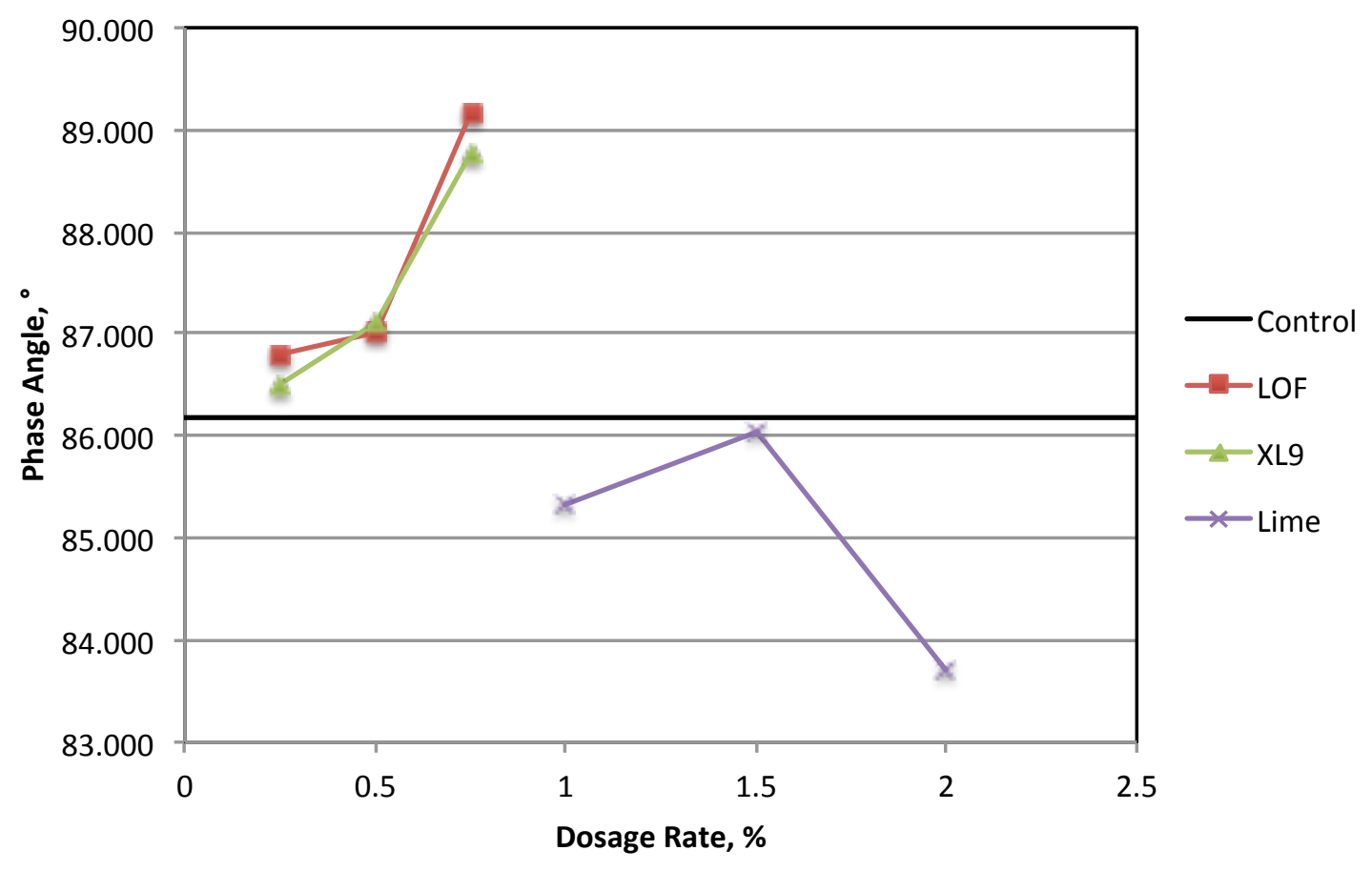

Figure 4.4.7: Phase Angle Results For Conditioned Binder

\subsection{Moisture Susceptibility Test}

Resistance of Compacted Asphalt Mixtures to Moisture Induced Damage test in accordance with AASHTO T 283-03 was used to evaluate the effects of saturation and accelerated water conditioning of compacted asphalt mixtures on the tensile strength. Description of the test along with the test results can be reviewed in Chapter 3 .

As shown In Figure 4.8 the tensile strength for the control specimen is approximately 433 psi. The tensile strength trends for the liquid antistripping and hydrated lime additives are presented In Figures 4.8 and 4.9, respectively. Tensile strength for the liquid antistripping additives decreased as the dosage rate increased as shown in Figure 4.8. As the dosage 
rate increases, the unconditioned liquid antistripping creates a less stiff binder, which results in a reduction in tensile strength.

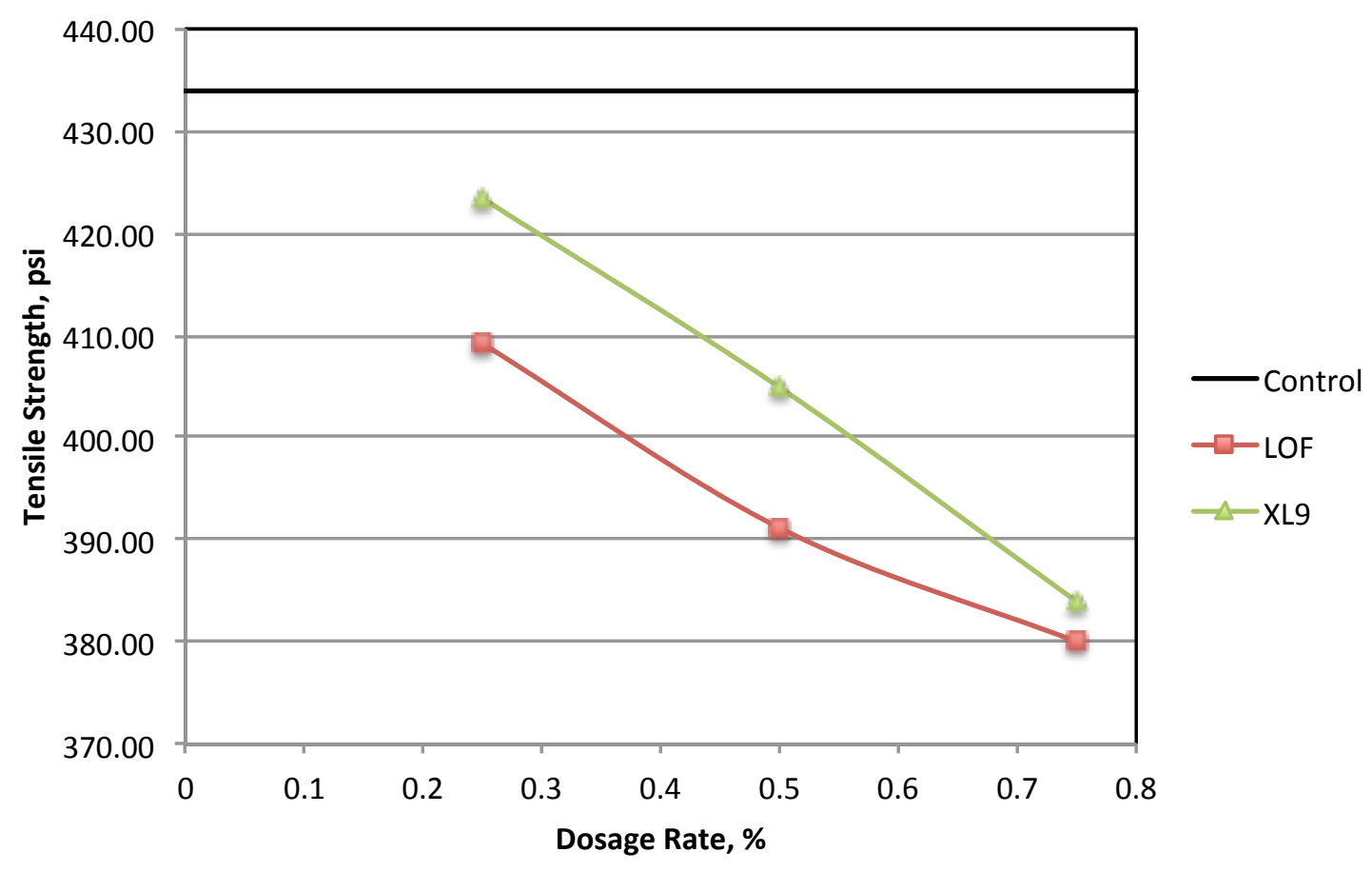

Figure 4.8: Tensile Strength Results For Unconditioned Liquid Antistripping Specimens

However, the opposite is the case for the hydrated lime as shown in Figure 4.9. Hydrated lime is applied as a powder, which essentially stiffen the asphalt binder and increases the elasticity/stiffness properties as seen in Figure 4.9. 


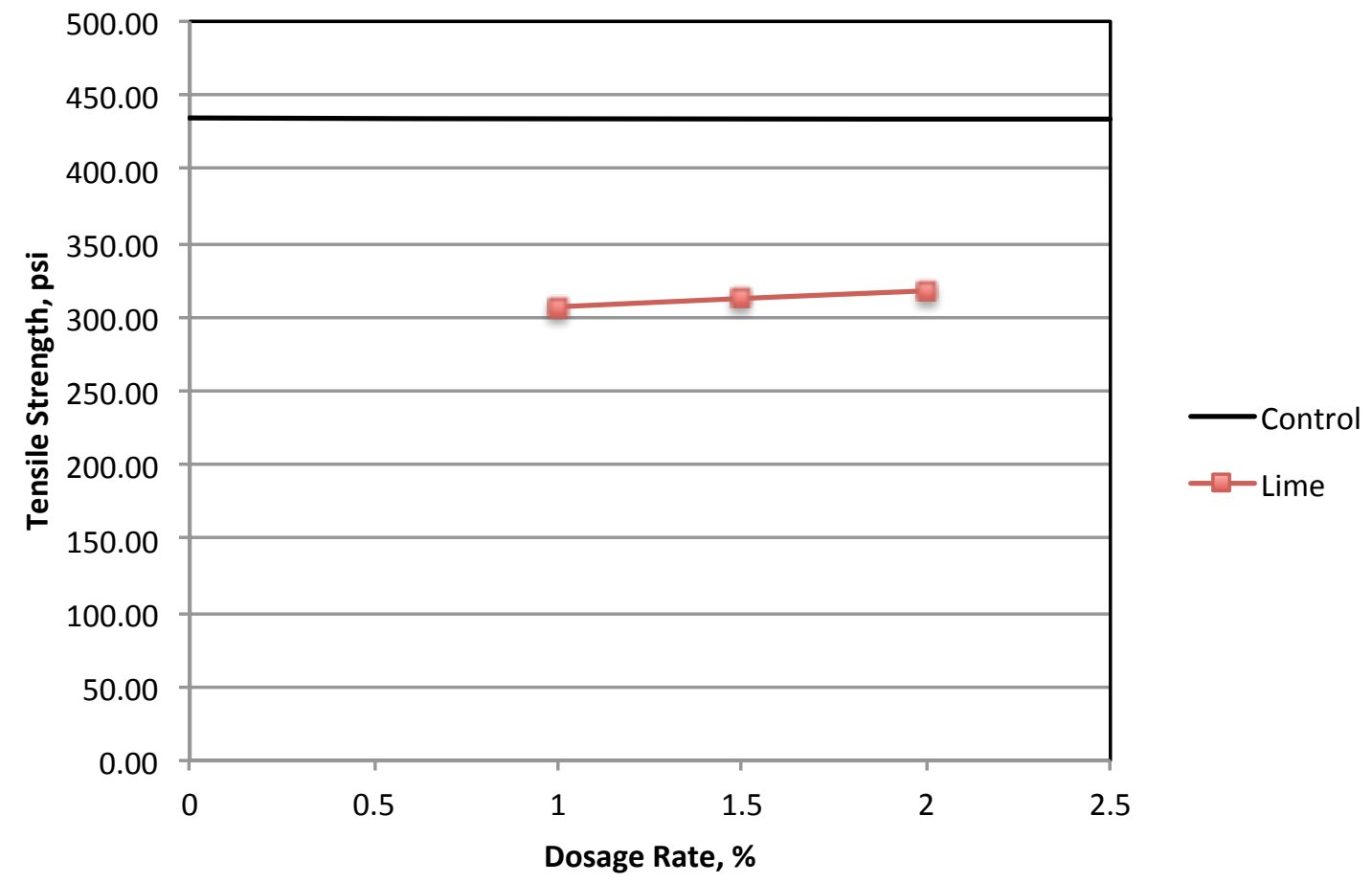

Figure 4.9: Tensile Strength Results For Unconditioned Hydrated Lime Specimens

Figure 4.10 presents the tensile strength of all unconditioned antistripping agents. It can be seen here that the control has an overall higher tensile strength than the enhanced specimens. The modification done to the enhanced chemicals (i.e. liquid antistripping agent and hydrated lime) could have negatively affected the tensile strength in its unconditioned state. 


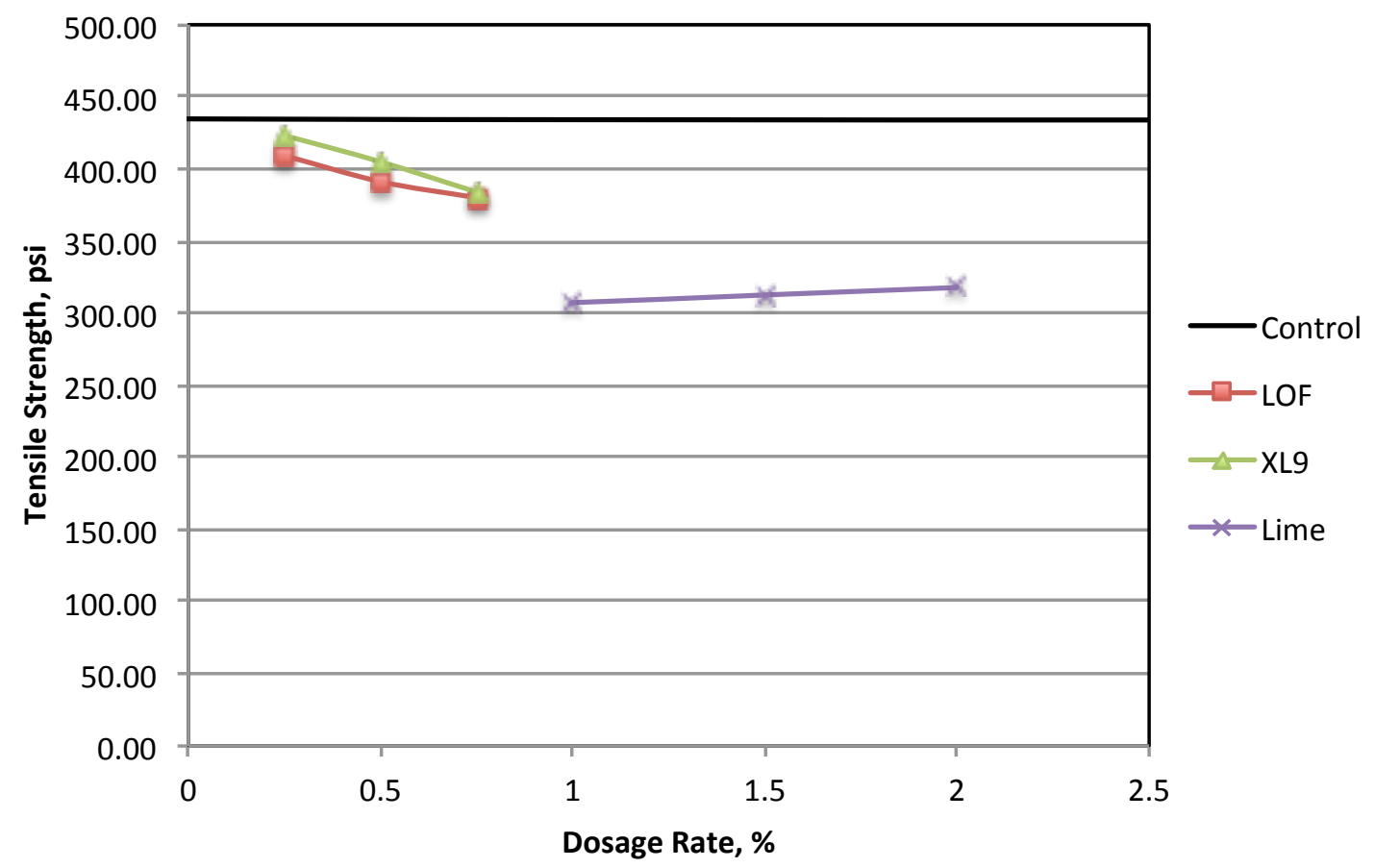

Figure 4.10: Tensile Strength Results For All Unconditioned Antistripping Specimens

The graphs below present the effects of tensile strength of conditioned specimens with their respective antistripping agent and dosage rates. Figure 4.11 shows the tensile strength of conditioned liquid antistripping agents with varying dosage rates. The trend for the both liquid antistripping agent is similar in many ways. The trend as the dosage rate increase directly relates to the increase in tensile strength for both chemicals at $0.25 \%$ and $0.50 \%$. After $0.50 \%$, the tensile strength for both chemicals decreases to a comparable, if not, lower than that of $0.25 \%$. The decrease signifies that somewhere between $0.50 \%$ and $0.75 \%$ the performance of the liquid antistripping has reached its peak. Any additional amount of liquid antistripping after $0.50 \%$ is rendered useless. 


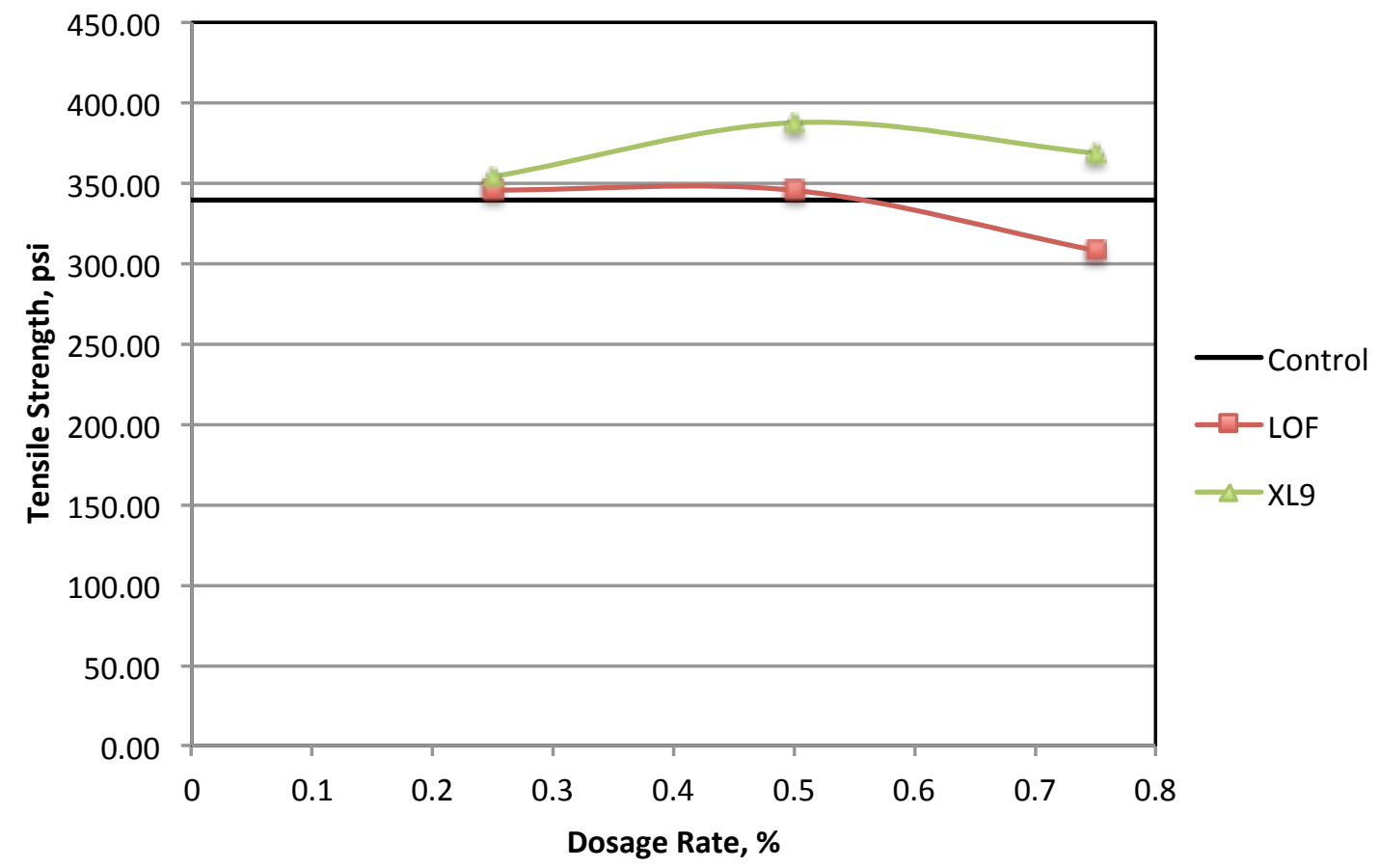

Figure 4.11: Tensile Strength Results For Conditioned Liquid Antistripping Specimens

Similar to the liquid antistripping agents, Figure 4.12 shows that hydrated lime results produce the same trend. The same reason why liquid antistripping agents have this trend, the hydrated lime results show that the performance properties hit a peak somewhere between $1.5 \%$ and $2.0 \%$. The effectiveness of hydrated lime is rendered useless approximately after $1.5 \%$ dosage rate. 


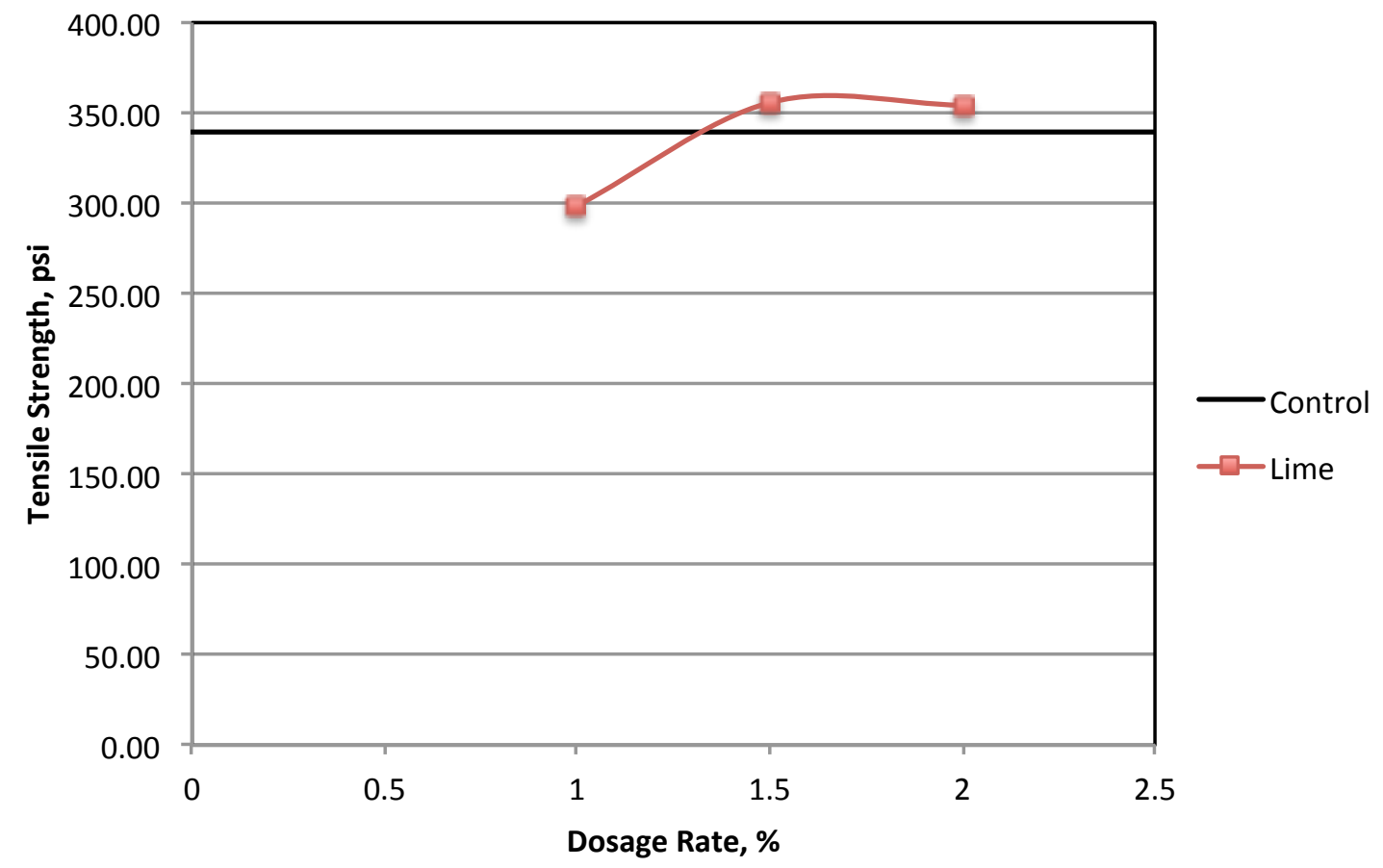

Figure 4.12: Tensile Strength Results For Conditioned Hydrated Lime Specimens

Figure 4.14 gives a better perception of the tensile strength of all conditioned antistripping agents compared to the control. It can be seen that the optimum performance for each treatment combination provides a higher tensile strength. 


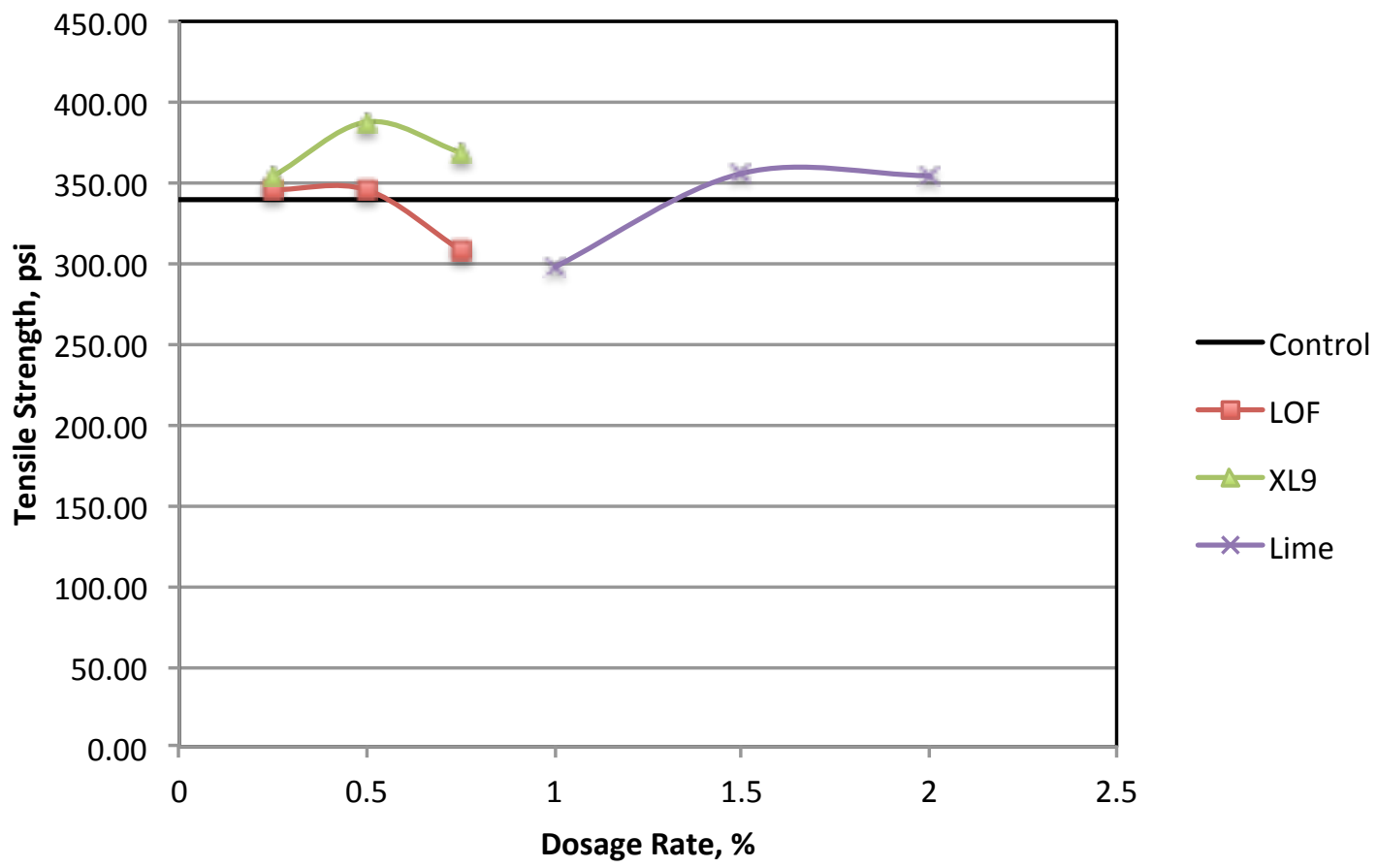

Figure 4.13: Tensile Strength Results For All Conditioned Specimens

Tensile Strength Ratio is normally used present the results for the AASHTO T 283-03

test. This ratio is calculated as the ratio of the tensile strength for conditioned specimens and that for unconditioned specimens and the minimum acceptable value is $70 \%$. It can be seen in Figure 4.14 and 4.15 that all specimens have exceeded the minimum TSR value of 70\%, while XL-9000 gives the best TSR values for the liquid antistrip additives and hydrated lime exceeds this $70 \%$ industry requirement. 


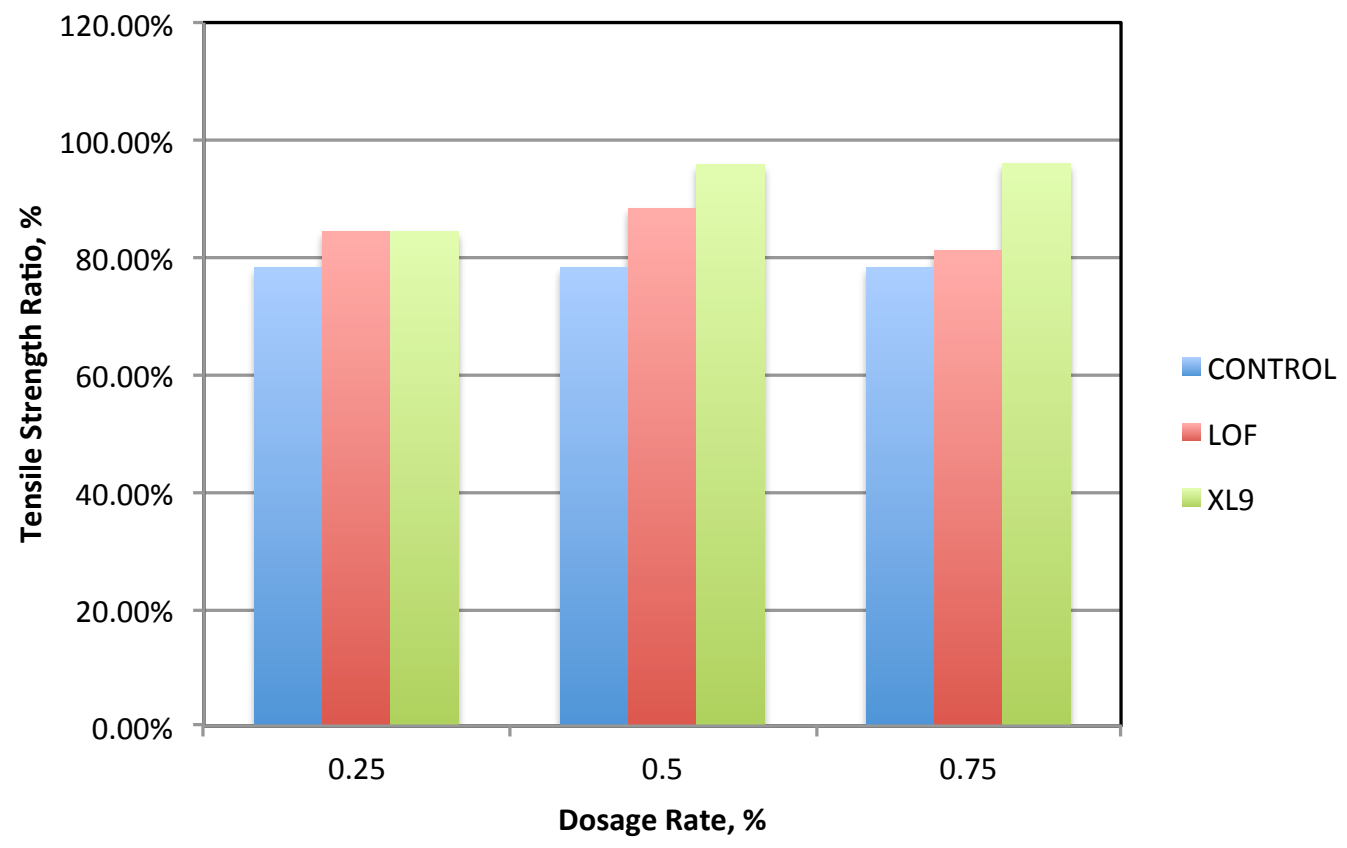

Figure 4.14: Tensile Strength Ratio (TSR) Results For Liquid Antistripping Specimens

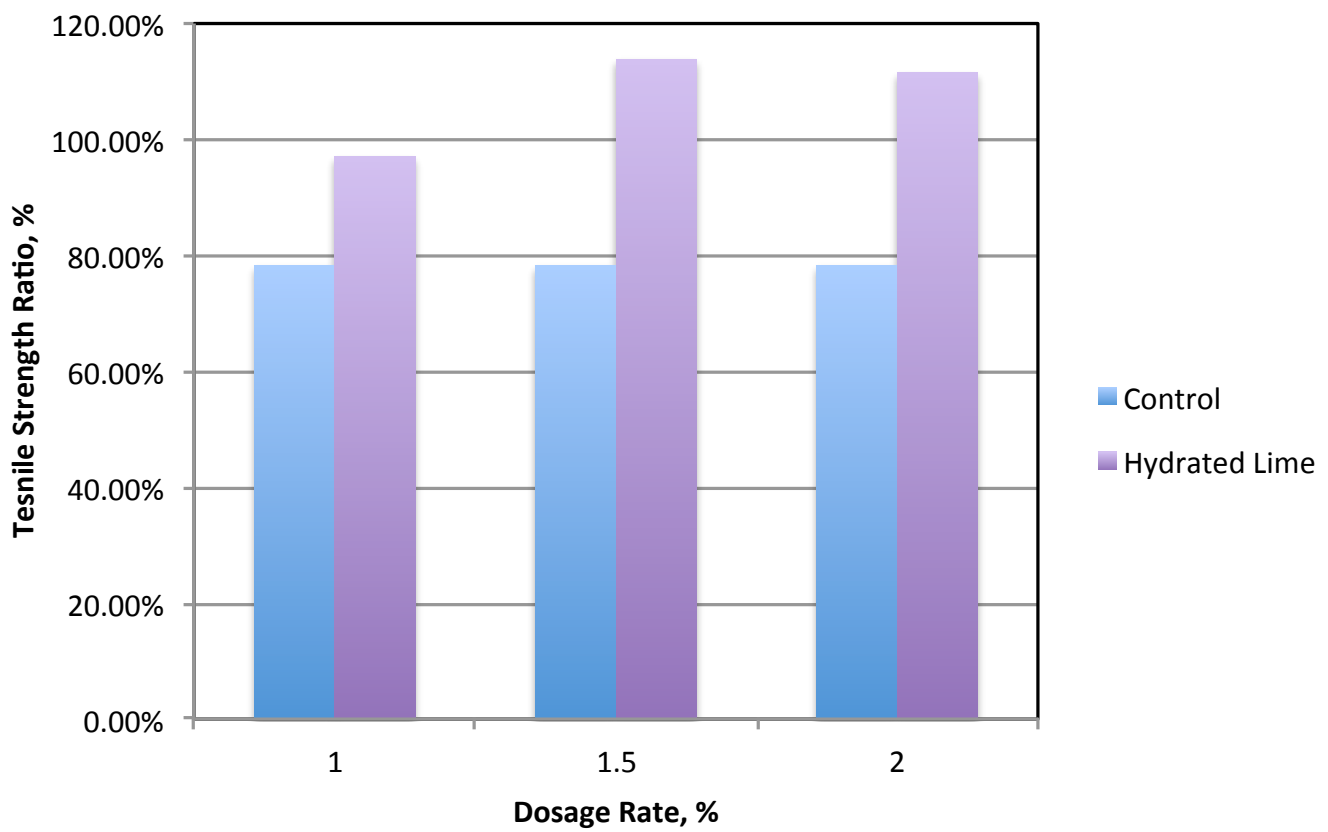

Figure 4.15: Tensile Strength Ratio (TSR) Results For Hydrated Lime Specimens 
Standard Test Method for Compressive Strength of Bituminous Mixtures (ASTM D 1074-96) was used to determine the compressive strength and how it may contribute to the overall mixture characterization and determine its suitability for use under given loading conditions and environment as a highway paving material. The measurements of interest for this test method are Maximum Load, Maximum Compressive Strength, and Young's (Elastic) Modulus. These data have been listed in the previous chapter and are presented graphically in this chapter.

The Maximum Compressive Strength results are presented in Figures 4.16 and 4.17 for liquid antistripping agents and hydrated lime, respectively. The trend for liquid antistripping agent LOF-6500 has an increase in compressive strength as the dosage rate increases from $0.25 \%$ to $0.50 \%$, where it peaks at its highest strength. The optimum dosage rate is most likely between $0.50 \%$ and $0.75 \%$ for liquid LOF-6500. Liquid agent XL-9000 does not have the same trend as the previous liquid agent. Liquid XL-9000 presents an increase in compressive strength with increasing dosage rate from $0.25 \%$ all the way to $0.75 \%$. The optimum dosage rate for this liquid is somewhere after $0.75 \%$. These two liquid antistripping agents have compressive strengths less than the control and this is likely due to the fact that the liquid antistripping agent could have made the binder more elastic in its unconditioned state. 


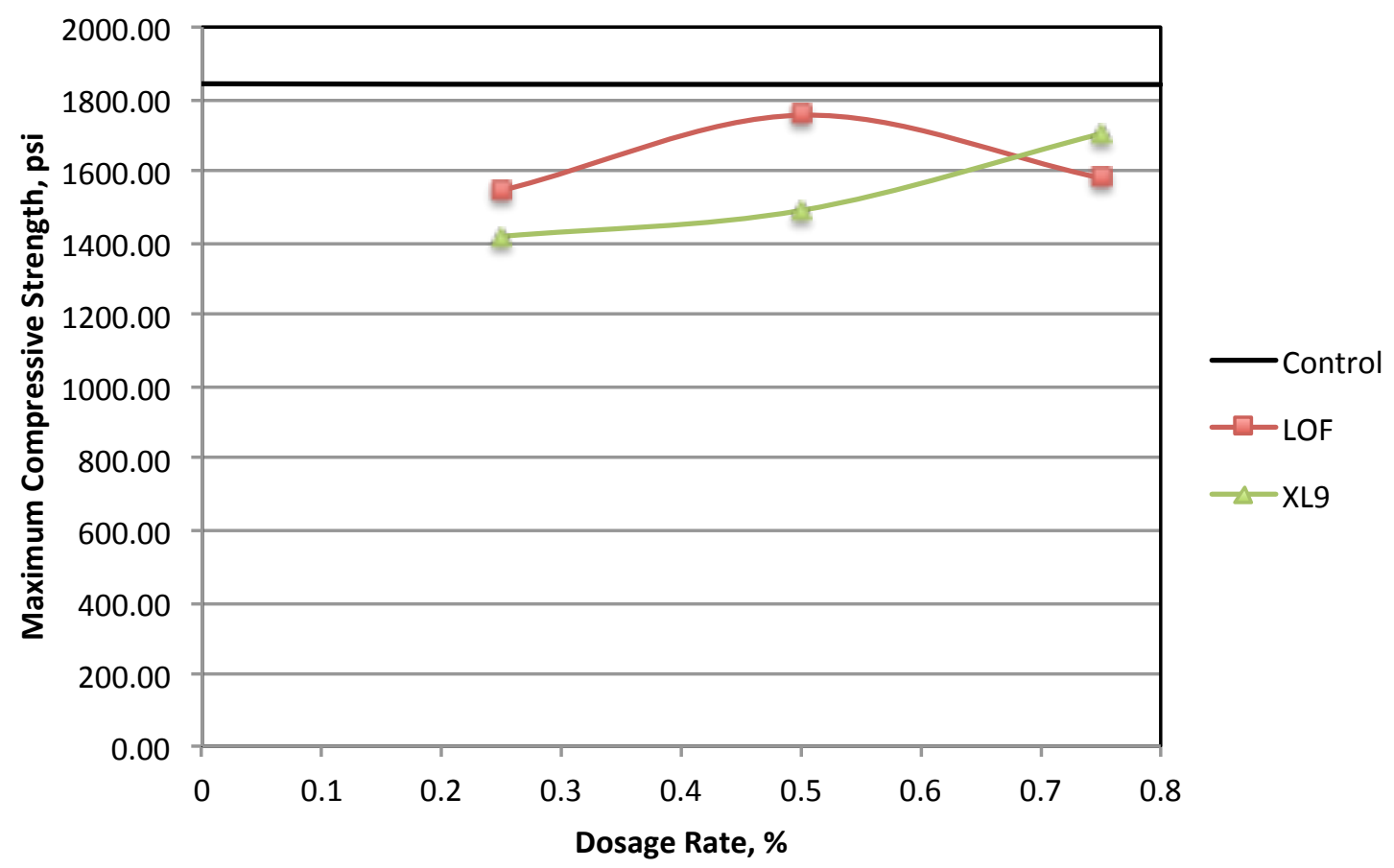

Figure 4.16: Maximum Compressive Strength Results For Unconditioned Liquid Antistripping Specimens

Figure 4.17 below presents the maximum compressive strength results for unconditioned hydrated lime specimens. The trend for the hydrated lime shows an increase in compressive strength as the dosage rate increases. The trend changes after $1.5 \% \mathrm{HL}$ dosage and decreases in strength as the dosage rate approaches $2.0 \%$. As noted in the figure, HL has reached its peak performance somewhere between $1.5 \%$ and $2.0 \%$. 


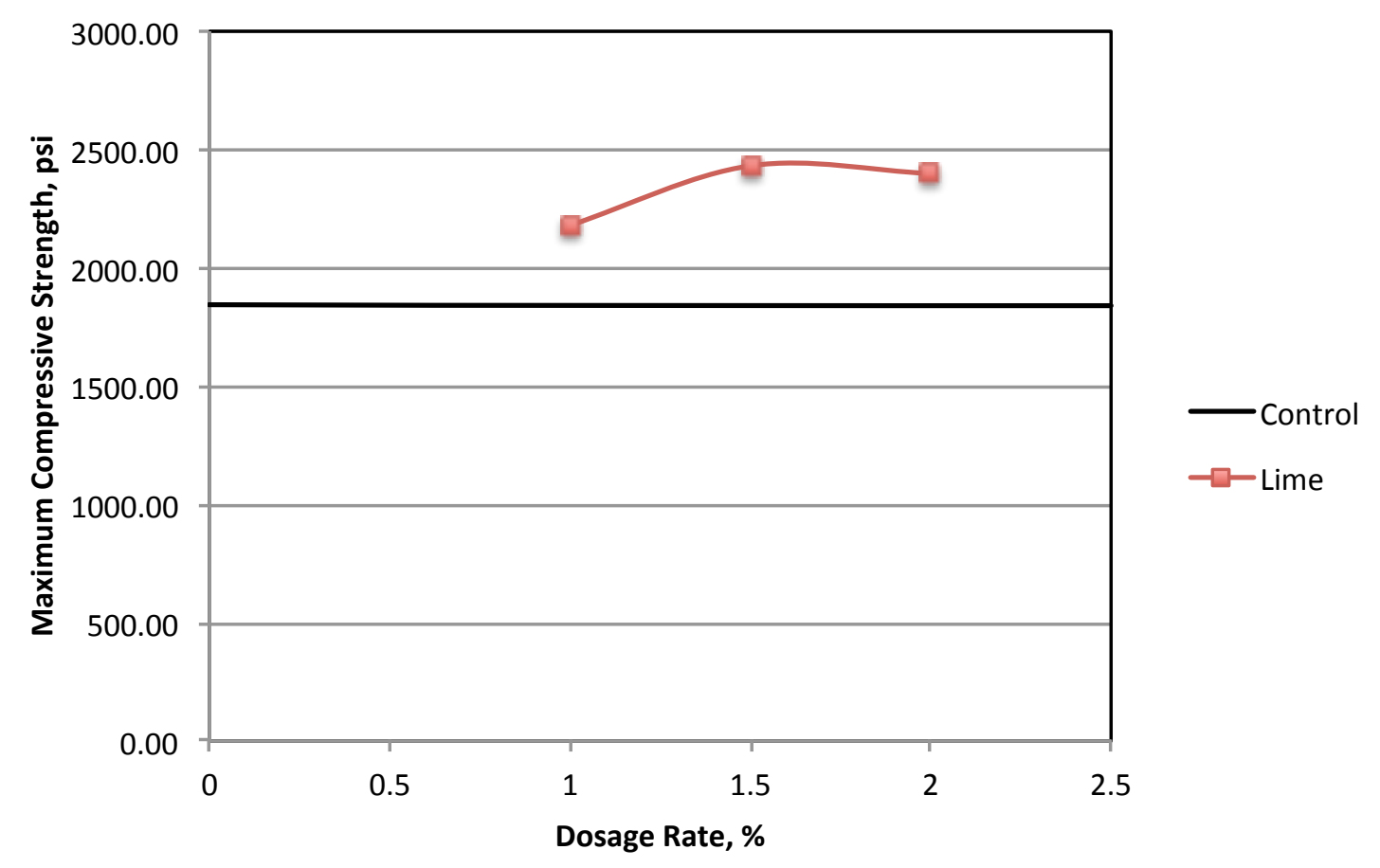

Figure 4.17: Maximum Compressive Strength Results For Unconditioned Hydrated Lime Specimens

Figure 4.18 presents unconditioned liquid and hydrated lime antistripping agents plotted against the control. It can be seen here that the liquid antistripping specimens inferior compressive strength compared to the control, whereas, hydrated lime specimens have a much higher compressive strength than the control. Again, the determining factor for this trend is because the liquid antistripping agents make the binder less viscous and the hydrated lime does the exact opposite to the asphalt binder. 


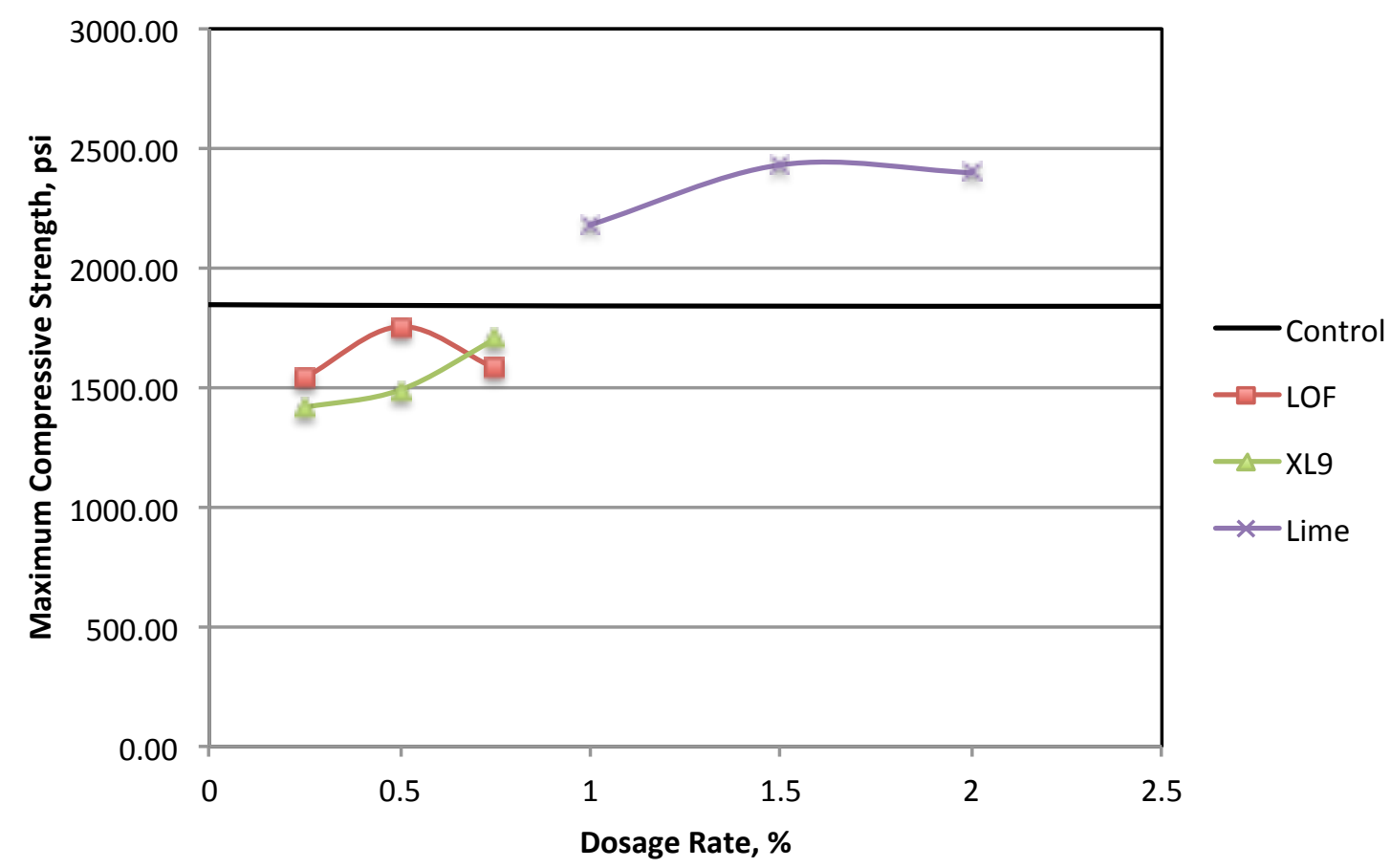

Figure 4.18: Maximum Compressive Strength Results For All Unconditioned Antistripping Specimens

Figure 4.19 presents the last measurement of interest for the Immersion Compression Test, which is the Young's Modulus. Young's Modulus (Elastic Modulus) is the slope taken from the straight tangent of the stress-strain curve. It measures the stiffness of the material, in this case, the asphalt mix. Figure 4.19 compares the unconditioned liquid antistripping specimen's elastic modulus to the control and it can be seen that the control has an overall higher modulus than all liquid antistripping specimens. During the study, unusual situation occurred with the compressive strength and elastic modulus values. A few instances show that the conditioned specimen had a larger elastic modulus value than its unconditioned counterpart. Possible reasoning behind this issue is that during the 
conditioning period, water may have seeped into the specimen pores making the sample less compressible and increase the compressive strength of the core specimen.

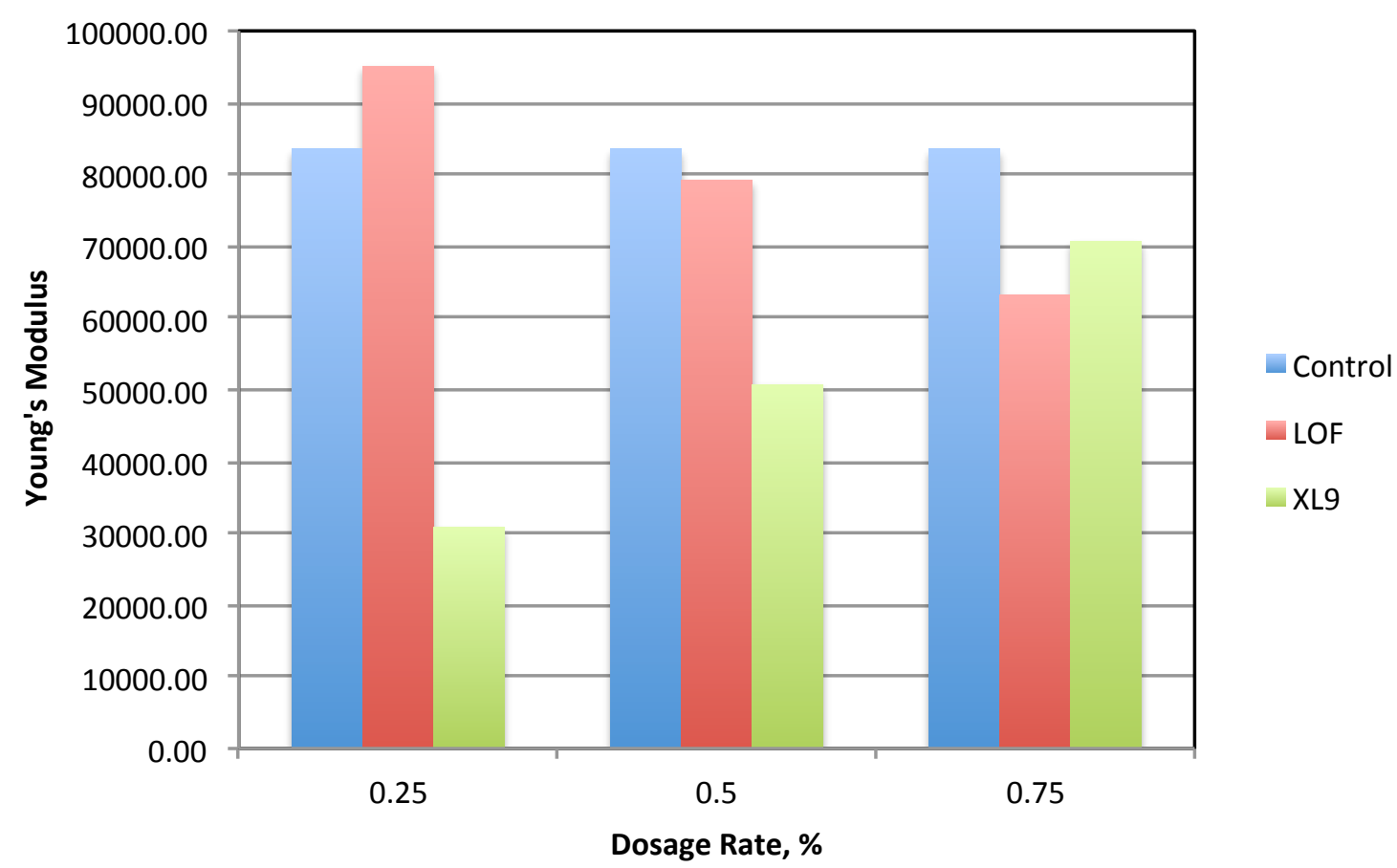

Figure 4.19: Young's Modulus Results For Unconditioned Liquid Antistripping Specimens

Figure 4.20 presents the Young's Modulus test results for the unconditioned hydrated lime specimens. As seen in the graph, HL dominates the control specimens in stiffness. HL is considerably stiffer because of the powder based and high acidic component of the agent. The elastic modulus results for HL are very pleasing. 


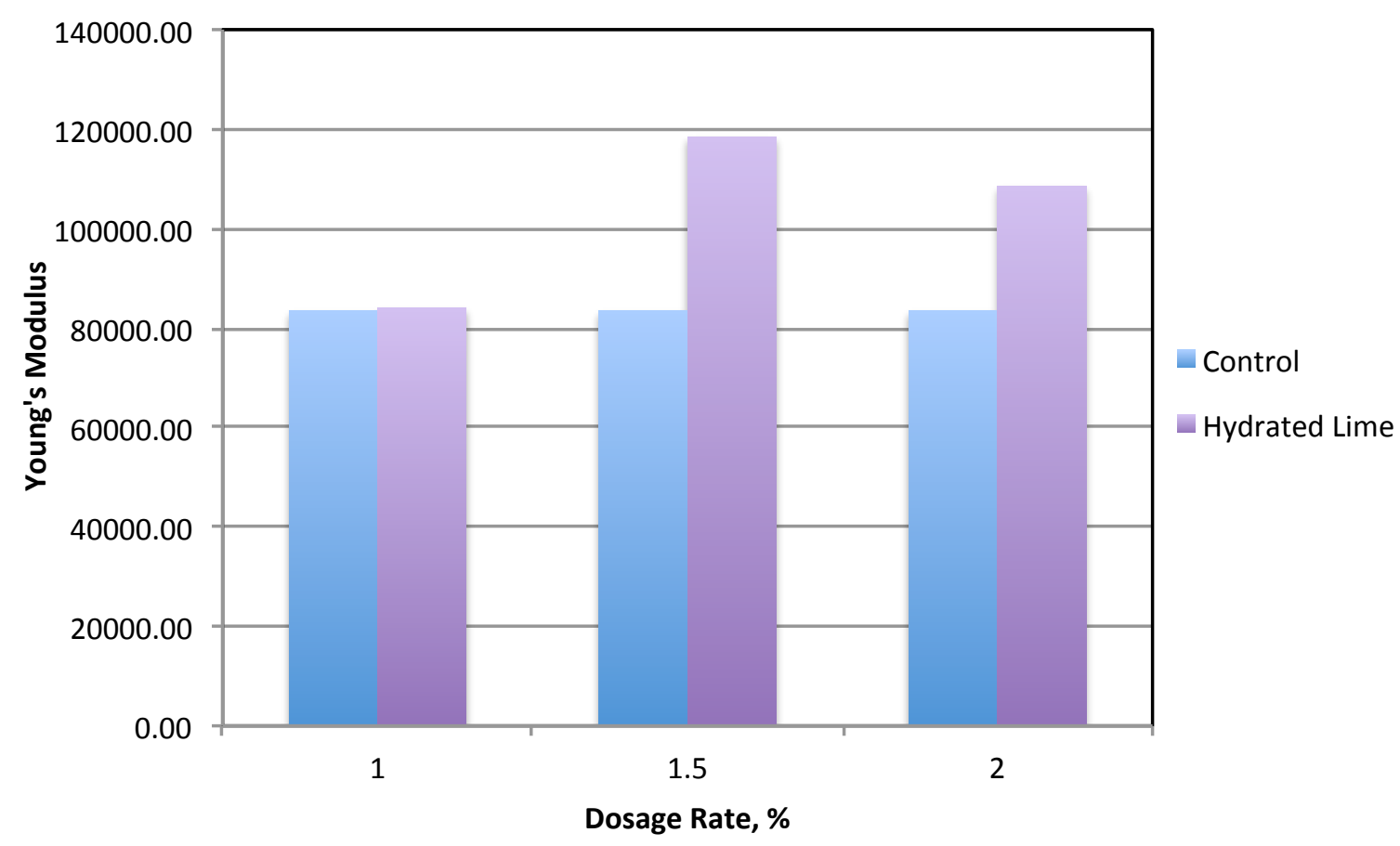

Figure 4.20: Young's Modulus Results For Unconditioned Hydrated Lime Specimens

Figure 4.21 presents the maximum compressive strength results for the conditioned liquid antistripping specimens. The trend for this situation shows a decrease in compressive strength as the liquid antistripping agent dosage rate increases. As mentioned earlier, this is an unusual case for the conditioned specimens to have a larger compressive strength than its unconditioned counterparts. 


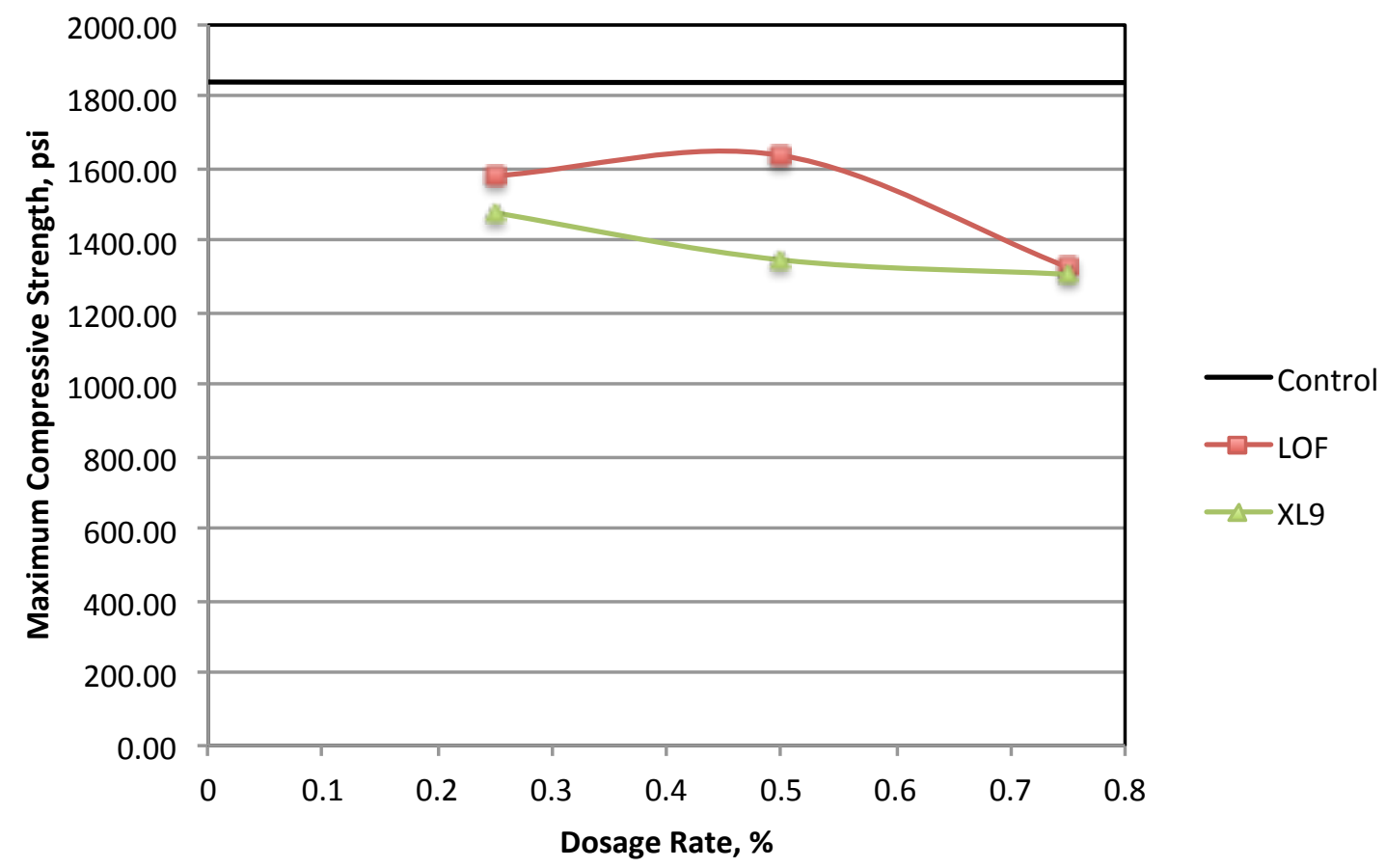

Figure 4.21: Maximum Compressive Strength Results For Conditioned Liquid Antistripping Specimens

Figure 4.22 presents the maximum compressive strength results for the conditioned hydrated lime specimens. Unlike the liquid chemical conditioned specimens, HL has an increasing compressive strength as the HL dosage rate increases. This shows that HL does significantly increase the compressive strength of the specimens and from the data presented; a higher dosage of HL may be used only if it doesn't hinder the other values (i.e. tensile strength). 


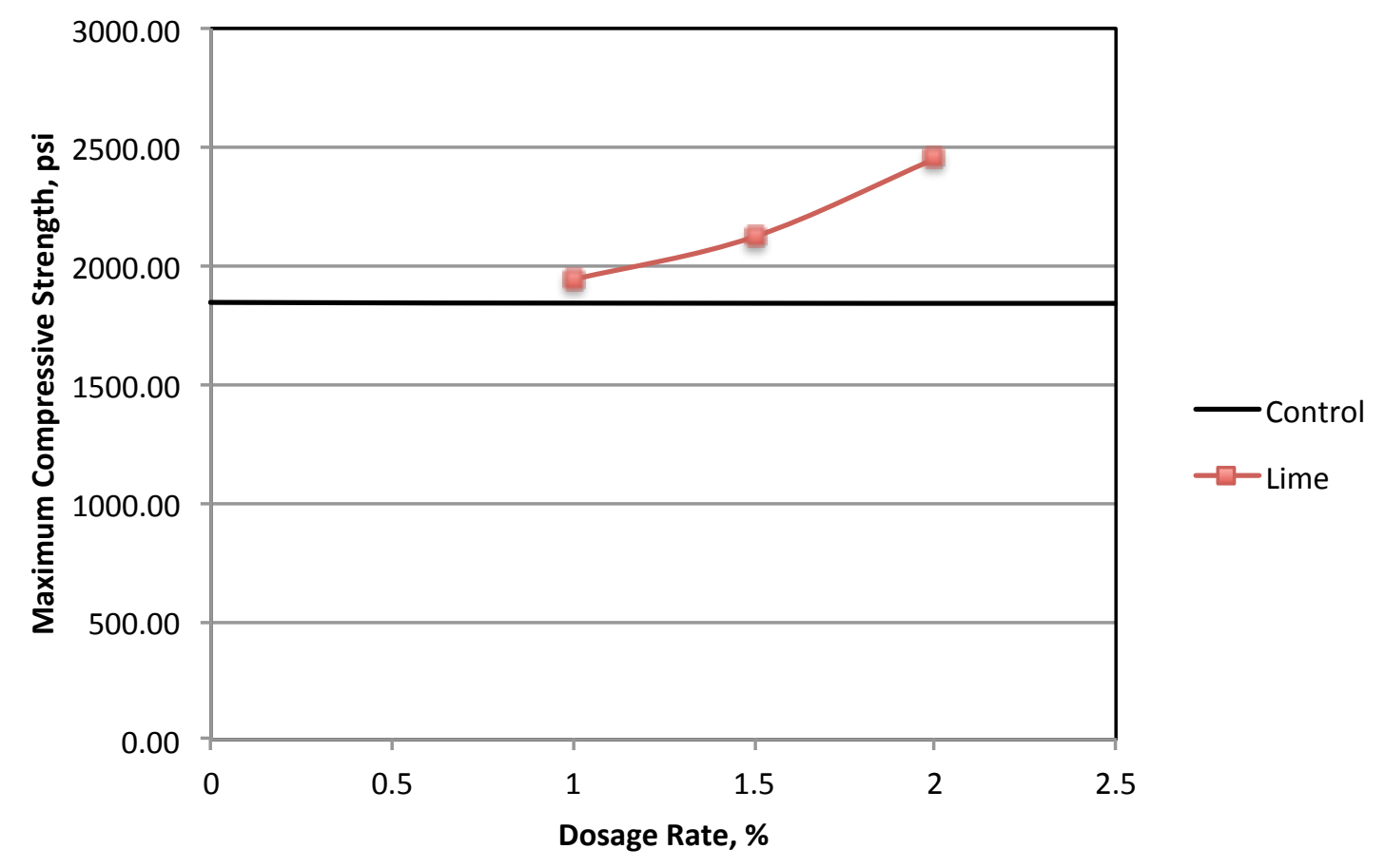

Figure 4.22: Maximum Compressive Strength Results For Conditioned Hydrated Lime Specimens

Figure 4.23 presents the maximum compressive strength results for all conditioned antistripping specimens. With all the antistripping agents on one graph, it can be seen that liquid antistripping agents are not significantly good or bad compared to the control and HL. Although the liquid antistripping agent trend is not accurate, at $0.25 \%$ dosage, it does possess good performance properties. The trend for the liquid specimens should ideally look like the trend of HL specimens but because of the unusual situation, this is not the case. 


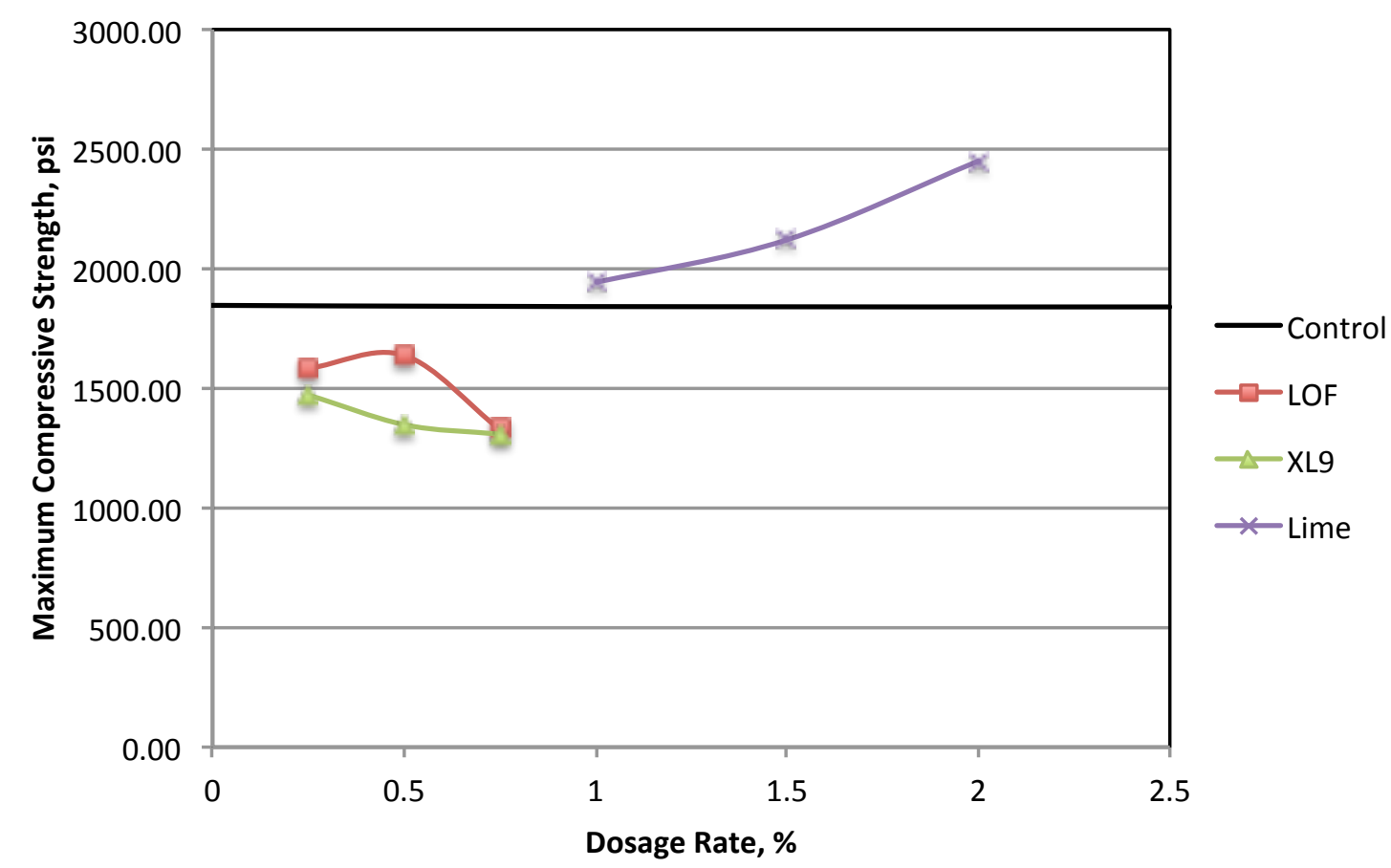

Figure 4.23: Maximum Compressive Strength Results For All Conditioned Antistripping Specimens

Figure 4.24 presents the Young's Modulus results for the conditioned liquid antistripping specimens. Under conditioned state, the liquid antistripping specimens show great improvement compared to its unconditioned state. As the liquid chemical dosage increased, the elastic modulus decreased, due to the unusual situation stated earlier. Although, it is feasible to say that the specimens treated with liquid antistripping agent could have optimized its performance around $0.25 \%$. 


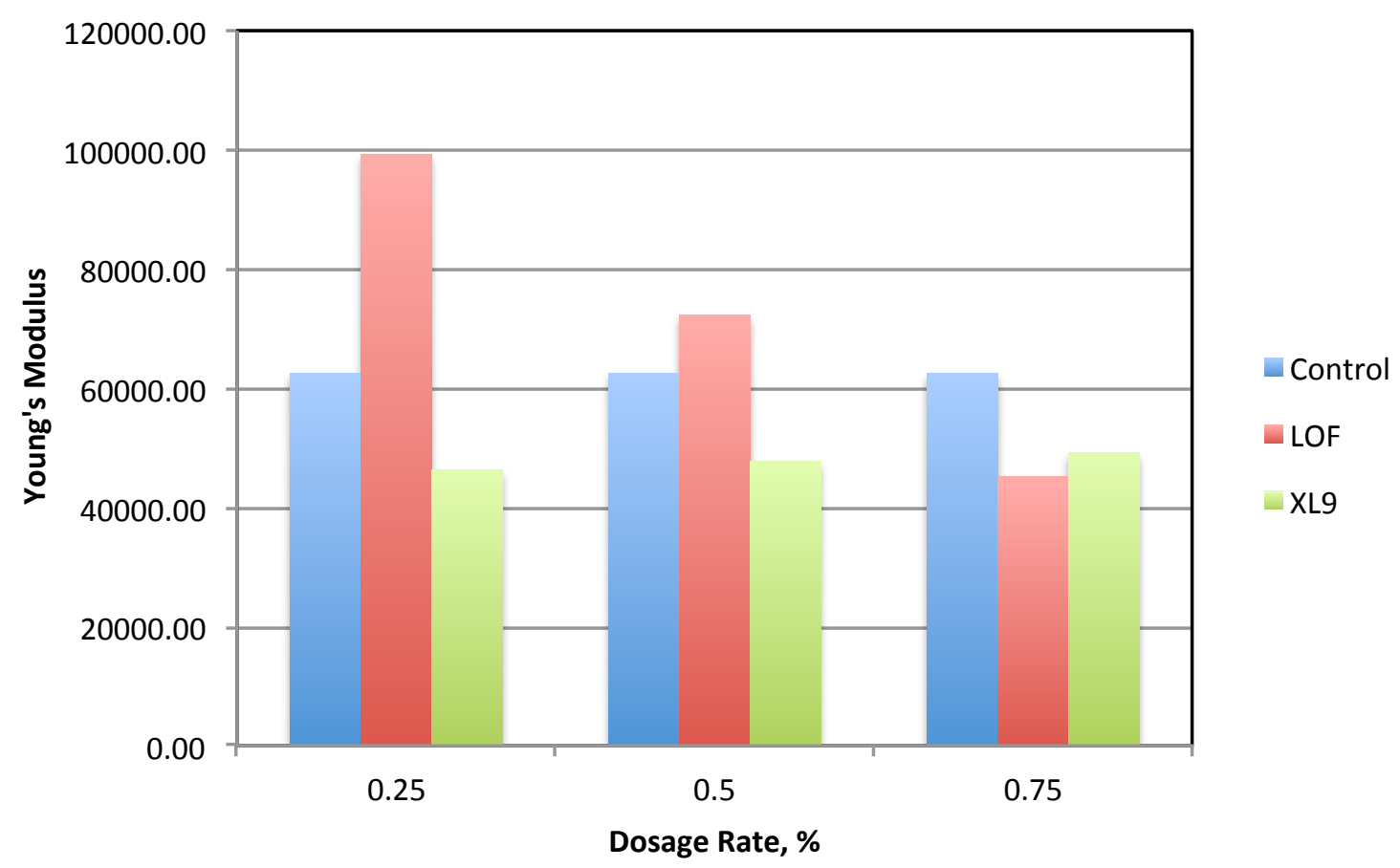

Figure 4.24: Young's Modulus Results For Conditioned Liquid Antistripping Specimens

Figure 4.25 presents the Young's Modulus Results of the conditioned hydrated lime specimens. The trend for the elastic modulus is a steady increase in stiffness as the dosage rate increases. This gives the specimen a higher point of failure, therefore, giving it a higher strength property. The performance properties for $\mathrm{HL}$ are far superior and can be seen in the figure below. 


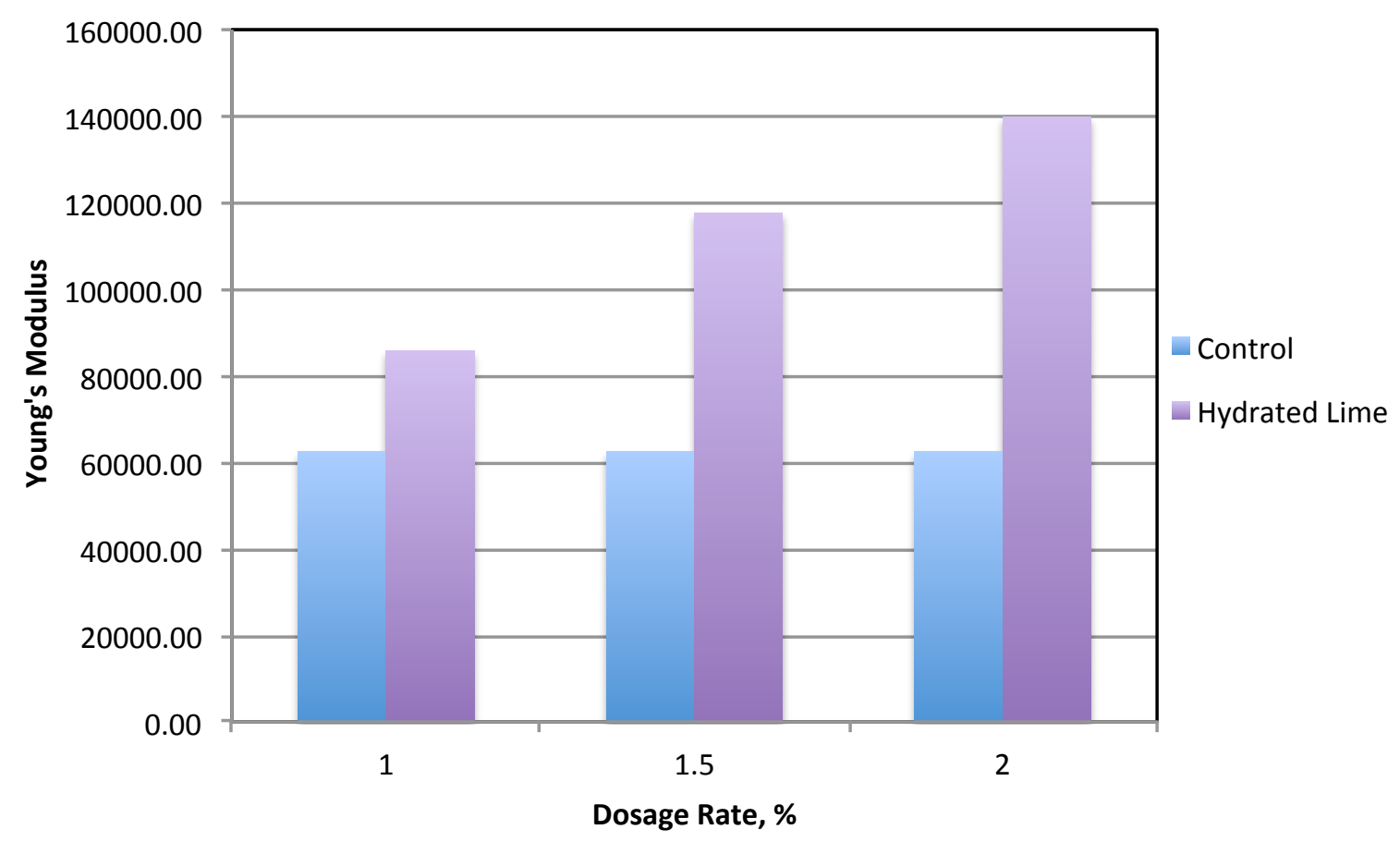

Figure 4.25: Young's Modulus Results For Conditioned Hydrated Lime Specimens

Compressive Strength Ratio is normally used present the results for the ASTM D1075 test. This ratio is calculated as the ratio of the compressive strength for conditioned specimens and that for unconditioned specimens and the minimum acceptable is value is 70\%. It can be seen in Figure 4.26 and 4.27 that all specimens have exceeded the minimum CSR value of 70\%, while LOF-6500 gives the best CSR values for the liquid antistripping additives and hydrated lime exceeds this $70 \%$ industry requirement. 


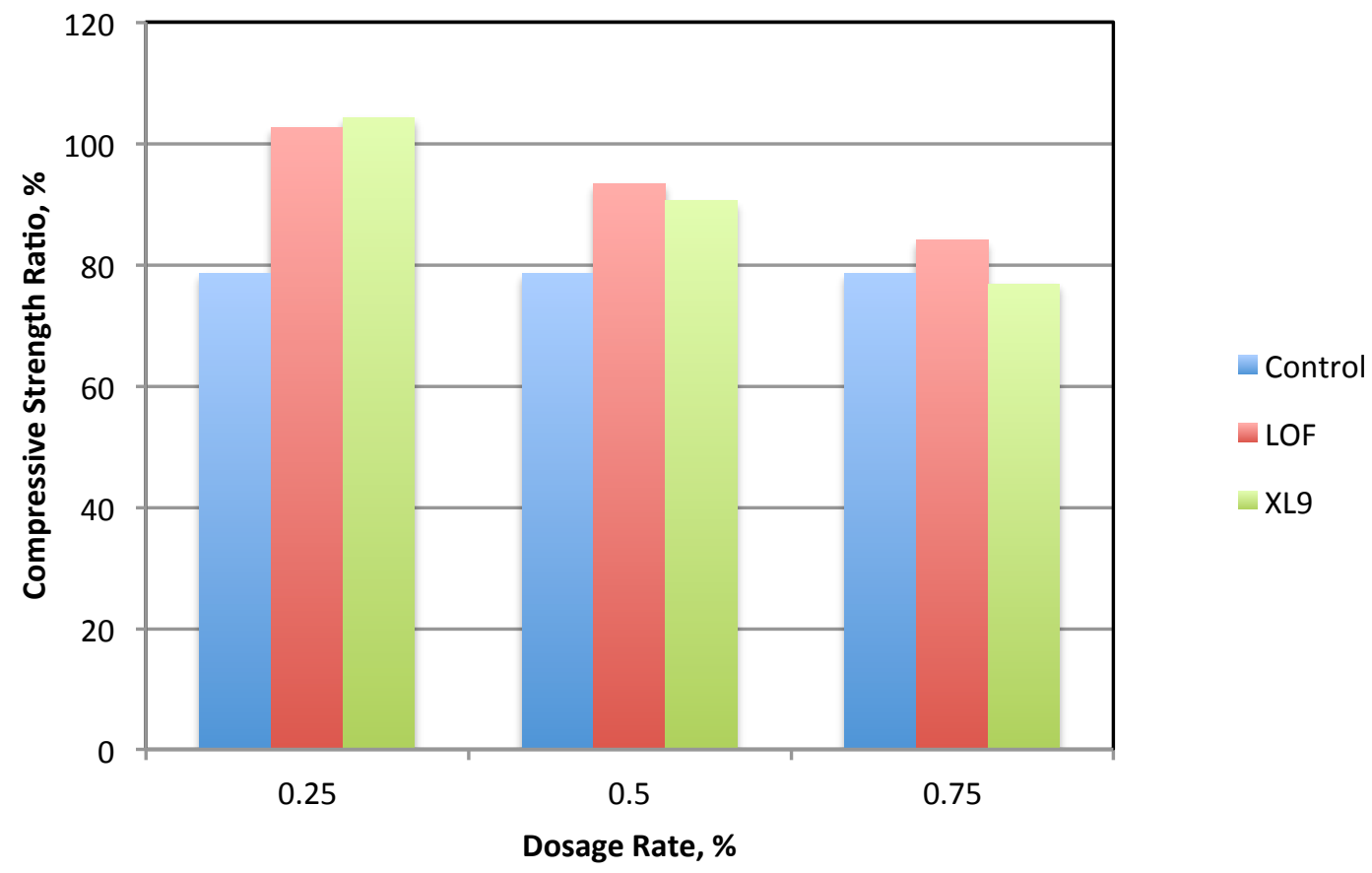

Figure 4.26: Compressive Strength Ratio (CSR) Results For Liquid Antistripping Specimens

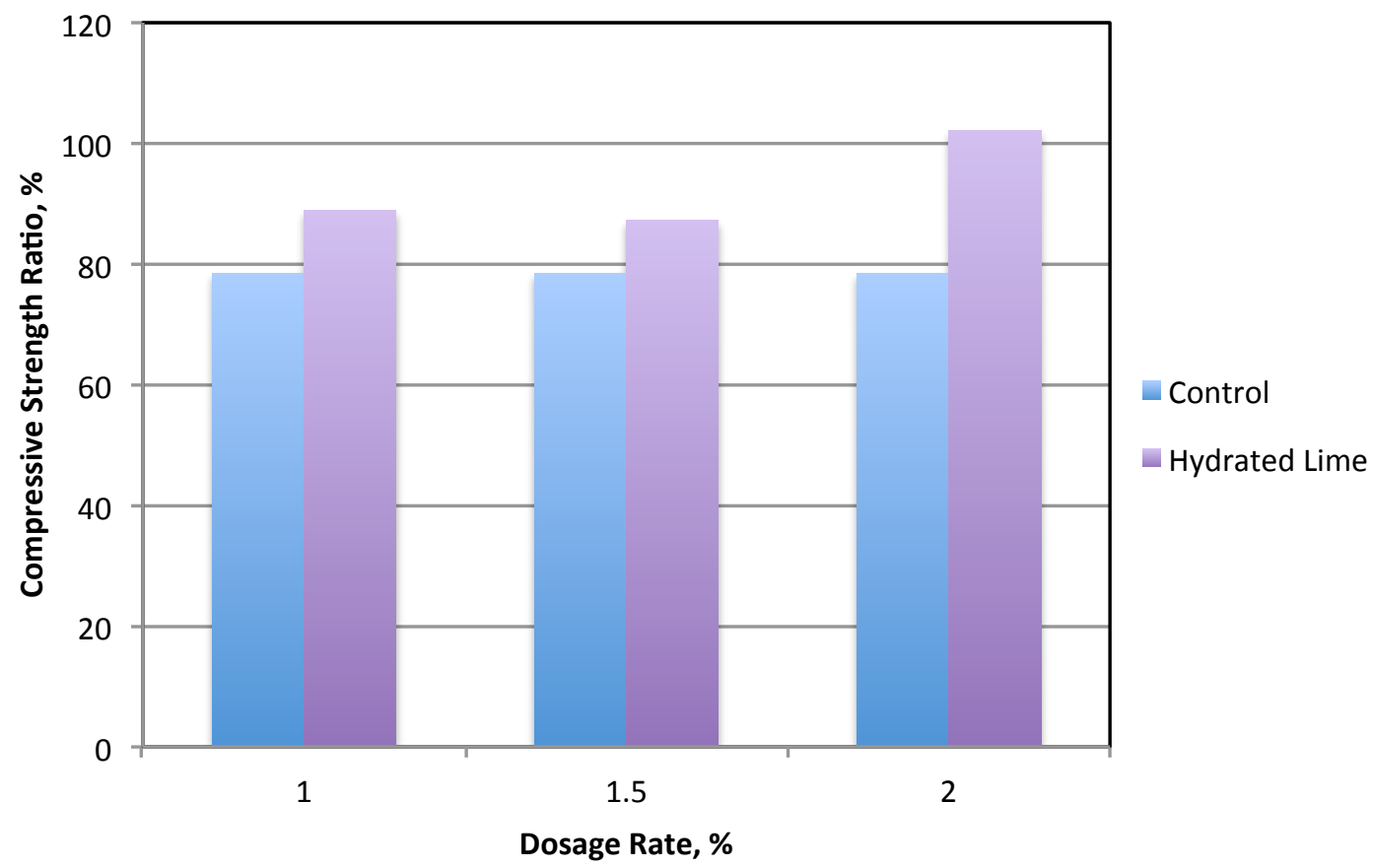

Figure 4.27: Compressive Strength Ratio (CRS) Results For Hydrated Lime Specimens 


\subsection{Cost Analysis}

As important as the performance of these antistripping agents, cost also is another major concern and therefore, a brief cost analysis is conducted in this study. Arr Maz CC quoted LOF-6500 at \$1.60 per pound and XL-9000 at \$2.25 per pound. According to Lhoist North America, the average cost of hydrated lime is about $\$ 150$ a ton, which comes out to be about $\$ 0.08$ a pound. For a one-ton HMA job, it would cost $\$ 16$ for LOF-6500 and $\$ 22.50$ for XL-9000, assuming a dosage rate of $0.50 \%$ of the total weight of the mix for the two liquid antistripping. For Hydrated Lime (HL) and assuming an optimum dosage rate of $1.5 \%$, the cost of HL is $\$ 2.40$ per one ton of HMA. To account for the extra labor involved in HL handling and preparation, this unit cost is escalated to $\$ 5.52$. From the test results and the market price for the antistripping agents, it can be concluded that hydrated lime would be the most cost effective among the three agents investigated in this study. However, the long-term performance of these agents has to be evaluated for more solid conclusion.

\subsection{Chapter Summary}

This chapter presents the analyses and discussion of the results obtained from the tests conducted in this research study.

The asphalt binder testing showed that both liquid antistripping agents and hydrated lime influenced the asphalt binder's complex modulus, elastic modulus, and phase angle. When unaged, the liquid antistripping mixtures provided a less viscous and more fluid asphalt binder, which resulted in a lower tensile and compressive strength than the control. However, the opposite was true for the hydrated lime mixtures. When aged, both 
Hydrated Lime and the liquid antistripping resulted in stiffer binder. These data provided the foundation to predict the range of antistripping agent dosage used for the mix design.

The results performed by the Lottman Test and Immersion Compression Test showed that all antistripping agents provided an improvement in HMA resistance to moisture-related damage. TSR results from the Lottman Test showed that the antistripping agents had a peak in performance at a certain dosage rate. It can also be seen that liquid antistrip additive XL-9000 at $0.50 \%$ is the best in its class and hydrated lime at $1.5 \%$ is the best antistripping additive tested in this study. Immersion Compression Test results gives a clear understanding that hydrated lime is the best antistripping agent investigated in this study. Young's Modulus from the Immersion Compression Test did not confirm a peak trend of the performance for liquid antistripping agents at any specific dosage rate.

Even though the phase angle decreased for both liquid antistripping agents, the trend is not reflected in the HMA Immersion Compression Test. There could possibly be some interaction between the fine powder of the aggregates and the liquid chemicals that has taken place in the mixing process. Powder interaction and pore water pressure are two main factors that may affect the compression strength and elastic modulus results. More testing is recommended for a conclusive understanding of the issue.

According to this study and the current market cost of the antistripping additives, the best performing antistripping additive for the cost would be hydrated lime at $1.5 \%$. 


\section{CHAPTER 5 - CONCLUSIONS AND RECOMMENDATIONS}

\subsection{Introduction}

The study evaluated the moisture sensitivity performance of liquid antistripping agents and hydrated lime as compared to non-enhanced asphalt mixes. Binder viscosity was tested under virgin and aged, non-treated and treated conditions.

Industrial hydrated lime from a local surplus store was used. Hydrated lime is added at $1.0 \%, 1.5 \%$, and $2.0 \%$. Two liquid antistripping agents are obtained from Arr Maz CC. Ad-Here LOF-6500 and XL-9000 were tested at $0.25 \%, 0.50 \%$, and $0.75 \%$. The effectiveness of minimizing moisture-related damage was measured from the two moisture susceptibility tests. Similar to Ad-Here LOF-6500, this chemical additive will also be tested at $0.25 \%, 0.50 \%$, and $0.75 \%$.

The mix design and specimen compaction were completed in accordance with SuperPave mix design. The two methods of evaluation used for this research include Indirect Tensile Strength Test and Immersion Compression Test. Each test required specimens compacted to a diameter of 4 inches and a height of approximately 2.83 inches. Each test required 6 specimens per treatment combination, therefore, a total of 120 specimens were made and tested.

\subsection{Conclusions}

The following section presents the conclusions drawn from the data collected and analyzed in this study. 
- According to the ITS results, for the unconditioned specimens treated with liquid additives, the tensile strength decreased with an increase in additive amount. The opposite is true for Hydrated Lime (HL) treated specimens. The tensile strength for HL samples displayed a linear increase in strength with an increase of HL.

- The ITS results for conditioned samples are quite interesting as a peak amount of dosage is seen for both liquid additives and hydrated lime. The exact amount of peak dosage was not determined but for liquid additives, it is between $0.50 \%$ and $0.75 \%$, and for hydrated lime, it is between $1.5 \%$ and $2.0 \%$.

- All treatment combinations had a Tensile Strength Ratio greater than the industry standard of $70 \%$.

- The best treatment combination based on Indirect Tensile Strength performance alone would be XL-9000 (0.50\%-0.75\%) due to the tensile strength ratio (the unconditioned to conditioned ratio of that specific treatment).

- The best treatment combination for hydrated lime would be at $1.5 \%$ based on this study but the optimum dosage is between $1.5 \%$ and $2.0 \%$.

- The best performing antistripping additive for the current market price would be hydrated lime at $1.5 \%$.

- Unconditioned compressive strength for liquid additive at $0.25 \%$ for LOF-6500 and XL-9000 is lower than the conditioned strength for the same treatment. Possible reasons for these results could be due to water seeping into the core specimens during the conditioning period, which make the specimens harder to compress, essentially, giving it more strength. Also, a chemical reaction between 
the fine powder of the aggregates and liquid antistripping agent could have caused these peculiar results.

- Similar to the compressive strength results, the elastic modulus values are a bit skewed for similar reasons. To obtain a better understanding of the data, values were interpolated to better demonstrate the expected results.

- All treatment combinations had a Compressive Strength Ratio greater than the industry standard of $70 \%$.

- The Immersion-Compression Test has produced retained strengths close to 100 percent even when stripping is visually evident in the cores. According to Roberts et al. 1996, this makes the test not sensitive enough to measure damage induced by moisture because of the problem that developed by internal pore water pressure.

\subsection{Recommendations}

- Due to a lack of a quick and convenient way of checking the amount of antistripping additives, the asphalt pavement material cannot be monitored effectively to measure the amount of antistripping additives. Once samples have been molded, there is no way to measure the consistency if the antistripping additive. Some sort of measuring device to measure the amount and consistency of the antistripping agent would be valuable to asphalt pavement studies.

- Consistency, with regards to conditioning, could be improved by having a more precise preparation, conditioning, and testing regimen. 
- In this study, it was shown that there exists a peak in performance for each type of treatment. Future studies could narrow down the dosage rate for all the antistripping agents used in this study.

- Immersion Compression Test should be reconsidered as a performance test to evaluate moisture susceptibility due to the internal water pressure issue and possible chemical interaction between fine powder of the aggregates and the liquid agent.

- Long-term moisture susceptibility evaluations of these additives and others may be considered.

- Newer liquid antistripping agents are constantly being made as well as other types of antistripping agents are being utilized. More testing with these new materials would help future asphalt studies.

- Along with new liquid antistripping agents, the use of recycled waste as additives may be considered for future studies. Recycled waste materials such as fly ash, bottom ash, and CKD are a few that may be considered to mitigate moisture susceptibility. 


\section{REFERENCES}

Aksoy, Atakan et al. "Effects of various additives on the moisture damage sensitivity of asphalt mixtures." Construction and Building Materials 19.1 (2005): 11-18.

Copeland, Audrey, Jack Youtcheff, and Aroon Shenoy. "Moisture Sensitivity of Modified Asphalt Binders: Factors Influencing Bond Strength.” Transportation Research Record: Journal of the Transportation Research Board. (2007): 18-28.

Epps, J. A., P.E. Sebaaly, J. Penaranda, M.R. Maher, M.B McCann, and A.J. Hand. "Compatibility of a Test for Moisture-Induced Damage With SuperPave Volumetric Mix Design." Transportation Research Record: Journal of the Transportation Research Board. (2000).

"Fly Ash.” 5 November 2010. U.S. Environmental Protection Agency. 25 Jan. 2011 $<$ http://www.epa.gov/climatechange/wycd/waste/downloads/fly-ash-chapter10-2810.pdf>

Hao, Peiwen and Liu, HongYing. A Laboratory Study of the Effectiveness of Various Additives on Moisture Susceptibility of Asphalt Mixtures. Journal of Testing and Evaluation. Vol. 34, No. 4. (2006).

Huang, Baoshan, M.ASCE1, Xiang Shu, Qiao Dong, and Junan Shen. "Laboratory Evaluation of Moisture Susceptibility of Hot-Mix Asphalt Containing Cementitious Fillers.” Journal of Materials in Civil Engineering. (2010): 667-673.

Kennedy, T., R. McGennis, and F. Roberts. Investigation of Moisture Damage to Asphalt Concrete and the Effect of Field Performance-A Case Study. Transportation Research Record 911. Washington D.C.: National Academy Press. (1983).

Kennedy, T., W. Ping. "Comparison Study of Moisture Damage Test Methods for Evaluating Antistripping Treatments in Asphalt Mixtures.” Transportation Research Record: Journal of the Transportation Research Board (1991): 94-111.

Kennedy, T., F. Roberts, and K. Lee. Evaluation of Moisture Effects on Asphalt Concrete Mixtures. Transportation Research Record 911. Washington D.C.: National Academy Press. (1983).

Lottman, R.P. Predicting Moisture-Induced Damage to Asphaltic Concrete. NCHRP Report No. 246. Washington D.C.: Transportation Research Board, National Research Council. (1982).

Lu, Qing and John T. Harvey. "Investigating of Conditions for Moisture Damage in Asphalt Concrete and Appropriate Laboratory Test Methods." Partnered Pavement Research Center Strategic Plan Element No. 4.9: "Investigation of Asphalt Concrete Moisture Damage" (2005). 
Lottman, R.P., L. White, and D. Frith. Methods of Predicting and Controlling Moisture Damage in Asphalt Concrete. Transportation Research Record 1171. Washington D.C.: National Academy Press. (1988).

Mohammad, Louay et al. "Mechanistic Evaluation of Hydrated Lime in Hot-Mix Asphalt Mixtures." Transportation Research Record: Journal of the Transportation Research Board 1723. (2000): 26-36.

Roberts, F. L., Kandhal, P. S., and Brown, E. R., Hot Mix Asphalt Materials, Mixture Design, and Construction, NAPA Education Foundation, Lanham, MD, (1996).

Sebaaly, Peter et al. "Impact of Lime and Liquid Antistrip Agents on Properties of Idaho Hot-Mix Asphalt Mixture.” Transportation Research Record: Journal of the Transportation Research Board. (2007): 65-74.

Solaimanian, M., J. Harvey, M. Tahmoressi, and V. Tandon. "Test Methods to Predict Moisture Sensitivity of Hot-Mix Asphalt Pavements." Transportation Research Record: Journal of the Transportation Research Board. (2003).

Stroup-Gardiner, M., and Epps, J. "Laboratory Tests for Assessing Moisture Damage of Asphalt Concrete Mixtures." Transportation Research Record: Journal of the Transportation Research Board. (1992): 15-23.

Tunnicliff, D. and R. Root. Use of Antistripping Additives in Asphaltic Concrete Mixtures. NCHRP Report No. 274. Washington D.C.: Transportation Research Board, National Research Council. (1984).

Wasiuddin, N.M., Chris M. Fogle, Musharraf M. Zaman, and Edgar A. O'Rear. Effect of Antistrip Additives on Surface Free Energy Characteristics of Asphalt Binders for Moisture-Induced Damage Potential. Journal of Testing and Evaluation, Vol. 35, No. 1 (2007).

Yoon, Hyon H., Arthur R. Tarrer. "Asphalt materials and mixtures.” Transportation Research Record: Journal of the Transportation Research Board (1988): 37-43.

Yoon, Hyon H., Arthur R. Tarrer, and Vinay P. Wagh. "Thermal Degradation of Antistripping Agents and Enhanced Performance by Curing." Journal of Materials in Civil Engineering 5.1 (1993). 